\title{
Evaluation of lubricants for cold forming of steels by double-cup extrusion tests
}

\author{
Shivakumaran Bharadwaj Venkataraman \\ West Virginia University
}

Follow this and additional works at: https://researchrepository.wvu.edu/etd

\section{Recommended Citation}

Venkataraman, Shivakumaran Bharadwaj, "Evaluation of lubricants for cold forming of steels by doublecup extrusion tests" (2000). Graduate Theses, Dissertations, and Problem Reports. 1030.

https://researchrepository.wvu.edu/etd/1030

This Thesis is protected by copyright and/or related rights. It has been brought to you by the The Research Repository @ WVU with permission from the rights-holder(s). You are free to use this Thesis in any way that is permitted by the copyright and related rights legislation that applies to your use. For other uses you must obtain permission from the rights-holder(s) directly, unless additional rights are indicated by a Creative Commons license in the record and/ or on the work itself. This Thesis has been accepted for inclusion in WVU Graduate Theses, Dissertations, and Problem Reports collection by an authorized administrator of The Research Repository @ WVU. For more information, please contact researchrepository@mail.wvu.edu. 


\title{
EVALUATION OF LUBRICANTS FOR COLD FORMING OF STEELS BY DOUBLE - CUP EXTRUSION TESTS
}

\author{
Shivakumaran B. Venkataraman
}

\author{
A Thesis Submitted to \\ The College of Engineering \\ at West Virginia University \\ In partial fulfillment of the requirements \\ for the degree of \\ Master of Science \\ in Mechanical Engineering \\ Donald Lyons Ph.D., Chair \\ Ken Means Ph.D. \\ Gary Morris Ph.D. \\ Jacky Prucz Ph.D.
}

Department of Mechanical Engineering

Morgantown, West Virginia 2000

Keywords: Cold Forging Lubricant, Friction, Friction Testing, Double Cup Backward Extrusion, Lubricant Testing 


\title{
EVALUATION OF LUBRICANTS FOR COLD FORMING OF STEELS BY DOUBLE - CUP EXTRUSION TESTS \\ By
}

Shivakumaran B. Venkataraman

\begin{abstract}
The double-cup extrusion testing method was chosen for measuring the pressure and material flow parameters in order to quantify the frictional shear factor between the workpiece and the forming tool in cold metal forming processes. The test was adapted to be used under production conditions and applied to characterize and compare the lubrication properties of different types of lubricants and coatings.
\end{abstract}

It was found to be a useful approach to estimate the relative efficiency of different lubricants and coating methods. It indicated that one specific lubricant has significantly superior lubricant characteristics than others.

FEA analysis of the experimental setup was constructed to generate calibration curves for the coefficient of friction, $m$, at various values of $m$ and deformation stroke by using the metal forming software package ANTARES. Statistical techniques were utilized to calculate the mean and variance of results obtained for various combinations of the experimental control variables.

Additional efforts are needed in order to make the test results more sensitive to slight variations of friction within a given lubrication method. 


\section{ACKNOWLEDGMENTS}

I would like to take this opportunity to thank the following people without whose help and guidance this experimental research project would not have been possible.

- Prof. Jacky Prucz, my Graduate Research Advisor, whose constant guidance and evaluation of my work help me keep focused on the scope of this project. Special thanks to him for his trips to Saginaw to evaluate this project and his encouragement given to me to complete this thesis.

- Dr. Ravi Duggirala, Staff Project Engineer, Process Engineering and Development, Delphi Saginaw Steering Systems - General Motors Corporation, who as my on-site advisor helped define the scope of the project and took time to explain its finer technical details.

- Mr. David Hitz, Chief Engineer, Process Engineering and Development, Delphi Saginaw Steering Systems - General Motors Corporation, for providing managerial support for this endeavor.

- Prof. Don Lyons, Head of the Department of Mechanical and Aerospace Engineering, West Virginia University, who was instrumental in leveraging my stay at Saginaw to complete this project. He was a major source of guidance and help at the crucial inception stage of this research project.

- Prof. Gary Morris and my thesis advisory committee for having guided and supported me during the course of this project. 


\section{TABLE OF CONTENTS}

CHAPTER \#

Chapter 1 Introduction - Object of research and overview of thesis

Chapter 2 2.1 Forging as a metal forming practice

2.2 Correlation of metal forming practice and theory

2.3 The finite element method as an analysis tool

Chapter 3 Friction

3.1 Introduction to friction

3.2 Theory of friction

3.3 Expressions for friction

Chapter 4

Lubricants

4.1 Introduction to lubrication

4.2 Classification of lubrication mechanisms

4.3 Characteristics of ideal lubricants

4.4 Process conditions and mechanisms of lubricants

4.5 Selection criteria for industrial lubricants

4.6 Types of lubricants used in industry

4.7 Table comparing lubricants

Chapter $5 \quad$ Friction test methods

5.1 Principles of friction testing

5.2 List of commonly used test methods

5.3 Comparison of test methods
Page \#

1

3

5

5

9

9

10

12

16

16

16

19

21

23

24

27

28

28

29

39

43

6.1 Purpose of test 43

6.2 Theory of double-cup backward extrusion test 44

6.3 Design of experiment 46

6.4 Description of apparatus 49

6.5 Method of fixing deformation stroke on the press $\quad 50$ 
CHAPTER \#

Chapter 6

Chapter 7

Chapter 8

$\begin{array}{ll} & \text { 8.1 Computer simulation } \\ & \text { 8.2 Discussion on calibration curves } \\ & \text { 8.3 Actual test results } \\ & \text { 8.4 Discussion of friction test results } \\ \text { Chapter } 9 \quad \text { Overall conclusions } \\ & 9.1 \text { Conclusions } \\ & 9.2 \text { Contributions } \\ & 9.3 \text { Recommendations } \\ & \text { References } \\ \text { APPENDIX } \quad & \\ \text { A. Tables of extruded cup heights from actual testing } \\ \text { B. Computer Simulation (ANTARES) generated data } \\ \text { C. Engineering drawings of dies used for test }\end{array}$

\section{TITLE}

6.6 Friction test procedure

6.6.1 Preparations prior to test

6.6.2 Test procedure for each run

FEA of double cup backward extrusion friction test

7.1 Introduction

7.2 Procedure for setting up simulation

7.2.1 Material spec. in the Material Data sub menu

7.2.2 Input sub menu

7.2.3 Simulate sub menu

7.3 Post processing simulation results

Friction test results

64

64

65

66

70

74

74

74

75

76

78

87

96 


\section{LIST OF SYMBOLS AND THEIR MEANINGS (NOMENCLATURE)}

$$
\begin{array}{ll}
\sigma_{0} & =\text { uniaxial yield stress } \\
\tau_{\mathrm{fr}} & =\text { avg. frictional shear strength at workpiece - tool interface } \\
\mathrm{K} & =\text { yield strength of workpiece } \\
\tau_{\mathrm{f}} & =\text { friction stress } \\
\mathrm{p} & =\text { interface pressure } \\
\mu & =\text { coefficient of friction } \\
\mathrm{N} & =\text { pressure in normal direction } \\
\mathrm{A}_{\mathrm{r}} & =\text { actual area of contact } \\
\mathrm{A} & =\text { area of workpiece undergoing deformation } \\
\mathrm{m} & =\text { friction factor } \\
\mathrm{U}_{\mathrm{s}} & =\text { relative sliding velocity of workpiece to forming tool } \\
\mathrm{V} & =\text { relative velocity } \\
\mathrm{V}_{\mathrm{w}} & =\text { workpiece velocity } \\
\mathrm{V}_{\mathrm{d}} & =\text { die velocity } \\
\mathrm{V}_{\mathrm{r}} & =\text { vertical ram velocity } \\
\alpha & =\text { ratio of real to apparent area of contact } \\
\mathrm{f} & =\text { friction factor at asperity - tool interface } \\
\mathrm{h}_{\mathrm{o}} & =\text { initial thickness of strip } \\
\mathrm{h}_{\mathrm{i}} & =\text { final thickness of strip } \\
\mathrm{S} & =\text { separating force in Rolls } \\
\mathrm{P} & =\text { drawing force in Rolls } \\
&
\end{array}
$$




\section{CHAPTER 1 \\ OBJECT OF RESEARCH AND OVERVIEW OF THESIS}

The main objectives of the research and experimental work in this thesis are:

- To investigate if, under "near production" conditions, the double cup backward extrusion method can be used as a robust testing method for testing lubricity of coatings.

- To investigate the friction between forming tools and workpiece material in cold forging of steel.

- To determine the stability of coatings at higher percentages of deformation and tonnage.

- To benchmark the lubricity of coatings currently used in Delphi Saginaw Steering Systems. The lubricity of the currently used coatings is benchmarked against specially designed formulations as possible replacements.

- To determine the sensitivity of the double cup extrusion method as a test to distinguish between a "good" and a "bad" coating within a specific coating application method.

The steps given below are followed in an attempt to achieve the above objectives:

1. To predict, using finite element analysis code ANTARES, the extruded cup heights under various shear friction coefficients $(0<m<0.2$ for cold forging [1]) input into the plastic metal forming simulation set-up. The shear friction factor, $\mathbf{m}$, is increased in steps of 0.02 for each iteration of the simulation. Predicted cup height ratios are plotted against the deformation (working) stroke of the press to generate calibration curves.

2. The predicted cup heights are then compared to the cup heights extruded in the experiments to determine the friction (in terms of the friction factor) between the forming tools and the workpiece.

3. Extruded cup height ratio is computed for each combination of a specific lubricant under a defined deformation stroke. Extruded cup height ratio is 
directly proportional to the shear friction factor $\mathbf{m}$. Friction is quantitatively expressed as the ratio of the extruded cup heights.

4. Using this experimental setup, lubricity (expressed as friction factor) of currently used coatings in Delphi Saginaw Steering Systems is determined.

5. Lubricities of currently used coatings are benchmarked against new coatings. These formulations are designed specially for evaluation by the competitors (of the current supplier) - Acheson Colloids and IRMCO.

Chapters 1 through 5 describe in detail the theoretical basis for conducting the research in an attempt to establish the above objectives. Chapters 6 and 7 describe the experimental work and the finite element technique used for this thesis respectively. Chapter 8 discusses the results of the experimental work. Chapter 9 discusses the contributions of this thesis and makes recommendations for future work. 


\section{CHAPTER 2}

\section{FORGING AS A METAL FORMING PROCESS AND THE FINITE ELEMENT METHOD AS AN ANALYSIS TOOL}

\subsection{Forging As A Metal Forming Process}

Metal forming is the term used to describe various processes of plastic deformation of metal into a wide variety of shaped parts by controlled flow techniques. Slugs of metal are forced to flow around punches and into or through shape-forming dies, thus producing parts of the desired configuration. The design and control of such processes depend on an understanding of the characteristics of the workpiece material, the conditions at the tool/workpiece interface, the mechanics of plastic deformation (metal flow), the equipment used, and the finished-product requirements. These factors influence the selection of tool geometry and material as well as processing conditions (for example, workpiece and die temperatures and lubrication). Models of various types, such as analytical, physical, or numerical models are often relied upon to design such processes because of the complexity of metal forming operations.

The domain of metal forming can be broadly classified into -- bulk metal forming (forging) and sheet metal forming. This thesis will concentrate on the characteristics associated with forging.

Metal forming technology has a special place because it helps to produce parts of superior mechanical properties with minimum waste of material. In metal forming, the starting material has a relatively simple geometry; this material is plastically deformed in one or more operations into a product of relatively complex configuration. Forming to near net shape dimensions drastically reduces metal removal requirements, resulting in significant material and energy savings. Metal forming usually requires relatively expensive tooling. Therefore the process is economically attractive when a large number of parts must be produced and/or 
when the mechanical properties required in the finished product can be obtained only by the forming process [2].

The following factors need to be taken into consideration in a forging process:

- Geometry and required dimensional accuracy of component

- Material of component

- Number of parts required of component

Based on the above factors, the following parameters need to be evaluated:

- Mechanics of plastic deformation such as effective strain (\% elongation) on the part

- Maximum strain or stress the part can take before it cracks

- Load required to impart the computed strain

- Number of steps required going to final geometry

- Conditions at tool/workpiece interface

- Temperature of operation

Based on the above evaluation, the following can be determined:

- Equipment to be used

- Progression design

- Tooling design

- Material of tooling

and other details such as material handling, lubricant coating, heat treatment cycle, heating equipment, etc. 


\subsection{Correlation of Metal Forming Practice and Theory}

The theory of plasticity studies and predicts shape change that occurs in metal forming using quantitative techniques. Plasticity theory makes certain assumptions and takes a simplified, mechanistic view of metal forming processes. At the outset it is important to understand the fundamentals and the basic terms generally used in plasticity theory before entering into a meaningful discussion of friction and its effects. The basic assumptions are that the deforming material is continuous, homogenous and isotropic. The theoretical treatment is further simplified if the material is also assumed to behave as a rigid/perfectly plastic (non-hardening) substance. This means that the material shows no elastic deformation but suddenly begins to deform plastically when the yield criterion has been satisfied. In simple tension or compression this occurs when the uniaxial yield stress of the material $\sigma_{0}$ is reached. It is then assumed to flow at the same stress. However, in the real world, all materials first suffer elastic deformation and - especially in cold working - also strain hardening, leading to a continuous rise in the yield stress. The ideal perfectly plastic behavior is sometimes approximated in hot working or by some heavily strainhardened metals (e.g. Aluminum) in cold working.

\subsection{Finite Element Method as an Analysis Tool}

The deforming workpiece material is subjected to an often rather complex combination of compressive, tensile, and shear stresses; these can be reduced to three (compressive and/or tensile) principal stresses. Plastic flow sets in only if the Stress State satisfies the yield criterion. The yield criterion of Tresca states that yielding occurs when the difference between the maximum and minimum principal stresses reaches $\sigma_{0}$. The more accurate and generally used Von Mises criterion takes also the intermediate principle stress into consideration.

The controlled change of the workpiece geometry in metal forming processes is influenced by such process parameters as the intrinsic workability of the 
engineering material, the tribological conditions between the workpiece and the tooling, the tool geometry, tool material, process temperature and the imposed strain-rate. Process modeling is a design procedure that is based on the theoretical and experimental process analysis. Process simulation follows logical steps, and it is closely related to process analysis. [3]

Often the preform and the die designs for the metalworking processes such as forging are too complicated to enable the development of simple and general methods for predicting working loads, metal flow and the occurrence of defects. The trial and error methods are not only expensive and time consuming, but they frequently require expensive experimental setups and difficult measurements. Additionally, they encroach on production time on the equipment thus preventing production of required components. Therefore, an ever-increasing amount of research has been and continues to be done to develop general mathematical and computer techniques that are capable of simulating metal forming processes under arbitrary conditions.

The development of powerful computer-based simulation techniques, such as those based on the finite-element method, has provided a vital link between advances in tooling and equipment design, on the one hand, and an improved understanding of the materials behavior on the other. Finite element analysis (FEA) is one of various methods used to mathematically model and analyze metal forming processes. It is based on the infinitesimal theory of plasticity. This theory discards the elastic part of the stress-strain curve and is based the following three assumptions:

1. The infinitesimal deformation at any time can be resolved into a sum of an elastic part and a plastic part.

2. A yield function in stress space exists.

3. The workpiece material is stable and continuos in the sense that any increase in deformation will not produce a decrease in the flow stress. 
In this method of analysis, a cross-section of deforming material, for either an axisymmetric or a plane strain problem is divided into a two-dimensional network of discrete elements called finite elements. The deformation at selected points called nodes in each element is determined by the application of some variational principle. Thus, by analyzing an aggregate of elements one at a time, the deformation pattern in a complex shape can be determined. The accuracy of the predicted deformation increases with the number of elements used.

Initially, codes based on the infinitesimal elastic-plastic theory were used to analyze small deflections and deformations. This code was restricted to metal forming problems in which plastic flow was tightly constrained. However, when researchers began applying it to the study of forging operations, i.e., operations in which there was significant shape change and hence plastic deformations being far greater than elastic deformations, it became evident that the codes required more sophistication. In analyzing problems that involved large plastic deformations, the material particles were found to undergo very large displacements and rotations in most cases.

Inputs to finite-element codes include the characteristics of the workpiece material (flow stress and thermal properties) and the tool/workpiece interface (friction and heat transfer properties), as well as workpiece and tooling geometry. Typical outputs include predictions of forming load; strain, strain rate, and temperature contour plots; and tooling deflections. This information is used in design considerations, such as selection of press capacity, determination of success or failure with regard to material workability, and estimation of likely sources of tooling failure (abrasive wear, thermal fatigue, and so on).

Advantages of the Finite Element Method

- FEM can incorporate different material properties for each element, since the properties of each element are evaluated separately.

- FEM can handle almost any degree of nonhomogenity. 
- There is no restriction as to the shape of the medium.

- FEM can accommodate many types of boundary conditions easily.

- FEM can easily handle factors such as nonlinearities, arbitrary loading conditions and time dependence.

- FEM can introduce most admissible velocity fields or shape functions.

- FEM has a unified treatment of the velocity fields in building the stiffness matrix at the elemental level.

- FEM can be used to achieve connected simulations for such sequential processes as forging, heat treating and machining and casting.

The ANTARES finite element code is an updated Langragian form that uses an appropriate time integration scheme. It is coupled with different related fields that include the following: thermal analysis, material workability modeling, die analysis and CAD/CAM systems. The package is capable of analyzing elastic-plastic, rigid-plastic, rigid-viscoplastic and rigid-thermoviscoplastic metal forming problems for both 2D and 3D cases. Quadratic elements are used in 2D analysis using the Quadtree Algorithm developed by RPI, Troy, NY. Automatic remeshing is done using an UES developed algorithm.

Process simulation techniques also provide a method for preform and die design through the ability to determine metal flow patterns without constructing tooling or conducting expensive in-plant trials.

(The literature on the finite element analysis as applied to metal forming is predominantly quoted from the book "Metal Forming and the Finite Element Method" by Kobayashi S., Oh S., Altan T. [2]) 


\section{CHAPTER 3}

\section{FRICTION}

\subsection{Introduction to friction}

The importance of friction and lubrication in deformation processes such as extrusion, forging, wire drawing, etc. has long been recognized by metal forming professionals. Metalworking is probably the earliest technological occupation known to mankind; native metals must have been forged and shaped more than 7000 years ago. Although, substantial advances have been made largely on an empirical basis, the need for a more systematic approach has become imperative over the years. Progress in this direction has however been rather slow, mainly because the subject does not fit conveniently into any of the established, classical scientific disciplines. Metal deformation processing itself is the domain of specialists working on the borders of metallurgy and mechanical engineering; metalworking lubrication necessitates a further involvement in fields traditionally cultivated by chemists and physicists.

Metals are capable of accommodating only a limited amount of tensile strain before necking sets in and fracture soon occurs. Much greater deformation may be achieved without fracture in compression; therefore, most practical metal working processes effect plastic deformation by applying a force through a suitable tool or die. Friction inevitably arises at the die - workpiece interface, and it is this friction that is the subject of the thesis.

Reducing friction, between the die and the workpiece, in general, reduces:

- the force and energy required for a given operation,

- reduces the stresses imposed on the dies,

- achieves larger changes in shape,

- promotes die filling, 
- reduces workpiece bulging and

- promotes more homogenous deformation

The theoretical background for a more systematic understanding and approach to friction dates as far back as 1508 when Leonardo da Vinci recognized the basic law of friction. Amontons later rediscovered this law in 1699. Since then, the concept of a coefficient of friction has been adopted, but it was almost a century before Coulomb developed a theory postulating that friction was due to both surface roughness and adhesion. Another hundred years later, at the end of the 19th century, the principles of hydrodynamic theory of lubrication were developed by a number of scientists, all working within a span of 20 years. Hardy closely investigated boundary lubrication, which plays such an important role in metalworking processes, in the years 1919 - 1933, and his work is still a foundation stone of present knowledge. Theories relating to dry and lubricated friction were developed in the late forties. The science of friction and lubrication is now being recognized as a discipline of its own, although it is still being practiced by researchers trained in related classical disciplines. Since then, more powerful drives on forming equipment have promoted increased production, heavier reductions, higher speeds and thereby imposed severe conditions on lubricants. New metals that were introduced to satisfy the needs of the developing aerospace, chemical and electronic industries often had properties quite different from the more common metals used thus far and continue to present some of the most difficult lubrication problems [4]. This has and continues to generate an unprecedented need to establish rigorous and systematic testing methods to further the cause of understanding lubricants and use them more efficiently. This thesis deals with one such technique to evaluate lubricants.

\subsection{Theory of friction}

Friction is the resistance to motion encountered when one body slides over another; in metalworking, it arises from sliding of the workpiece against the die. Figure 3.1 (a) shows a schematic of a die - workpiece interface (macro 
view). The existence of friction increases the value of deformation force and makes deformation more inhomogeneous which in turn increases the propensity for fracture. If friction is high, seizing and galling of the workpiece surfaces occur, and surface damage results. Relative motion is opposed by friction, which can be simply (and accurately) described by assigning an average frictional shear strength $\tau_{\mathrm{fr}}$ to the interface. When this value reaches the shear flow strength of the workpiece material $\mathrm{K}$, it is energetically more favorable for deformation to take place by internal shearing in the body of the workpiece (sticking friction condition). However, the macroscopic view is inadequate if the characteristics of friction and the mechanisms of lubrication are to be understood. On the microscopic scale, both die and workpiece show minute peaks, asperities, and valleys (figure $3.1(\mathrm{~b})$ ). Relative motion between such surfaces is impeded by contact under pressure.

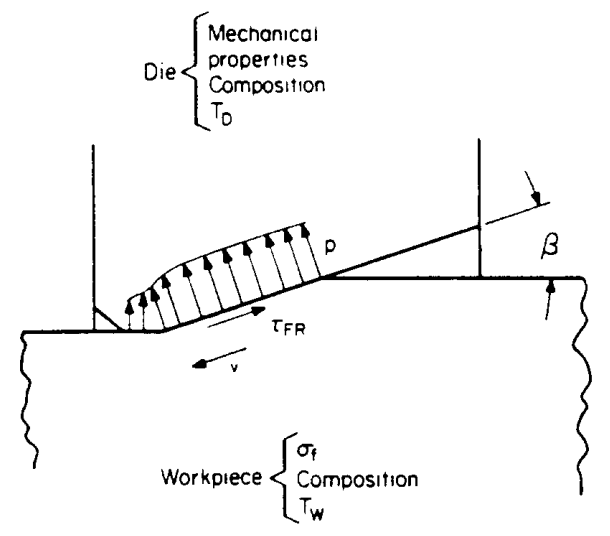

(a)

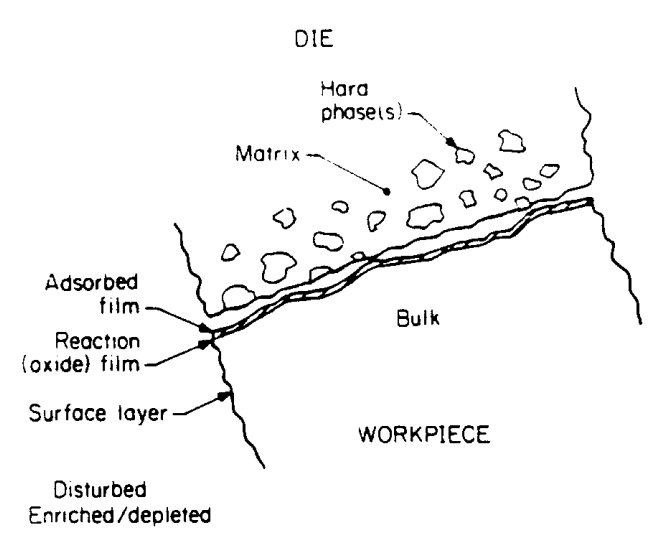

(b)

Fig 3.1 Die - Workpiece Interface (a) on the macroscale (b) on the microscale [4]

The magnitude and the directionality of this microgeometry plays an important role in creating friction and also in establishing and sustaining lubricant films designed to mitigate friction. Break-up of the original surface and temperature gradient in workpiece and die during the deformation process, and rubbing process in metal forming accelerates chemical reactions, etc.

In forging, friction greatly influences metal flow, pressure distribution, load and energy requirements. In addition to lubrication effects, the effects of die chilling or 
heat transfer from the hot material to colder dies must be considered. For example, for a given lubricant, friction data obtained from hydraulic press forging cannot be used for mechanical press or hammer forging even if die and billet temperatures is comparable. High friction leads to various defects that limit workability. However, for most workability tests, conditions are selected under which friction is either absent or easily controlled. Most workability tests make no provision for reproducing the frictional conditions that exist in the production process; consequently, serious problems can result in the correlation of test results with actual production conditions. Surface contact and friction theories are described below and further in ref. [4]

\subsection{Expressions for friction}

The mechanics of friction at the tool / workpiece interface are very complex; therefore, simplifying assumptions are usually used. Listed below are various friction models based on fundamental laws of friction and theories based on them.

\subsubsection{Coulomb model}

The most commonly used method of modeling friction between contacting surfaces, whether lubricated or not, is the Amontons - Coulomb Law [8]. The law implies that the friction stress $\tau_{f}$ opposes relative surface motion and is proportional to the interface pressure $\mathrm{p}$ as:

$$
\tau_{\mathrm{f}}=\mu p
$$

where the constant of proportionality is called the coefficient of friction. In bulk metal forming $A_{r}$ (actual area of contact) is nearly equal to $A$ (area of the workpiece undergoing deformation). This representation is valid primarily for light loads and when near complete hydrodynamic effects occur, such as in high speed thin strip rolling. As $p$ increases, $\tau_{f}$ may exceed the shear yield strength of the workpiece material, $\mathrm{K}$, changing the mechanism of friction. 


\subsubsection{Shear factor model:}

The strong relationship between friction and the workpiece shear strength is expressed by:

$$
\tau_{\mathrm{f}}=\mathrm{mK}
$$

where $\mathbf{m}=$ friction factor $(0<\mathrm{m}<1)$ and $\mathbf{K}$ is the yield stress in pure shear

In solid film or boundary lubrication, $\mathrm{m}$ represents the ratio of interface film strength to workpiece shear strength. Friction during most forging and extrusion operations is best described by the friction factor. While this model has a fundamental basis where the surfaces are completely separated by a film of a perfectly plastic lubricant, the main reason for its use is pragmatic empiricism since it uncouples the friction stress from the interface pressure. Eqs. (3.1) and (3.2), both specify $\tau_{\mathrm{f}}$, but in different terms

3.3.3 Chen and Kobayashi [1] introduced a variation of the model of friction factor $m$ as:

$$
\tau_{f}=m K\left(2 / \pi^{*} \tan ^{-1}\left(\left|U_{s}\right| / U_{0} A\right)\right) n
$$

where, $\tau_{f}$ is the frictional stress, $n$ is the unit vector in the opposite direction of relative sliding, $U_{s}$ is the sliding velocity of a material relative to die velocity, and $U_{0}$ is a small positive number compared to $U_{s}$. The above expression represents that the magnitude of the frictional stress is dependent on the magnitude of the relative sliding velocity and direction. The approximation of the frictional stress by the arctangent function of the relative sliding velocity eliminates the sudden change of direction of the frictional stress $\mathrm{mK}$ at the neutral point, which can cause numerical errors.

Recent investigation [9] indicate that friction is more correctly represented as a function of relative velocity between the two surfaces. This implies that the 
lubricant films can be considered as viscous hydrodynamic films in which shear stress is related to sliding velocity difference.

$$
\begin{array}{ll} 
& \tau_{f}=m K v \\
v & =\text { dimensionless relative velocity }=\left(V_{w}-V_{d}\right) / V_{r} \\
V_{w} & =\text { workpiece velocity } \\
V_{d} & =\text { die velocity (usually zero) } \\
V_{r} & =\text { vertical ram velocity }
\end{array}
$$

\subsubsection{Friction model based on slip - line theory}

Wanheim and Bay [10] have analyzed the deformation of surface asperities on the specimen by means of slip lines assuming shear factor friction at the asperity - tool interface. They have shown that below a certain surface pressure $\mathrm{P}^{*}$ it is reasonable to assume constant friction $\mu$ and above a pressure $P^{* *}$ it is reasonable to assume $\mathbf{m}$ - friction. In the range $\mathrm{P}^{*}$ and $\mathrm{P}^{\star *}$ neither $\mu$ - friction nor $\mathbf{m}$ - friction provides a good representation for friction. Wanheim and Bay express friction as

$$
\tau_{f}=(\alpha) f K
$$

where,

$\mathrm{f}=\mathrm{=}$ is the friction factor in the asperity - tool interface,

$\alpha \quad=$ is the ratio between real and apparent area of contact and

$\mathbf{K}=$ is the yield stress in pure shear.

At high normal pressures $(\alpha)$ approaches 1 . In the pressure range where Coulomb's law is valid the correlation between and $\mathrm{f}$ is expressed as,

$$
\mu=\frac{f}{1+\Pi / 2+\cos ^{-1} f+\sqrt{1-f^{2}}}
$$

\subsubsection{Other models}

Ramaekers and Kals [11] have provided some mathematical representation of friction in metal forming analysis and support the inclusion of the relative displacement between tool and workpiece and increase of the nominal area of 
contact between tool and workpiece (surface - extrusion). Daulkert and Wanheim [12] suggest a model that uses $\mu$ and $\mathbf{m}$ for different regions in simple upset tests. $\tau_{f}=P$ in the slip zone ( outer zone of cylinder $), \tau_{f}=m K\left(R / R_{c}\right)$ in the stick zone ( center portion of the cylinder ) and, $\tau_{f}=\mathbf{m K}$ in the drag zone (intermediate zone of the cylinder) where $\mathrm{R}$ is the distance from the center of the cylinder to the location under consideration, and $R_{c}$ is the critical radius where drag zone and stick zone are divided.

\subsubsection{Realistic friction models}

Models based on the fundamental mechanisms of friction are required where the process is very sensitive to friction and friction is strongly influenced by changes in the variables under study. The key to developing better friction models is to take account of the local, current lubrication regime which requires a knowledge of the local current film thickness and surface roughness. For the thick-film regime the friction model may be represented as

$$
\tau_{f}=\mu(U-V) / h
$$

where $\mathrm{U}$ and $\mathrm{V}$ are the workpiece and tooling velocities and $\mathrm{h}$ is the local film thickness [13].

Simple friction models such as Coulomb and Shear-factor are useful in investigating the influence of friction stress on a particular process or in processdesign simulations where friction variability is small. However, they fail to represent the influence of processing conditions on friction, particularly when the system undergoes a transition from one regime to another or where more than one regime exists concurrently. Under these conditions, models that are more realistic require knowledge of the local current lubrication regime. Some such models are also presented in $[4,5]$ for different lubrication regimes. 


\section{CHAPTER 4}

\section{LUBRICANTS}

\subsection{Introduction to Lubrication}

Lubrication is of great importance in forging operations to reduce friction between the die and the workpiece. Considering the importance of lubricants in the deformation processes, it is amazing that no account of their use can be found until relatively recent times. This can be attributed to the fact that the composition, manufacture, and use of lubricants were - and to some extent, still are - closely guarded secrets. Additionally, it is quite possible that lubricants assumed a vital role only at a later stage of development of forging as a technology [4].

Effective lubrication provides better surface finish, die life and workability. Two of the most significant lubricant developments occurred during World War II. The phosphate conversion coating was adopted in Germany for severe cold deformation (such as drawing and extrusion) of steel. These developments are in practice even today.

\subsection{Classification of lubrication mechanisms}

In forging, as in most other metal forming operations, friction modeling is complicated by the fact that any of several different regimes of lubrication can exist at the billet-die interface. Lange [5] classifies the lubricating mechanisms as:

\subsubsection{Dry interfaces}

Under "dry" conditions, no lubricant is present at the interface and only the oxide layers deposited on the die and workpiece materials may act as a "separating" layer. In this case, friction is high, and such a situation is desirable in only a few selected forming operations, such as hot rolling of plates and slabs and 
nonlubricated extrusion of aluminum alloys. This kind of a situation is desirable because it allows the rolls to get a better grip of the workpiece.

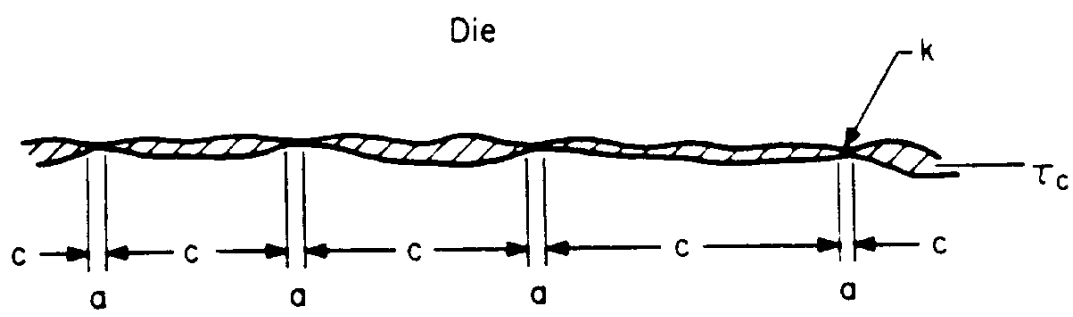

Workpiece

Fig. 4.1 A dry interface. a - proportion of surface area that has been pressure welded; c proportion of surface covered with contaminant film of $\tau_{\mathrm{c}}$ shear strength. [12]

\subsubsection{Solid-film lubrication}

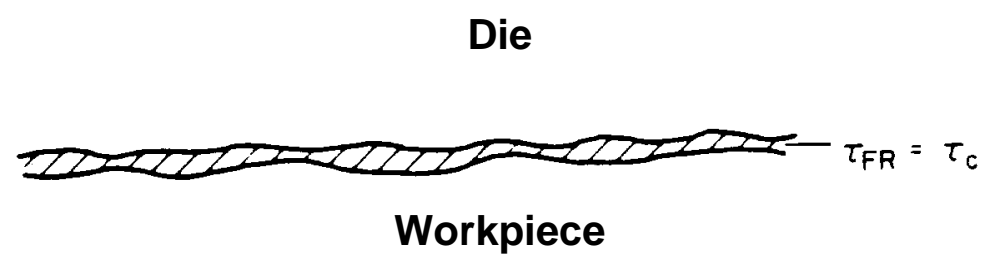

Fig. 4.2 Solid - Lubricated interface [8]

A continuous solid film, thick enough to separate die and workpiece surfaces everywhere along their interface acts as a lubricant if $\tau_{\mathrm{C}}<\mathrm{K}$. Coatings of a soft, ductile metal deposited on the workpiece surface are among the most effective solid lubricants. A chemical reaction film at the die - workpiece interface provides a lubricant with strong resistance to destruction during sliding contact both for the substrate and itself. It is also more durable than a film formed by a purely physical process.

\subsubsection{Extreme pressure lubrication}

The surface film is formed by reaction of the metal with an organic compound containing phosphorous, sulfur or chlorine. The reaction product has low shear strength and is firmly attached. The shear strength of these films is sensitive to imposed pressure. 


\subsubsection{Boundary lubrication}

"Boundary" Lubrication is the most widely encountered situation in metal forming. Increases in temperature at the interface and the relatively high forming pressures do not usually allow the presence of a hydrodynamic lubrication regime. Boundary lubrication does not lend itself to 'classical' analysis and consequently most of the available knowledge is empirical.

\subsubsection{Hydrodynamic lubrication}

"Hydrodynamic" conditions exist when a thick layer of fluid lubricant is present at the interface between the dies and the workpiece. The friction conditions are governed by the viscosity of the lubricant and by the relative velocity between the die and the workpiece. As the viscosity of most lubricants decrease rapidly with increasing temperature and thinning occurs, in most metal-working situations, some asperity contact is unavoidable, sliding speeds may be too low, heating of the lubricant film and interface pressures maybe too high for efficient metal forming.

\subsubsection{Mixed-film lubrication}

Many metal -working lubricants are liquid or are dissolved or dispersed in a liquid carrier

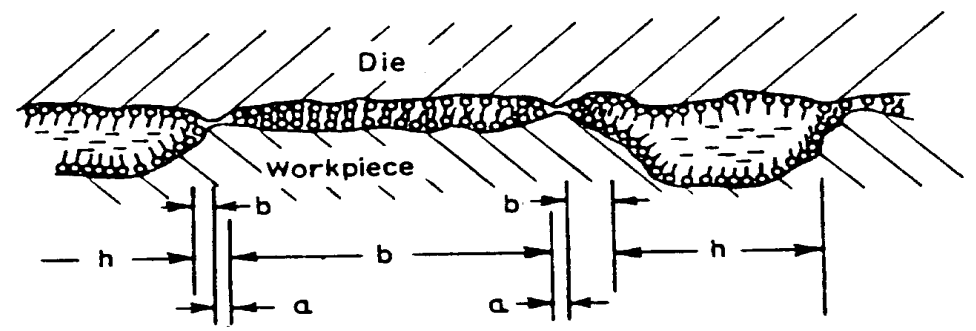

Fig. 4.3 Mixed film lubrication at die - workpiece interface [5]

for a variety of reasons. Therefore, there will be substantial entrapment of liquids, and the limited compressibility of such liquids result in the formation of hydrodynamic (hydrostatic) pockets in the surface of the deforming workpiece, 
while the rest of the workpiece is in boundary contact with the die. Friction in mixed-film lubrication depends greatly on the micro-geometry of the interface.

Other classifications of lubrication regimes are presented in [4,5,6,7]. Effect of hydrostatic pressure on the shear strength of various substances is shown below in fig. 4.4

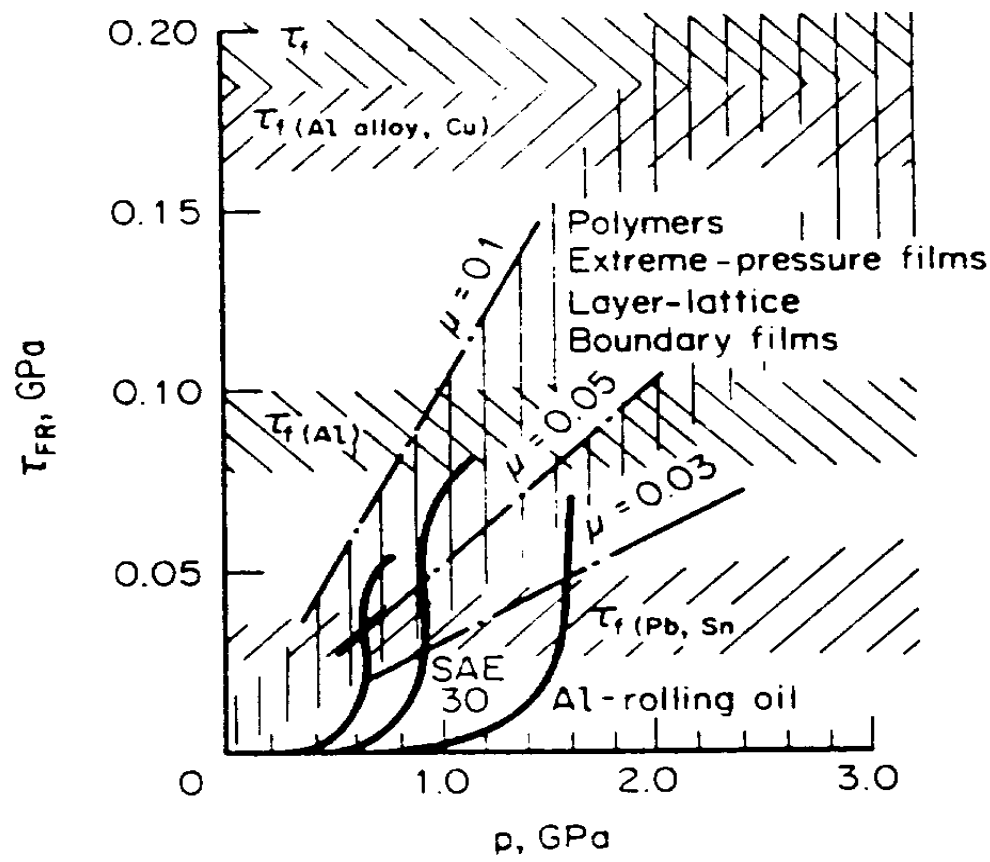

Fig. 4.4 Effect of hydrostatic (normal) pressure on the shear strength of various substances [4]

\subsection{Characteristics of ideal lubricants}

In metal forming, friction is controlled by the use of appropriate lubricants for given applications. There are some attributes that are generally valid for the majority of applications, based on an evaluation by Schey [4]. In forging, the ideal lubricant is expected to:

- Control friction - Reduce sliding friction between the dies and the forging in order to reduce pressure requirements, to fill the die cavity, and to control metal flow. 
- Separation of surfaces - Act as a parting agent and prevent local welding and subsequent damage to the die and workpiece surfaces.

- Reduced Wear - should reduce wear of die while limiting wear of workpiece material to tolerable proportions.

- Protection of old and new surfaces - should cover both old and new surfaces generated during deformation efficiently by possessing wetting and spreading characteristics.

- Adaptability to varied working conditions - Function at varying pressures, temperatures and relative sliding velocities.

- Thermal Insulation - Possess insulating properties so as to reduce heat losses from the workpiece and to minimize temperature fluctuations on the die surface.

- Rapid response - should exert its influence in a short time (order of a few milliseconds.)

- Durability of liquid film - Capable of withstanding continued or repeated encounters.

- Cooling - Also function as a coolant in high rate forming.

- Stability - Should be unaffected by temperature, oxidation, contamination, bacteriological attack, etc..

- Reactivity - Should not be corrosive to the dies or workpiece.

- Harmless residues - Should not cause unwanted physical, chemical or metallurgical changes in the products.

- Application and removal - Should be easy. 
- Disposal - Should be possible to reclaim some lubricant and easy to treat effluents.

- Cost - Commercially available at reasonable cost.

- Handling and Safety - Non toxic, non carcinogenic, etc..

- Integrated Approach - As part of the activity of technology.

- Cover the die surface uniformly so that local lubricant breakdown and uneven metal flow are prevented.

- Be free of residues that would accumulate in deep impressions.

- Develop a balanced gas pressure to assist quick release of the forging from the die cavity; this characteristic is particularly important in hammer forging, in which ejectors are not used.

No single lubricant can fulfill all of the requirements listed above; therefore, a compromise must be made for each specific application. Various types of lubricants are used, and they can be applied by swabbing or spraying. The simplest is high flash point oil swabbed onto the dies. Colloidal graphite suspensions in either oil or water are frequently used. Synthetic lubricants can be employed for light forging operations. The water-base and synthetic lubricants are extensively used primarily because of cleanliness.

In addition, no single test method can evaluate all of these characteristics simultaneously. Therefore, various testing methods exist for evaluation of one or more lubricant characteristic [4].

\subsection{Process conditions and mechanisms of lubricants used in forging}

Schey [4] provides a detailed description of lubrication in cold and hot forging covering different materials such as iron-base alloys, light metals, non-ferrous, etc. In cold forging the initially entrapped lubricant cushion is sealed at the edges, 
where a zone of pure boundary contact develops. Thus, lubrication is mixed in the macroscopic sense, with PHD (Plasto hydrodynamic) conditions in the center and boundary conditions at the edges. As deformation proceeds, the film thins out as it follows the expansion of the end face, and roughening of the workpiece results in a shift toward conventional (microscopic) mixed-film lubrication in the original PHD zone. At lower speeds of forming, oil-base lubricants are needed and high viscosity alone can ensure film formation. Adequate viscosity is crucial in forming of nonreactive metals, and in lubricating the freshly formed end faces in forging from a bar. If additives are added, care should be taken not to hurt the dies in the first few contacts when the reactive reactions have not yet taken place.

Elastic deformation of dies especially flat platens, can help in trapping lubricant and may be a major source of squeeze-film lubrication. Relubrication by interrupting upset and by superimposing a vibration on the platen can aid in replenishing squeeze films. Such films are also formed in plane-strain compression, but this film is then gradually washed out from the work zone.

In hot forging, workpieces are heated to typical hot working temperatures but dies are usually substantially colder. Therefore a lubricant not only should ensure die / workpiece separation and lower friction, but preferably also act as a heat insulator. Excessive heating of the dies would lead to die damage and wear, and the lubricant - or its carrier - should also perform a cooling function. High temperatures at the interface severely limit the choice of lubricant; solid forms being important. Oxides and scale substitute as lubricants but they are generally not competitive with layer-lattice substances, and most forging lubricants contain graphite and Molybdenum sulfide at lower temperatures.

Lubricant breakdown and oxidation are functions of contact time, die and workpiece temperature, and surface deformation and sliding. Heat transfer characteristics are also important to prevent die chilling. A thicker oxide is, in general, a better heat insulator and the reduced heat flow reduces the 
temperature gradient in the surface layer of the die. Another important function of the lubricant in hot forging is cooling the die. Aqueous lubricants are the most effective. With higher forging speeds, flow stress increases because the strain rate increases, contact time is reduced and cooling is minimized, the time of exposure of the lubricant to high temperature is reduced and in the presence of a liquid carrier or carrier residue, squeeze-film effects develop. Die geometry, temperature, and application method are other factors that influence the selection of lubrication for hot forging.

\subsection{Selection criteria for industrial lubricants}

Some of the criterion used for industrial lubricant selection is [14]:

Tooling: What is the die alloy? How hot will it get? How complex is the die?

Workpiece: What is its composition? What is its proper forging temperature?

Forging equipment: Press? Hammer? Type and size/capacity?

Forging sequence: Number and type of die stations? Function of each? Cycle times?

Lubricant used: Perceived advantages? Disadvantages? Application methods used.

Lubricants have to be chosen based on the operating temperatures, relative velocities of workpiece and die, interface pressures, adhesion to the materials involved and the lubricant regime under these conditions. Therefore lubrication in hot forging and cold forging are different, the former in the regime of solid-film and the latter in the regime of mixed-film. Hot forging involves less pressures and higher temperatures than cold forging. Table 4.1 shows some typical lubricants used in hot and cold forging. Schey has described extensively different lubricants, their constituents, application, and etc. [4]. 
A review of cold working lubrication and hot working lubrication is presented by Male [30]. The types of lubricants and lubrication systems used in cold working vary with the particular material and the severity of the operation. The basic lubrication mechanism is, however, of the boundary type in a high proportion of these processes, although hydrodynamic conditions do exist in some high-speed operations. In cold strip rolling and wire drawing, water is still used as a coolant and as a lubricant with some mix of oil. Synthetic emulsions of oil and water are also being used. In cold working operations, where there is substantial deformation and surface extension of the workpiece, higher viscosity oils and appropriate additives are used as the regime tends toward hydrodynamic and EP. Protective phosphate coatings are used for extremely arduous cold forming operations.

Historically, for many years lubrication in the majority of hot working operations consisted of swabbing the tooling with oil or tallow-base concoctions containing graphite, and the judicious application of a handful of sawdust and water. The use of glass-type lubricants has ushered a new wave in hot forming lubrication.

\subsection{Types of lubricants used in industry}

The great variety of processes calls for a yet larger variety of lubricants, and their operative mechanisms are best discussed according to workpiece temperature, starting with the simpler cold forging mechanisms and progressing to the complexities introduced by higher temperatures. A brief review of the different lubricant types used and their application in the different lubrication regimes and forging processes is presented.

\subsubsection{Oil-base lubricants}

Mineral oils obtained from the distillation of crude oils (or their synthetic equivalents) provide the base for many well-established industrial lubricants. Their viscosity is usually chosen to assure predominantly hydrodynamic lubrication at the existing velocities, pressures, temperatures, and during plastic 
deformation even in cold working, and this leads to a reduction in their viscosity, counterbalanced by the usually exponential increase in viscosity with pressure. Above some critical pressure, oils become solids and behave as a polymer film would.

In cold working, lubrication is mostly of the mixed-film type and additives are almost invariably incorporated to protect against direct metal-to-metal contact at asperities. The types of additives depend on the workpiece and die compositions and on the severity of the operation. Different additives enable use of oil-base lubricants for boundary and EP regimes over a wide temperature and pressure range. Natural oils, fats, etc. offer a wide range of viscosity, relatively low solidification pressures, and usually also contain some free boundary agents. When their viscosity is too high, they may be deposited from a volatile solvent as is done with lanolin in the coating of Al slugs for cold extrusion. All oils ignite at their flash point and while the residue may lubricate, especially if the oil contains additives, the resulting pollution is objectionable and has led to a diminishing use of oil-base lubricants for hot-working processes.

\subsubsection{Aqueous lubricants}

Water, although the best coolant has too low a viscosity for lubrication. With chemicals added for corrosion protection, it is still used for its cooling qualities in the hot rolling of steel where iron oxide acts as the lubricant. However, hot rolling of nonferrous metals and all cold-working operations are conducted with emulsions in which water serves as the carrier for an oily phase, dispersed with the aid of emulsifiers. Technical, economic, and ecological consideration demand that aqueous lubricants be circulated in a system that has filters for the removal of debris, etc.

\subsubsection{Soaps and greases}

Soaps are the reaction products of a metal hydroxide with a fatty acid. With the exception of alkali metal soaps they are water-soluble. At high pressures and 
shear rates they behave as Non - Newtonian substances and are capable of forming thick lubricant films, as in the dry drawing of steel wire. Their apparent viscosity decreases with temperature. Thus friction first decreases, but after reaching a minimum at around $400^{\circ} \mathrm{F}$, it increases because of increasing boundary contact. Greases with boundary, EP, and lamellae additives are used when process conditions are not favorable for establishing a thick enough lubricant film with an oil or emulsion.

\subsubsection{Solid films}

Soft metal films are still used when the base metal cannot be effectively lubricated. The coating is chosen for its low shear strength, high ductility, good adhesion to the base, reduced adhesion to the die and improved reactivity with the lubricant. Molten glass films may act simply as low-shear-strength films (as in the hot forging of titanium), as gradually melting films (as in hot extrusion of steel and $\mathrm{Ti}$ and $\mathrm{Ni}$ based alloys), or as hydrodynamic agents (as in hot extrusion with predeposited films). Layer-lattice compounds are the only alternative to glass in hot forging. Graphite and $\mathrm{MoS}_{2}$ based lubricants may be used but the difficulty is in depositing a uniform and continuous film and as they do not spread easily they need a carrier. 
4.7 Table 4.1: Typical Lubricants Used In Cold Working And Representative Coefficients Of Friction

\begin{tabular}{|c|c|c|c|c|c|c|c|c|c|}
\hline Process & & $\mu$ & $\begin{array}{l}\text { Stainless Steel }{ }^{a} \text {, } \\
\text { Nickel base }^{c}\end{array}$ & $\mu$ & Titanium $^{\mathbf{b}}$ & $\begin{array}{l}\text { Copper, } \\
\text { Brass }\end{array}$ & $\mu$ & $\begin{array}{l}\text { Aluminum, } \\
\text { Magnesium }^{\mathrm{d}}\end{array}$ & $\mu$ \\
\hline Rolling & $\begin{array}{l}\text { FO } \\
\text { FO - EM } \\
\text { (FO - MO) }\end{array}$ & $\begin{array}{l}0.03 \\
0.07 \\
0.05\end{array}$ & $\begin{array}{l}\mathrm{GL}-\mathrm{MO}^{\mathrm{e}} \\
\mathrm{GL}-\mathrm{FO}-\mathrm{EM}\end{array}$ & $\begin{array}{l}0.07 \\
0.10\end{array}$ & $\begin{array}{l}\text { FO-MO } \\
\text { SP }\end{array}$ & $\begin{array}{l}\text { FO-MO(10-50) } \\
\text { FO-MO-EM }\end{array}$ & $\begin{array}{l}0.03 \\
0.07\end{array}$ & $\begin{array}{l}1-5 \% \text { FA-MO } \\
\text { (Synthetic MO) }\end{array}$ & 0.03 \\
\hline $\begin{array}{r}\text { Extrusion } \\
\text { Light }\end{array}$ & EP - MO & 0.10 & GL-MO & 0.10 & $\begin{array}{ll}\text { SP or GR grease on } \\
\text { fluoride-PH } & 0.05 \\
\end{array}$ & FO-MO & 0.10 & Lanolin & 0.05 \\
\hline Severe & $\begin{array}{l}\mathrm{SP} \text { on } \mathrm{PH} \\
\mathrm{MoS}_{2}+\mathrm{SP} \\
\text { on } \mathrm{PH}\end{array}$ & $\begin{array}{l}0.05 \\
0.05\end{array}$ & $\begin{array}{l}\text { SP on } \\
\text { oxalate }\end{array}$ & 0.05 & & $\begin{array}{l}\text { GR-FO } \\
\text { GR-grease }\end{array}$ & $\begin{array}{l}0.05 \\
0.05\end{array}$ & $\begin{array}{l}\text { Zn Stearate } \\
\text { SP on PH }\end{array}$ & $\begin{array}{l}0.05 \\
0.05\end{array}$ \\
\hline \multirow{2}{*}{$\begin{array}{r}\text { Forging } \\
\text { Light } \\
\text { Severe }\end{array}$} & EP - MO & 0.10 & EP-MO & 0.10 & As extrusion & $\mathrm{FO}$ & 0.05 & FO & 0.05 \\
\hline & $\mathrm{SP}$ on $\mathrm{PH}$ & 0.05 & $\begin{array}{l}\text { GL-MO } \\
\text { SP on oxalate }\end{array}$ & $\begin{array}{l}0.10 \\
0.05\end{array}$ & & SP & 0.05 & Lanolin & 0.05 \\
\hline
\end{tabular}

Typical Lubricants Used In Hot Working And Representative Coefficients Of Friction

\begin{tabular}{|c|c|c|c|c|c|c|c|c|c|c|}
\hline Process & \multicolumn{2}{|l|}{ Steel } & \multicolumn{2}{|c|}{$\begin{array}{l}\text { Stainless Steel, } \\
\text { Nickel base } \mu\end{array}$} & \multicolumn{2}{|c|}{ Titanium } & \multicolumn{2}{|l|}{$\begin{array}{l}\text { Copper, } \\
\text { Brass }\end{array}$} & \multicolumn{2}{|l|}{$\begin{array}{l}\text { Aluminum, } \\
\text { Magnesium, }\end{array}$} \\
\hline Rolling & $\begin{array}{l}\text { None } \\
\text { (GR suspension) }^{c} \\
\text { (MO-FA-EM) }^{\text {MO-F }}\end{array}$ & $\begin{array}{l}\mathrm{ST}^{\mathrm{a}} \\
0.20 \\
0.20\end{array}$ & As Steel & & & & MO-FA-EM ${ }^{\mathbf{b}}$ & 0.20 & MO-FA-EM & 0.20 \\
\hline Extrusion & $\begin{array}{l}\mathrm{GL} \\
(\mathrm{GR})\end{array}$ & $\begin{array}{l}0.02 \\
0.20\end{array}$ & $\mathrm{GL}$ & 0.02 & $\mathrm{GL}$ & 0.02 & \begin{tabular}{|l} 
None \\
(GR)
\end{tabular} & $\begin{array}{r}\text { ST } \\
0.20\end{array}$ & None & ST \\
\hline Forging & $\begin{array}{l}\text { None } \\
\text { GR }\end{array}$ & $\begin{array}{c}\text { ST } \\
0.20\end{array}$ & GR & 0.20 & $\begin{array}{l}\mathrm{GL} \\
\mathrm{MoS}_{2}\end{array}$ & $\begin{array}{c}0.02 \\
0.10\end{array}$ & GR & $0.10-0.20$ & $\begin{array}{l}\mathrm{GR} \\
\mathrm{MoS}_{2}\end{array}$ & $\begin{array}{l}0.10-0.20 \\
0.10-0.20\end{array}$ \\
\hline
\end{tabular}

a The symbol ST indicates sticking friction

${ }^{b}$ Hyphenation indicates that several components are used in the lubricant

${ }^{c}$ Less frequent lubricant usage is shown in parentheses

${ }^{d}$ Interface pressures can be very high, and sticking may occur even if $\mu$ is low

EM - emulsion; the listed lubricants are emulsified and $1-5 \%$ is dispersed in water FA - fatty acid, alcohol, amines, esters

$\mathrm{GL}$ - glass (sometimes in conjunction with GR on the die)

GR - graphite

$\mathrm{MO}$ - mineral oil 


\section{CHAPTER 5}

\section{FRICTION TEST METHODS}

\subsection{Principles of friction testing}

Tribology in metalworking is most reliably studied, and lubricants are best evaluated and developed, in an actual production situation. Full-scale trials interrupt production and especially if a lubricant fails, may carry an exorbitant price tag because the product is ruined. Also, uncontrollable and often unrecognized variables may creep into the evaluation. Therefore, a great deal of effort has been expended in attempts to develop laboratory tests that are, hopefully, less expensive and easier to control and evaluate while still retaining their relevance to production. Alan T. Male has presented $[16,30,31]$ several discussions on ring tests, lubricant requirements and evaluation. From the discussions on testing, the tests may be evaluated based on their ability to:

- be used for different temperature ranges

- ease of testing

- exposure of fresh surfaces to closely imitate real forming problems

- produce the required range of pressures as in real practice

- provide sufficient sensitivity to friction factor change in value

- represent different lubrication regimes presented earlier

- simplicity and methods for generating analytical curves

- effects of material, rates, speeds, relative motions, etc. to be depicted

There has been extensive literature on testing, testing methods, applications based on material, temperature range, etc. The tests are conducted under controlled conditions, sometimes with elaborate measuring devices. Several 
correction factors need to be applied to test results such as accounting for barreling, deflections of equipment, heat loss, etc. Analysis methods may not precisely duplicate test conditions [16] to provide the comparative calibration curves. The friction models (shear factor, friction factor, etc.) also do not represent friction conditions for all ranges of pressure, temperature, and lubrication regimes.

However, a knowledge of the different lubrication regimes, lubrication test methods, their limitations and scope, the requirements for a lubricant and a good understanding of the tribology and requirements of the application under consideration, enables one to judiciously select the required lubrication. "Periodically, a test method emerges with some claims to universality, only to fall into disrepute as experience accumulates. Considering the complexity of the system it is clear that there is no universal test that will be found. The best that one can hope for is to establish tests that simulate particular aspects of the systems and then select a group of these tests that will provide adequate coverage of all aspects of importance" [4].

\subsection{List of commonly used test methods}

\subsubsection{The ring compression test}

Lubricity is a means of expressing friction between the workpiece and the die. It is a property of the lubricant and is defined by the friction factor $f$, or the shear factor, $\mathbf{m}$. It is most commonly measured by using the ring test $[16,17]$. In the ring test a flat ring-shaped specimen is compressed to a known reduction (fig. 5.1). The change in internal and external diameters of the forged ring is very much dependent on the friction at the tool/specimen interface. If friction were equal to zero, the ring would deform in the same way as a solid disk, with each element flowing radially outward at a rate proportional to its distance from the center. With increasing deformation, the internal diameter of the ring reduces if friction is high and increases if friction is low. Thus, the change in the internal diameter represents a simple method for evaluating interface friction. 
The ring test has an advantage when applied to the study of friction. In order to measure friction with this test, the force necessary to deform the ring and the flow stress of the specimen material do not have to be known. Thus evaluation of test results is greatly simplified. Several theoretical analyses are available to obtain the magnitude of the friction factor from the experiment $[15,18,19]$.

(a)

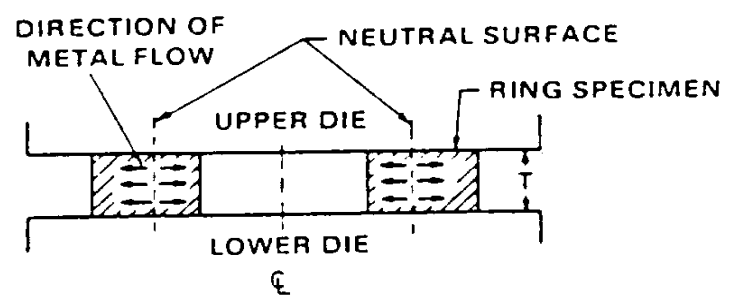

(b)

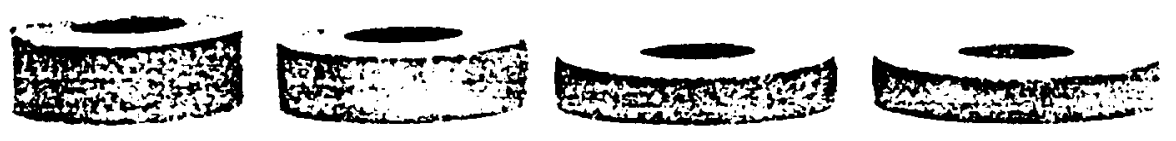

Fig. 5.1 The ring compression test: (a) schematic of metal flow; (b) E.g.: rings upset to various reductions in height (Altan et. al., 1983) [2]

In one of the analysis [15] a computer program has been developed for mathematically simulating the metal flow in ring compression with bulging. From the ring dimensions at various reductions in height, the results are plotted in the form of "theoretical calibration curves" as shown in fig. (5.2).
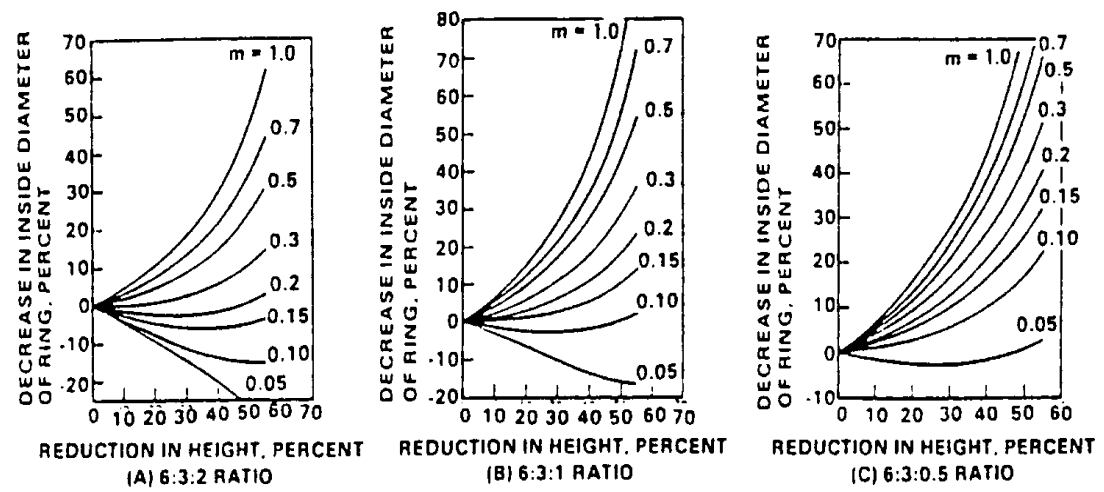

Fig. 5.2 Theoretical calibration curves for upsetting rings having indicated OD: ID thickness ratio [2] 


\begin{tabular}{|c|c|c|c|c|c|}
\hline Material & $\begin{array}{c}\text { Specimen } \\
\text { tempera- } \\
\text { ture, F }\end{array}$ & $\begin{array}{l}\text { Frictional } \\
\text { shear } \\
\text { factor }(m)\end{array}$ & $\begin{array}{l}\text { Contact } \\
\text { time, s }\end{array}$ & $\begin{array}{l}\text { Ring } \\
\text { ratio(a) }\end{array}$ & $\begin{array}{l}\text { Lubrication } \\
\text { system }\end{array}$ \\
\hline $6061 \mathrm{Al}$ & $\begin{array}{l}800 \\
800 \\
800\end{array}$ & $\begin{array}{l}0.4 \\
0.31 \\
0.53\end{array}$ & $\begin{array}{l}0.038 \\
0.047 \\
0.079\end{array}$ & $\begin{array}{l}6: 3: 0.5 \\
6: 3: 1 \\
6: 3: 2\end{array}$ & $\begin{array}{l}\text { (b) } \\
\text { (b) } \\
\text { (b) }\end{array}$ \\
\hline $\mathrm{Ti}-7 \mathrm{Al}-4 \mathrm{Mo}$ & $\begin{array}{l}1750 \\
1750 \\
1750\end{array}$ & $\begin{array}{l}0.42 \\
0.42 \\
0.7\end{array}$ & $\begin{array}{l}0.033 \\
0.044 \\
0.056\end{array}$ & $\begin{array}{l}3: 1.5: 0.25 \\
3: 1.5: 0.5 \\
3: 1.5: 1\end{array}$ & $\begin{array}{l}\text { (c) } \\
\text { (c) } \\
\text { (c) }\end{array}$ \\
\hline $403 \mathrm{SS} \ldots$ & $\begin{array}{l}1800 \\
1800 \\
1800 \\
1950 \\
2050\end{array}$ & $\begin{array}{l}0.23 \\
0.24 \\
0.34 \\
0.28 \\
0.35\end{array}$ & $\begin{array}{l}0.029 \\
0.039 \\
0.047 \\
0.06 \\
0.06\end{array}$ & $\begin{array}{l}3: 1.5: 0.25 \\
3: 1.5: 0.5 \\
3: 1.5: 1 \\
3: 1.5: 1 \\
3: 1.5: 1\end{array}$ & $\begin{array}{l}\text { (c) } \\
\text { (c) } \\
\text { (c) } \\
\text { (c) } \\
\text { (c) }\end{array}$ \\
\hline Waspaloy & 2100 & 0.18 & 0.06 & $3: 1.5: 1$ & (c) \\
\hline 17-7PH SS & $\begin{array}{l}1950 \\
2100\end{array}$ & $\begin{array}{l}0.28 \\
0.35\end{array}$ & $\begin{array}{l}0.06 \\
0.06\end{array}$ & $\begin{array}{l}3: 1.5: 1 \\
3: 1.5: 1\end{array}$ & $\begin{array}{l}\text { (c) } \\
\text { (c) }\end{array}$ \\
\hline $\mathrm{Ti}-6 \mathrm{Al}-4 \mathrm{~V}$ & $\begin{array}{l}1700 \\
1750\end{array}$ & $\begin{array}{l}0.3 \\
0.46\end{array}$ & $\begin{array}{l}0.06 \\
0.06\end{array}$ & $\begin{array}{l}3: 1.5: 1 \\
3: 1.5: 1\end{array}$ & $\begin{array}{l}\text { (c) } \\
\text { (c) }\end{array}$ \\
\hline Inconel $718 \ldots$ & $\begin{array}{r}2000 \\
2100\end{array}$ & $\begin{array}{l}0.18 \\
0.33\end{array}$ & $\begin{array}{l}0.06 \\
0.06\end{array}$ & $\begin{array}{l}3: 1.5: 1 \\
3: 1.5: 1\end{array}$ & $\begin{array}{l}\text { (c) } \\
\text { (c) }\end{array}$ \\
\hline Ti-8Al-1Mo-1V & $\begin{array}{l}1750 \\
1800\end{array}$ & $\begin{array}{l}0.27 \\
0.27\end{array}$ & $\begin{array}{l}0.06 \\
0.06\end{array}$ & $\begin{array}{l}3: 1.5: 1 \\
3: 1.5: 1\end{array}$ & $\begin{array}{l}\text { (c) } \\
\text { (c) }\end{array}$ \\
\hline Udimet & 2050 & 0.4 & 0.06 & $3: 1.5: 1$ & (c) \\
\hline $7075 \mathrm{Al}$ & $\begin{array}{r}700 \\
800\end{array}$ & $\begin{array}{l}0.37 \\
0.31\end{array}$ & $\begin{array}{l}0.06 \\
0.06\end{array}$ & $\begin{array}{l}5: 3: 1 \\
5: 3: 1\end{array}$ & $\begin{array}{l}\text { (b) } \\
\text { (b) }\end{array}$ \\
\hline
\end{tabular}

(a) Ring dimensions in inches, OD:ID:thickness. (b) Caustic precoat + graphite coating Dag 137 (Acheson) on the specimens and graphite spray Deltaforge 43 (Acheson) on the dies. (c) Glass-base coating Deltaforge 347 (Acheson) on the specimens and graphite spray Deltaforge 43 (Acheson) on the dies.

Table 5.1 Values of frictional shear factor, $\mathrm{m}$, obtained from ring tests conducted in a mechanical press (temperature of the dies $=300^{\circ} \mathrm{F}$, surface finish $=25$ micro - in.) [2]

In determining the value of the shear factor, $\mathbf{m}$, for a given experimental condition, the measured dimensions are placed on the appropriate calibration curve. From the position of that point with respect to theoretical curves given or various values of $\mathbf{m}$, the value of the shear factor, $\mathbf{m}$, which existed in the experiment, is obtained. Table 5.1 shows the results of tests conducted [17] for various materials. Ring tests can be used to measure m conveniently at the high 
temperature and strain rate typical of hot working processes. If the deformation pressure is measured during compression it is possible to calculate the flow stress as well [20]. Ring tests have been used for porous materials also [9]. Misra et al [21] have used the ring test on different lubricants for warm and hot forming operations of Inconel 718,625, and Ti-6AL-4Va and have used the results in selection of lubricant for warm-working of sheet metal.

\subsubsection{Plane-strain drawing tests}

A flat bar or strip of thickness $h_{0}$ is drawn between inclined die surfaces to a thickness $h_{\mathrm{i}}$. The strip is free to spread to the side, and lubricant can escape in that direction too. The converging gap may be produced by two rollers fig. 5.3(a) and the strip drawn first with rolls freely rotating and then with rolls clamped. The difference in measured draw forces is approximately equal to the frictional force. By keeping the rolls clamped, but measuring the separating force $S$, as well as the draw force $\mathrm{P}$, an average coefficient of friction can be calculated using simplifying assumptions [24]. An advantage of this test is that the strip need not be pointed as the dies can indent it before commencing the test. Also new surfaces are generated by means of deforming the specimen through its entire thickness.

Wedge-shaped dies are also used with various ingenious design solutions; one such is shown in figure $5.3(\mathrm{~b})$. Other devices by Kudo et. al. and Wilson and Cazeault are described in [4].

The devices enable reducing errors due to elastic deflections, varying reductions that can be taken with dies at different angles, thereby evaluating lubricant and material parameters simultaneously, and providing for varying interface pressures figure 5.3(c).

Figures 5.4(a) through 5.4(d) show other proposed test methods for evaluating forging lubricants [4]. Forging of a rectangular slab between inclined die surfaces 
results in a shift of the neutral plane toward the converging side and an increased material flow toward the expanding side.

This principle is widely utilized when material movement in a certain direction is desired. It is also suitable for lubricant evaluation, because the position of the neutral plane depends not only on the angle of inclination but also on frictional resistance figure 5.4(a), just as it does in rolling. A better lubricant allows more material flow in the widening direction, and lubricants can be ranked by simply observing flow, or by determining average external $\mu$ or $m$ values from an appropriate theory.

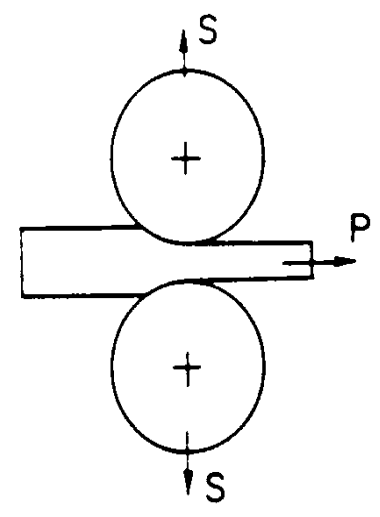

$(10 i j$

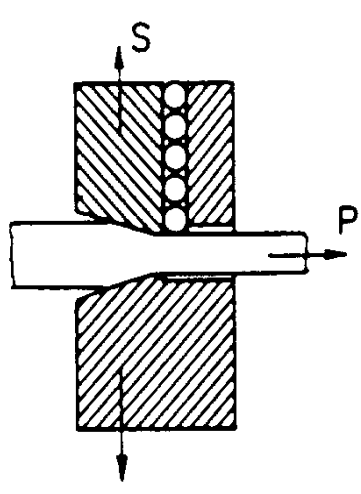

(b)

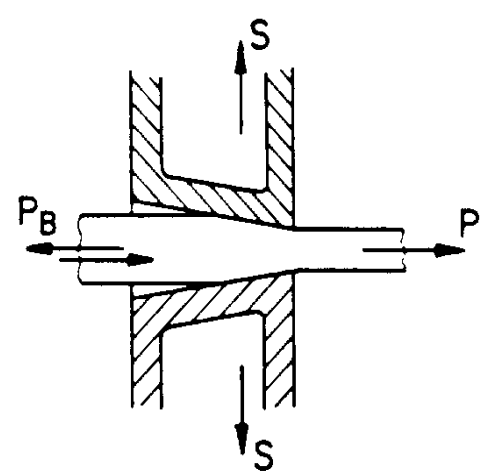

(c)

Fig. 5.3 Plane strain drawing (a) between rolls (b) with low-friction die supports and (c) with a deflecting die frame and provision for push - pull operation. [4]

Figure 5.5 shows tests involving one-sided reduction subjecting the two faces to different conditions. When the die set is composed of one flat and one angled surface figure 5.5(a), an approximate coefficient of friction can be derived at least for small die angles simply from the ratio of pull force to die separating force. The arrangement in figures 5.5(b) and 5.5(c) reduce alignment errors.

In yet other variations of plane-strain drawing, the strip is wrapped around a punch that constitutes the flat die surface (figure 5.6). Variations of this method are shown in figures $4.6(\mathrm{~b})$ and $4.6(\mathrm{c})$. Figure 5.7 shows another plane-strain drawing test configuration and its variation by Sachs [23]. Further details on these tests are included in [4]. 
Other tests that generate new surfaces while sliding under high normal pressures that serve to break through surface oxide films are shown in fig. 5.8. In one group of tests the specimen is upset [24], in another group the specimen is pushed (fig. 5.8(c)) [25] or drawn (fig. 5.8(d)) [26] through a converging die gap. In the third group of tests indenting the workpiece (fig. 5.9) generates the new surface. [4]

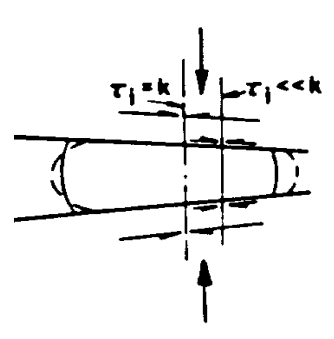

(a)

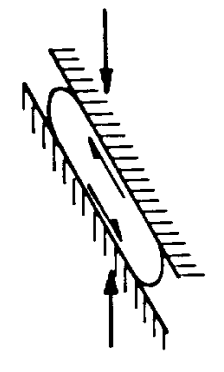

(b)

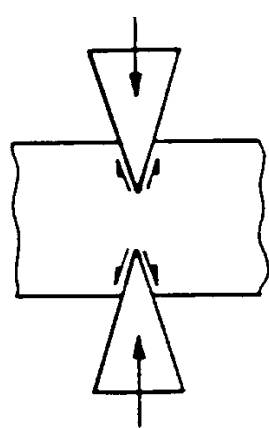

(c)

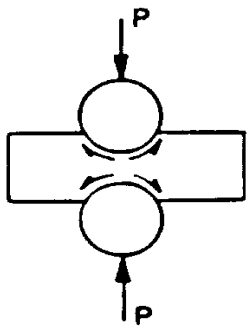

(d)

Fig. 5.4 Proposed test method for evaluating lubricants [4]

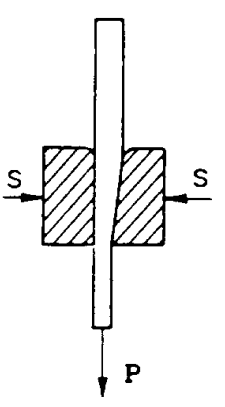

(a)

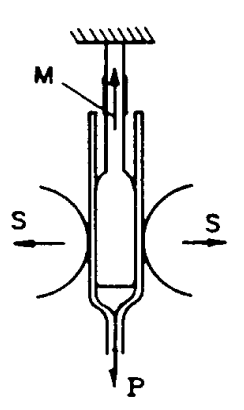

(b)

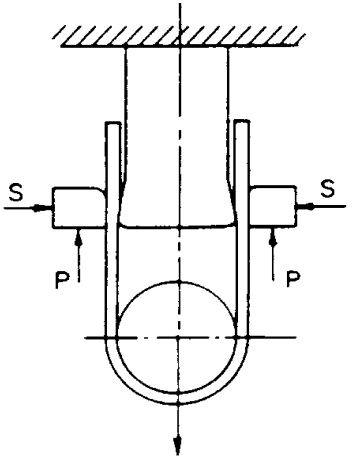

(c)

Fig. 5.5 Plane - strain drawing with one - sided reduction [4]

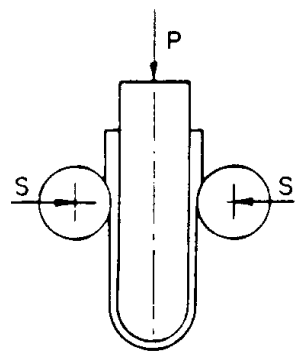

(a)

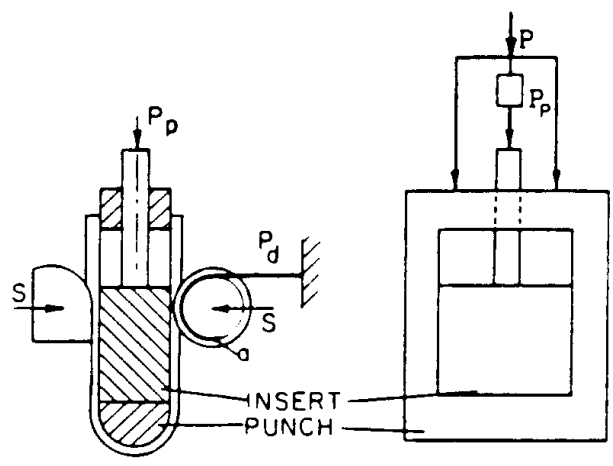

(b) (c)

Fig. 5.6 Plane - strain drawing over a stationary punch [4] 


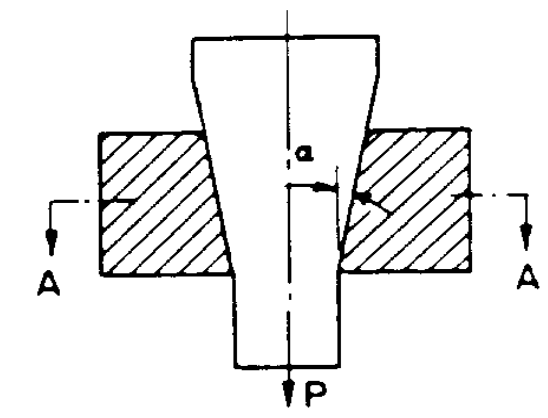

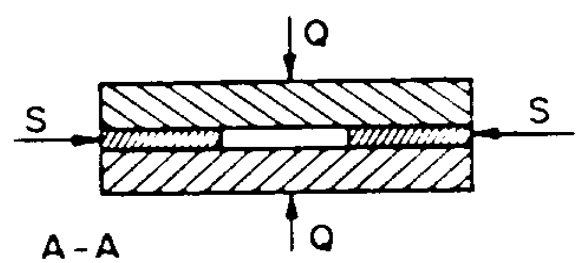

(a)

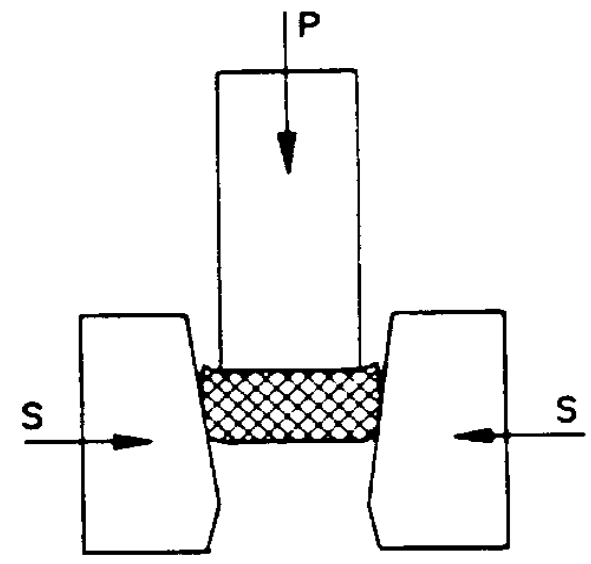

(b)

Fig. 5.7 Pulling (a) and pushing (b) in plane strain [4]

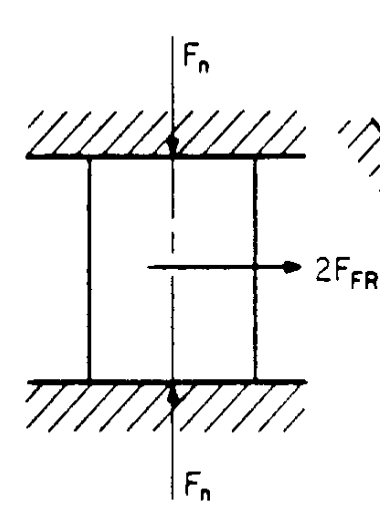

(a)

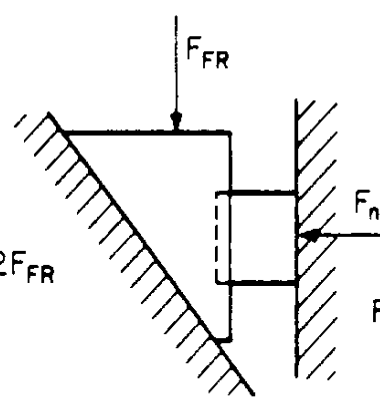

(b)

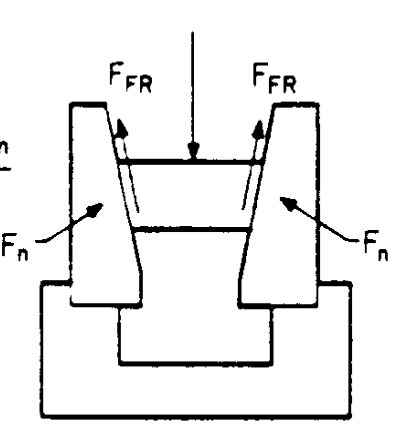

(c)

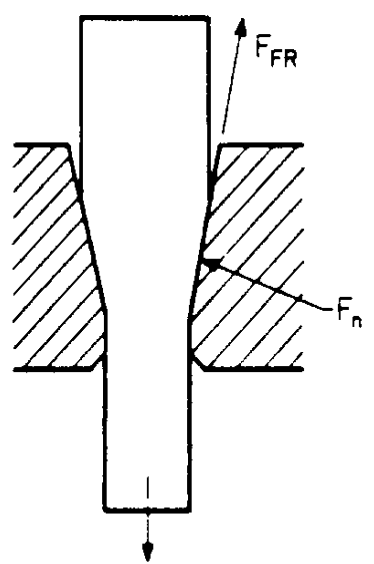

(d)

Fig. 5.8 Simulating tests with bulk deformation: (a) and (b) Upsetting with sliding. (c) Pushing through. (d) Flat bar drawing [4]

The above tests however may be good for studying lubricants used in machining.

\subsubsection{Back extrusion test}

Back extrusion is particularly sensitive to lubricant depletion under the punch and is often used as a small-scale test. Punch force $P$, normal force $S$ and frictional force $F$ are measured in a plane strain condition to determine the effect of process variables (fig. 5.9). 


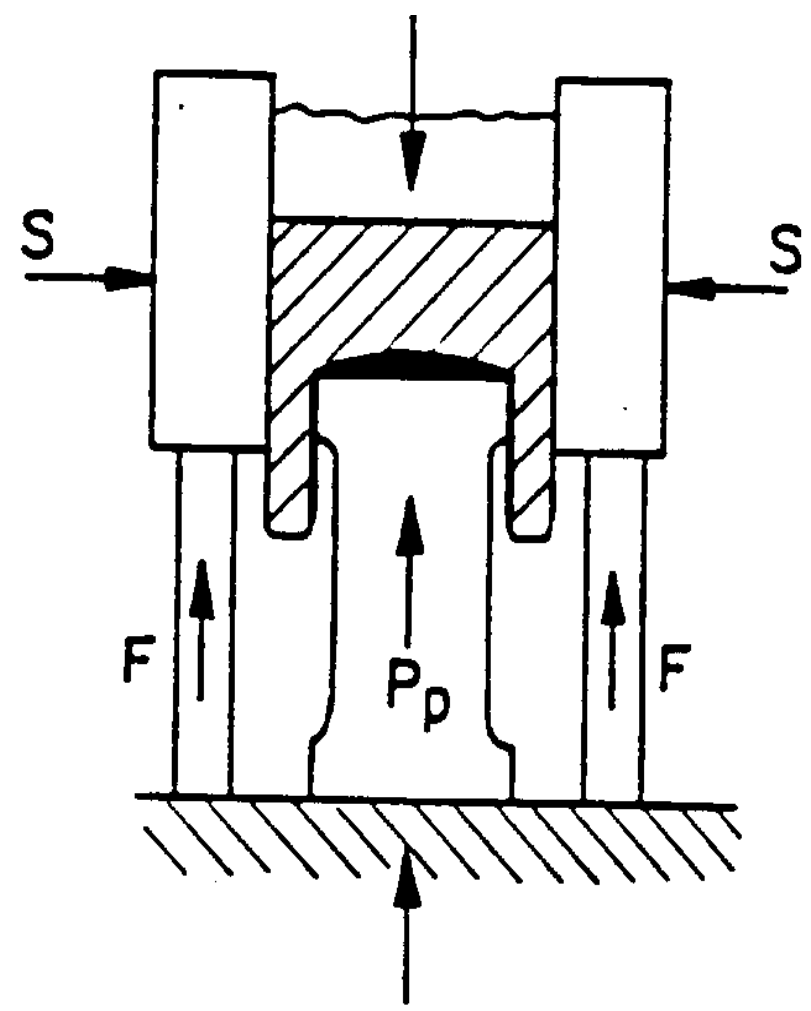

Fig. 5.9 Back extrusion test (plane strain) [27]

\subsubsection{Bucket test}

A circular billet is backward extruded to form a "bucket". The surface area of this part increases significantly during forging making it a good test for the lubricant's ability to move material. The bucket tests were conducted and the results detailed in [28]. The part does not comply as an axisymmetric or plane strain part. Both approximations were attempted on the appropriate sections of the forging and 2-D metal flow analysis conducted using 'ALPID'. Figs. 5.10, 5.11 show variation of loads and bottom thickness for different lubricants. The thickness of the bottom of the bucket with respect to stroke represents the ease of metal flow up the bucket walls for different lubricants. The bucket test provides a more complex geometry to evaluate friction with (versus simple ring tests). Higher pressures are encountered in the bucket test compared to the ring test. The correlation of experimental results with FEM analysis with axisymmetric or plane-strain assumptions are questionable. Also FEM analysis of bucket geometry requires remeshing. 


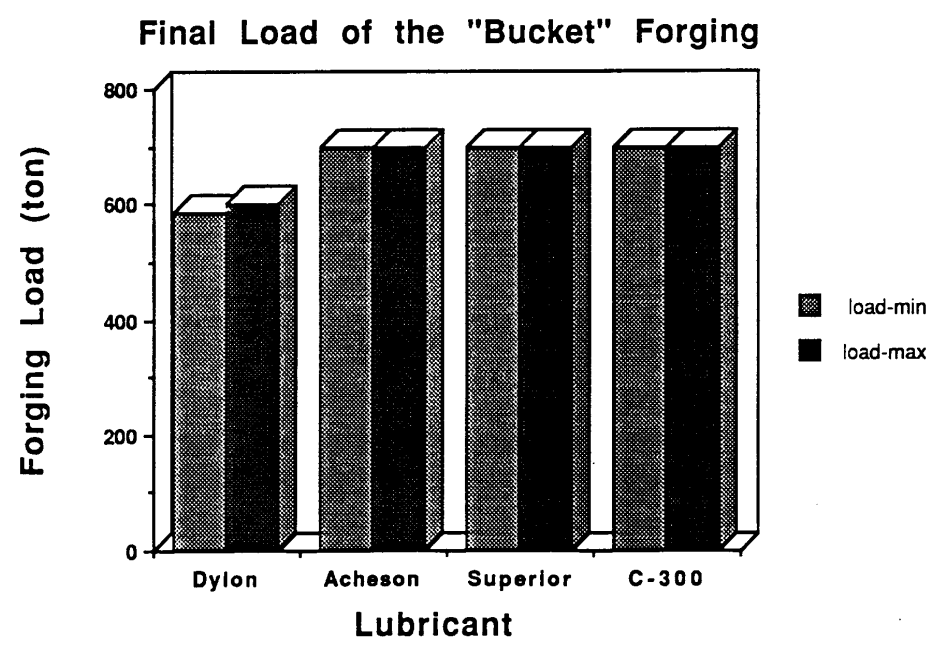

Fig. 5.10 Comparison of the final forging load in Bucket tests [28]

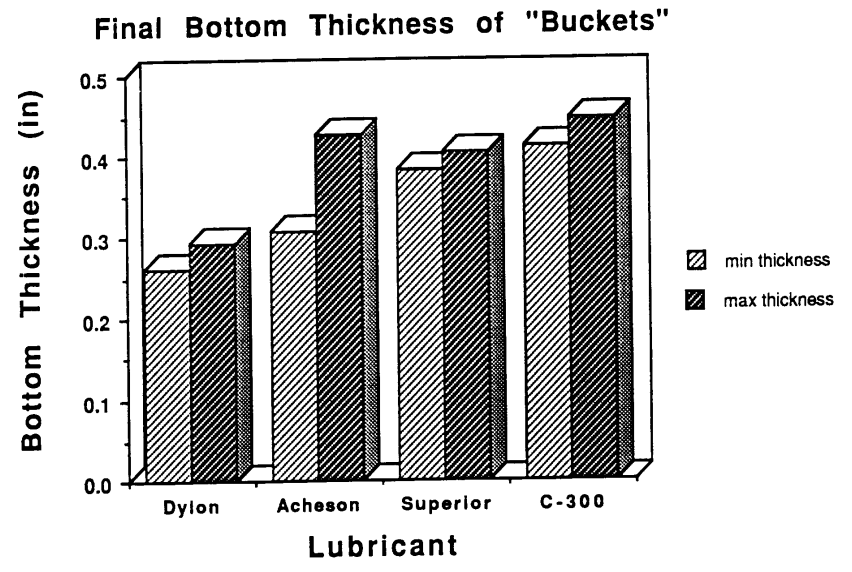

Fig. 5.11 Comparison of the final bottom thickness in bucket tests [28]

\subsubsection{Cold forging test- (cetim-forgelube test) [29]}

Figure 5.12 shows the set-up of the above test. The forging operation is a nonsymmetrical upsetting (heading). The slug surface is lubricated and pressed against a flat plate the roughness of which is tightly controlled and maintained constant. It is pressed through a cavity that is lubricated.

In the second step the head of the upset workpiece is rotated upon two bearing balls. Balls are locked in rotation. The test goes on until lubricant film breaks down. The load and rotation speeds remain constant. 
The variation of the surface expansion of the head as well as the strain hardening of the material represent friction conditions during the test. Figure 5.13 represents FEM simulation of heading used to determine calibration curves. Figure 5.14 shows experimental surface expansion versus varying $\mathbf{m}$. The second part of the test covers issues of lubricant and specimen tool surface (tribological test).
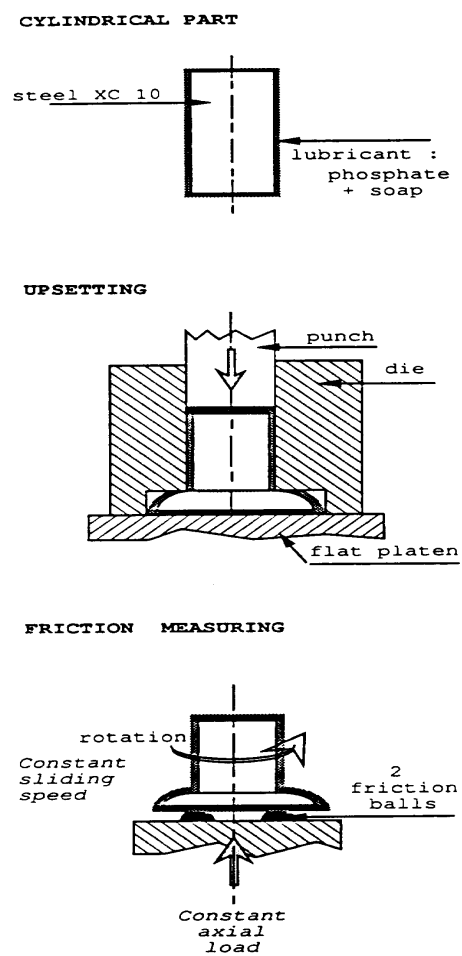

Fig. 5.12 CETIM - FORGELUB Friction test [29]

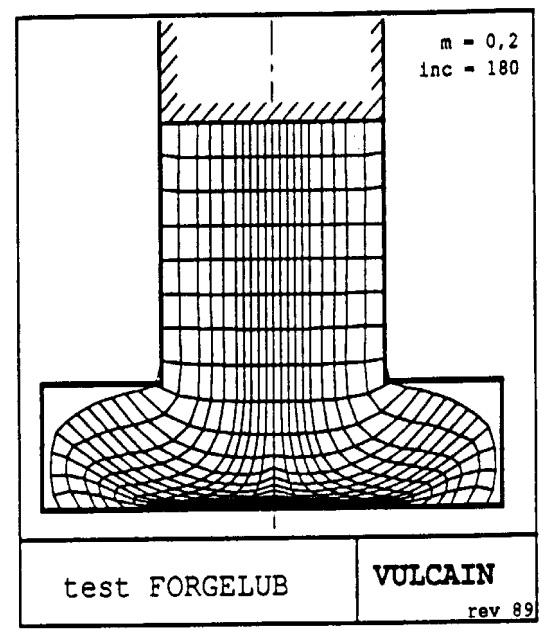

Fig. 5.13 FEM Simulation [29] 


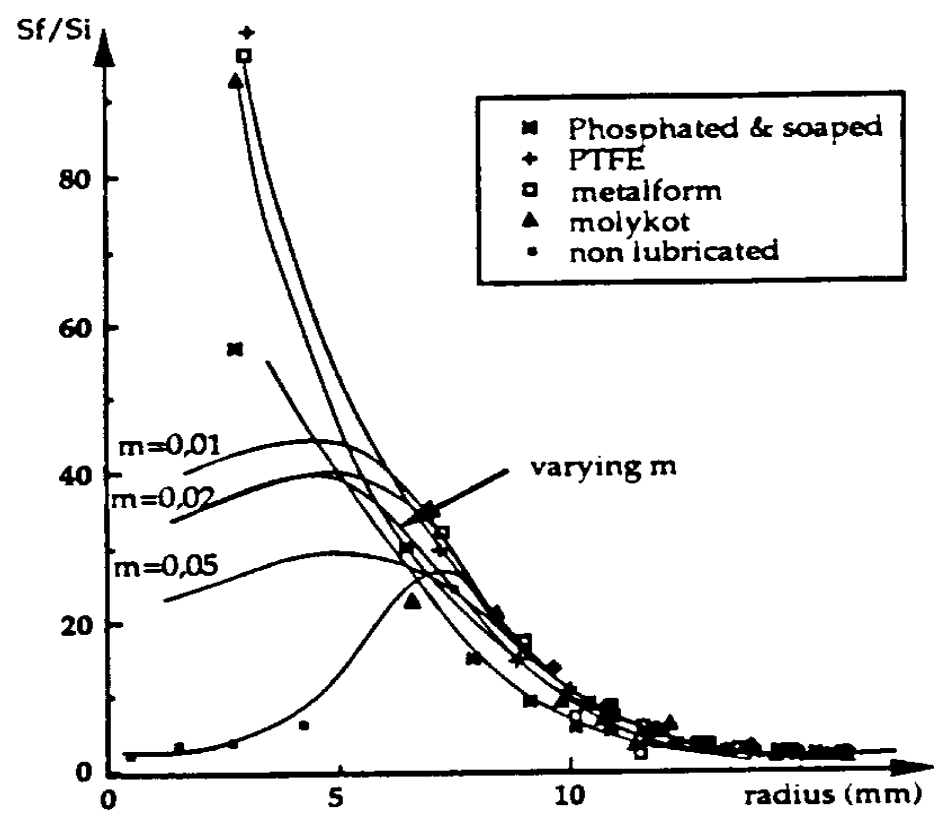

Fig. 5.14 Experimental surface expansion [29]

\subsection{Comparison of various testing methods}

Schey discusses [4] some of the lubrication evaluation methods for different operations for different materials. There is no doubt that back extrusion is the most discriminating test for judging the resistance of the lubricant to breakdown. Ring compression tests have also been done for friction evaluation of hot forging processes.

The Ring test is useful in determining friction factor, $\mathbf{m}$, for a given lubrication and specified forging conditions. The ring test correctly predicts such features as the breakdown of the phosphate / soap system above $200^{\circ} \mathrm{C}$ and the improvement in lubricating performance with increasing coating weight in cold extrusions. However, metal flow and die geometry is simple and the characteristics of a forging lubricant cannot be fully evaluated. Nevertheless, the ring test helps identify and eliminate lubricants with high friction factors. The bucket test was used to further evaluate lubricants under a condition similar to backward extrusion with a higher forging pressure. Under a pre-designated press load, the best lubricant can forge the bottom of the part to the minimum thickness in the 
bucket test. Oil base and water-base lubricants used in the test behaved differently. Shen, et. al. [28] proposed an approach to generate friction calibration curves for bucket type of forging instead of evaluating relative performance of the lubricants.

In a ring test, the forging load and the I.D. (inner diameter) of the ring are influenced by friction but only the I.D. is considered in friction calibration, as the former is not a friction sensitive parameter. However, in a bucket test the forging load and the bottom thickness can be chosen together to represent friction. Also an axisymmetric bucket is proposed for the test for ease of evaluation by analysis methods.

Another advantage claimed with the bucket test is that the load and bottom thickness can be obtained without stopping the test. Thus the experimental friction value at any specific stage can be obtained after the test. The factoring of load and bucket bottom thickness as a friction evaluation parameter is empirical. However, work hardening has a major effect on results. The bucket-test is material dependent.

For various forming conditions, the values of $m$ vary as follows: [1]

- $\mathbf{m}=0.05$ to 0.15 in cold forming of steels, aluminum alloys and copper, using conventional phosphate-soap lubricants or oils.

- $\mathbf{m}=0.2$ to 0.4 in hot forming of steels, copper and aluminum alloys with graphite-base (graphite-water or graphite-oil) lubricants.

- $\mathbf{m}=0.1$ to 0.3 in hot forming of titanium and high-temperature alloys with glass lubricants.

- $\mathbf{m}=0.7$ to 1 when no lubricant is used, e.g., in hot rolling of plates or slabs and in nonlubricated extrusion of aluminum alloys. 
Therefore the testing method must be sensitive in the ranges of friction factors that normally occur in cold and hot forming to be applied for lubrication evaluation in that particular process (hot or cold). In determining the friction factor, $f$, or the shear factor, $\mathbf{m}$, for hot forming, in addition to lubrication effects, the effects of die chilling or heat transfer from the hot material to colder dies must be considered. Therefore, the lubrication tests used for determining friction factors must include both lubrication and die-chilling effects. Consequently, in hot forming, a good test must satisfy as much as possible the following requirement [2]:

- The specimen and die temperatures must be approximately the same as those encountered in the actual hot forming operation.

- The contact time between specimen and tools under pressure must be approximately the same as in the forming operation of interest.

- The ratio of the new generated deformed surface area to the original surface area of the undeformed specimen must be approximately the same as in the process investigated.

- The relative velocity between deforming metal and dies should have approximately the same magnitude and direction as in the forming process.

As long as the evaluation method can be performed at cold and hot working temperatures, are able to handle the different lubrication systems, account for heat transfer, die chilling and different friction ranges at the hot forming temperatures, it may be applied to evaluate friction for both processes. Therefore, some methods may be preferred in cold to hot forging and vice-versa. In general, friction evaluation methods at high temperatures need to maintain the die and workpiece at the hot working temperatures or appropriately compensated by analysis methods for heat loss, temperature gradients etc. Ring tests, upset tests, compression tests, etc. can be performed to evaluate lubricants both for hot and cold forging but the choice is made based on factors discussed. 
In most forming applications, the lubricity of a lubricant is the single most significant factor since it directly determines the interface friction, which in turn influences the stresses, the forming load and energy. In order to evaluate the performance of various lubricants and to be able to predict forming pressures, it is necessary to express the interface friction quantitatively, in terms of a factor or coefficient [15]. 


\section{CHAPTER 6}

\section{DOUBLE CUP BACKWARD EXTRUSION TEST}

\subsection{Purpose of test}

The objective of the double cup backward extrusion test is to establish a correlation between the ratio of the extruded cup-heights to the friction conditions between the billet surface and the punch and die container. The friction conditions at the workpiece - die container interface is expressed as a number known as the friction factor $\mathbf{m}$ which varies between 0 and 1 . If such a correlation can be established, then the existing friction conditions can be quantified. The goal of the double cup backward extrusion test method is to:

1. determine a friction factor using experiments on the one hand and appropriate calibration curves (determined by computer - aided metalflow simulations) on the other

2. provide information on the quality of a lubricant coating from a production coating line using workpieces from that line and

3. compare various lubricants

This particular test method was chosen because it provides an effective means of measuring friction in cold forging operations. The concept was initially explored by Dr. Taylan Altan from Ohio State University and Dr. Klauss Weinmann [33] from Michigan Technological University. The test method has the additional advantage of measuring friction with a technique that closely simulates cold forging conditions at Delphi Saginaw Steering Systems, which are:

- time of contact between the workpiece and the die under pressure

- amount of new surface generation

- simultaneous backward and forward extrusions 
- high forming pressures

Conditions encountered in industrial production are therefore closely reflected by this test method i.e. high surface pressure, severe material flow, substantial surface enlargement, etc.

\subsection{Theory of double-cup backward extrusion test}

In this test, the top punch is moved downwards, while the bottom punch and the die are kept stationary. The reduction ratios are the same for both the top and the bottom extrusion dies. Additionally, the diameters of the punch and the anvil are the same. The billet is placed in the die container. The billet extrudes simultaneously in the backward and forward directions as shown below in fig. 6.1.

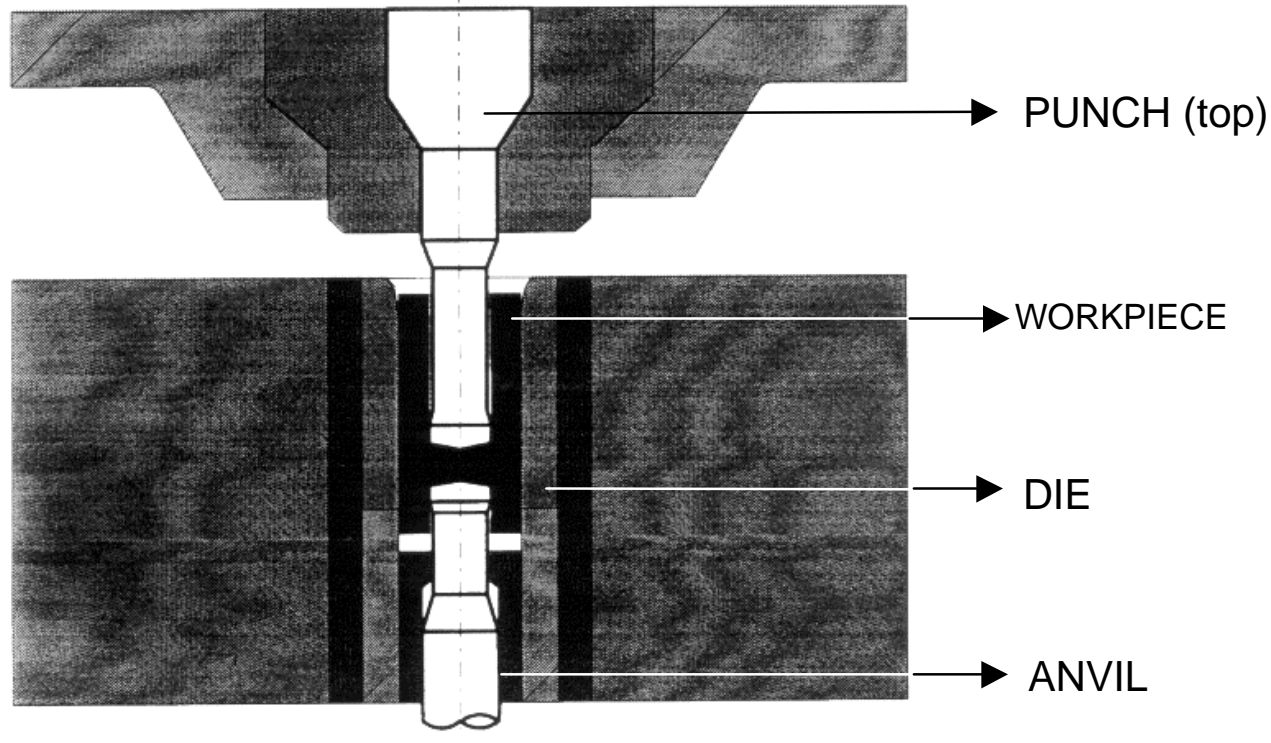

Fig. 6.1 A geometric representation of the test set up.

If the friction conditions between the die wall and the billet were to be zero, the length of the forward extrude would be equal to the length of the backward extrude. However, due to friction, the backward extruded cup is longer than the forward extruded one. The difference in the extruded lengths becomes larger as the friction increases. 
In this study, the friction shear factor $\mathbf{m}$ was chosen for characterization of friction because it represents the friction conditions in forging, where the interface stresses are large, better than the Coulomb law.

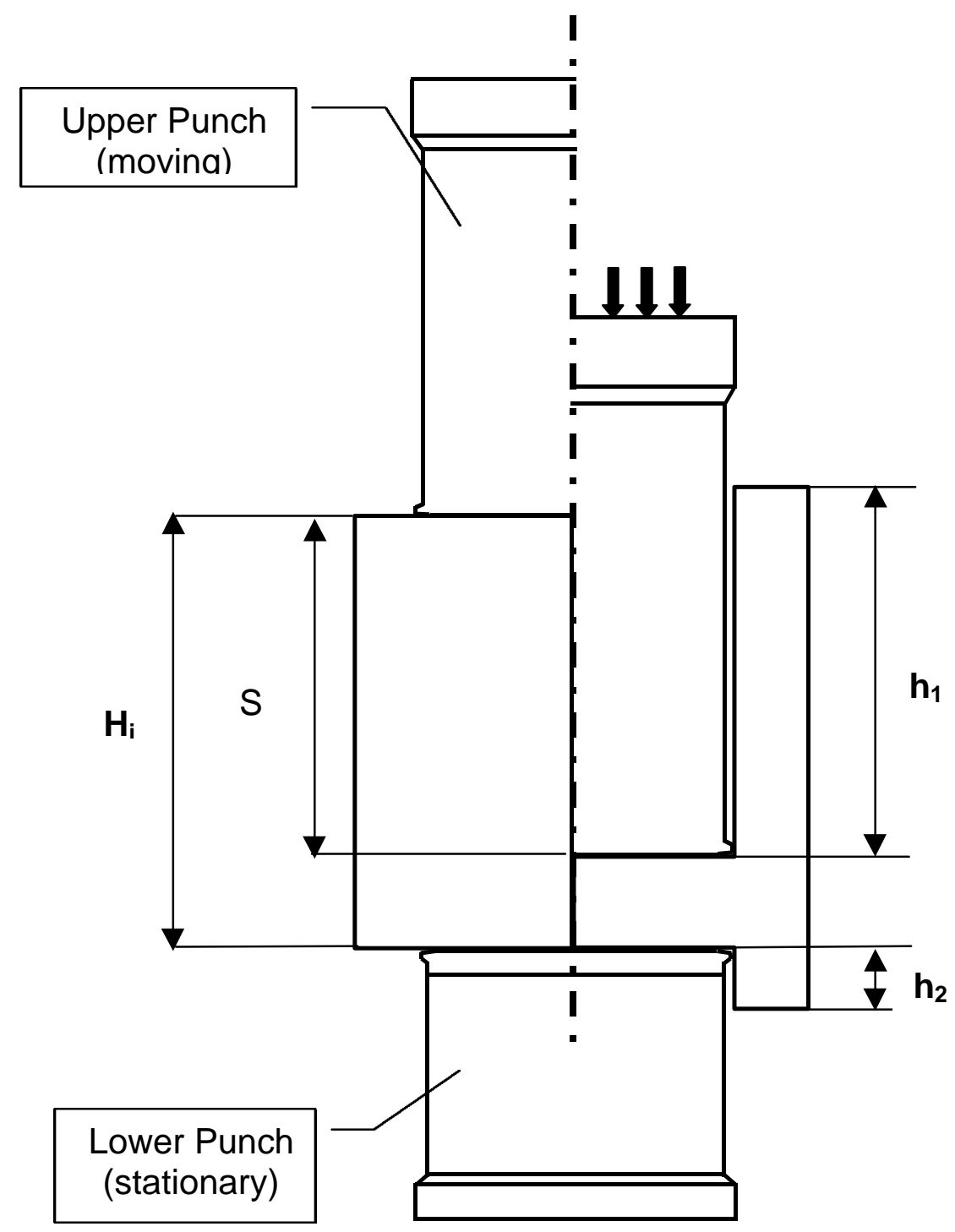

Fig. 6.2 The billet / workpiece before and after deformation

Furthermore, the $\mathbf{m}$ value is very common in USA. Therefore, any results from the test could easily be compared with other methods or data. Shown in fig. 6.2 is a sketch of the billet before and after the test. The height $\mathbf{h}_{1}$ and $\mathbf{h}_{\mathbf{2}}$ is measured. 
The ratios are calculated and tabulated for a given lubricant type and relative stroke.

The ratios of the cup heights are then plotted against the relative stroke. This plot is then calibrated against a graph generated by computer simulations of the process with varying values of $\mathbf{m}$. The simulation plots cup - height - ratios (CHR) for incremental values of stroke. Many such curves are generated for different values of friction conditions (friction factor $\mathbf{m}$ ) in the simulation. The CHR obtained from the experimental results are then be compared with these plots to determine the friction factor $\mathbf{m}$. A higher value of the CHR denotes a higher friction condition and therefore poor lubricity of the coating.

Each curve in the calibration curves generated from the FEA simulations reaches a maximum after the initial increase. With increasing percentage deformation (deformation stroke of the punch), the magnitudes of initial peaks decrease. This is attributed to the fact [33] that the peak coincides with the punch stroke that provides the lower cup height close to the length of the extrusion land on the lower punch (anvil). As the top surface of the lower cup passes through the space between the punch land and the die insert, the resistance to metal flow in the lower cup increases, compared to that of the upper cup. This transitional behavior of the cup heights is dependent on the length of the extrusion land.

\subsection{Design of experiment}

The main task for this effort is to find a combination of process parameters that would best indicate a small change in the lubrication conditions. The friction conditions might change towards the end of the deformation due to thinning of the lubrication layer, but this effect can be neglected if the punch does not move very deep into the workpiece.

- Relative stroke is defined as the ratio of the amount of travel of the punch (after making contact with the workpiece) to the initial height of the workpiece 
(3-in.). In other words, relative stroke is defined as the ratio of the deformation stroke to the initial height of the workpiece. From fig. 6.2:

$$
\text { Relative Stroke \% = }\left(\mathrm{S} / \mathrm{H}_{\mathrm{i}}\right) \times 100
$$

(Note: $S$ need not be equal to $h_{1} . h_{1}$ is a function of the lubrication at the workpiece die interface as is $h_{2}$.)

- Reduction ratio: defined as [33]

$$
\begin{array}{ll}
\mathrm{e} & =d_{\text {punch }}^{2} / d^{2}{ }_{\text {billet }} \\
\mathrm{e} & =d_{\text {punch }} / d^{2}{ }_{\text {container }}
\end{array}
$$

Punch Diameter for the experimental setup:

$25.40 \mathrm{~mm}(0.999 " / 1.001 ")$

Billet Diameter for the experimental setup:

$49.81 \mathrm{~mm}(1.960 " / 1.962 ")$

Container Diameter the experimental setup:

$49.87 \mathrm{~mm}(1.963 " / 1.964 ")$

The reduction ratio for this experimental setup is: 0.26

Studies [33] have shown the difference in the cup heights is maximum for the reduction ratio $\mathrm{e}=0.20$ thereby allowing for better detection of change in friction condition in the experimental setup. A reduction ratio $\mathrm{e}=0.26$ was chosen for this experimental setup since punches with small diameters are difficult to manufacture and may fail relatively easily. The thinner a punch is compared to its height; the higher is the possibility of vertical bending of the punch. This results in eccentric parts, which would impair the quality of the experiments. In the worst case bending could even lead to failure of the punch.

- The height of the billet is: $76.20 \mathrm{~mm}(2.999 " / 3.001 ")$

Billet Diameter for the experimental setup:

$49.81 \mathrm{~mm}(1.960 " / 1.962 ")$

The ratio of billet height to diameter $h_{0} / d_{0}$ for setup is

Studies [33] have shown that the difference in the cup heights is maximum for the ratio of billet height to diameter $h_{0} / d_{0}=2.0$. The study also shows the magnitude of the cup height ratio does not increase significantly in the range from $h_{0} / d_{0}=1.5$ to $h_{d} / d_{0}=2.0$. Therefore the $h_{0} / d_{0}$ ratio does not have to be any bigger than 1.5. Moreover, the height of the extrusion punch should not 
exceed 2.5 times its diameter to prevent failure. The unsupported height of the punch used for this experimental setup is 1.742" and its diameter is 1.000". This causes a limitation to the punch travel for the chosen geometry. The stroke of the upper punch should be less than $35 \mathrm{~mm}$ for a reduction ratio of $e=0.25$. To be thorough, punch strokes up to $30 \mathrm{~mm}$ have been investigated. Since for $h_{0} / d_{0}=2.0$ the workpiece is not deformed sufficiently with this limited punch travel, $m$-value variations have been examined for $h_{0} / d_{0}$ ratio $=1.53$ for this experimental setup.

- Tooling set-up and dimensional details of the individual pieces of perishable tooling are shown in appendix $\mathrm{D}$. The tooling design is based on principles of die design as outlined in Verson's book on Impact Machining [31]. The backward extrude punch and anvil designs are based on studies conducted by Altan et. al. in their publication on design parameters effecting the punch and anvil in the double backward extrusion of aluminum and steel [33].

- Three different percentages (30\%, $40 \%$ and $50 \%$ ) of relative stroke are employed to reduce the height of the billets. Six billets are used for each lubricant and relative stroke combination. This is done to obtain more repeatable results and also determine the statistical variance.

Two companies that manufacture industrial lubricants were also invited to participate. The companies are IRMCO and Acheson Colloids. The research and development departments from both companies have developed cold forging lubricants which are seen as an alternative to the acid pickling and coating process that is currently in place. A list of coatings is shown in the table below. Eleven different coatings are tested and evaluated. While the coatings "Fitch", "Karst", "Black lubricant" and Polymer are applied in house using current coating processes that are used in production, the coatings from the companies IRMCO and Acheson Colloids were coated on the outside by the companies themselves. The billets for all these coatings, however, are provided for by Delphi Saginaw Steering Systems. 
- The FITCH and KARST coatings are the regular phosphate coatings that are typically used in cold forging applications. These two coatings get their unique names from the two coating lines in Plant 4, Delphi Saginaw Steering Systems.

- "Black lubricant" is a non-reactive lubricant used at Plant 5, Delphi Saginaw Steering Systems. The Mn stearate soap applied on the $\mathrm{Zn}$ phosphate surface does not react with it. The polymer coating is a lubricant applied over the $\mathrm{Zn}$ phos coat.

- IR-1, IR-2, IR-3 \& IR-4 are coatings from the company IRMCO. While IR-1 \& IR-2 are coatings that were deposited on a surface that had been phos coated, coatings IR-3 \& IR-4 were lubricants deposited on surfaces that had no phos coat.

- $\mathrm{AC}-1, \mathrm{AC}-2, \mathrm{AC}-3$ are coatings from the company Acheson Colloids.

\begin{tabular}{|c|c|c|}
\hline SL. \# & PLANT No. & COATER TYPE / I.D. \\
\hline 1 & 4 & FITCH \\
\hline 2 & 4 & KARST \\
\hline 3 & 5 & BLACK LUBE \\
\hline 4 & 5 & POLYMER \\
\hline 5 & IRMCO & IR-1 \\
\hline 6 & IRMCO & IR-2 \\
\hline 7 & IRMCO & IR-3 \\
\hline 8 & IRMCO & IR-4 \\
\hline 9 & ACHESON COLLOIDS & AC-1 \\
\hline 10 & ACHESON COLLOIDS & AC-2 \\
\hline 11 & ACHESON COLLOIDS & AC-3 \\
\hline
\end{tabular}




\subsection{Description of apparatus}

The tests are conducted on a 1000-Ton vertical acting mechanical press. The manufacturer of the press was USA Clearing Ltd. The press specifications are given below:

\section{Press Specifications}

SSG \# 45933

Style S-1

Shut height 44.0"

Tonnage $1000 \mathrm{~T}$
Model \# F-1

Bed (LR) 42"

Stroke length 20"
Serial \# 17352

Size (FB) 42"

Strokes/min 45

Shut Height of a press is defined as the distance between the bottom of the ram of the press and the top of die bed.

Stroke length of a mechanical press is defined as the distance between the "Top dead center" and the "Bottom dead center" of the press.

\subsection{Method of determining and setting the ram stroke}

The stroke of the press ram can be adjusted by electrically turning the worm which in turns the threads on the slide thus increasing or decreasing the length of the pitman. A button on the control panel of the press activates a motor that turns the worm. The amount of travel is shown on the ram shut height counter that is located on the slide of the press. The counter is calibrated to the thousandths of an inch. The line diagram of this set - up is shown in the fig. 6.3.

The three levels of relative stroke to obtain the deformation percentages $(30 \%$, $40 \%$ and $50 \%$ ) for experiments are obtained by lowering the ram in steps by turning the worm as mentioned before. The exact amount of descent of the ram is verified both on the ram counter as well as the distance traveled by affixing an indicator to one of the guide pins of the press. 

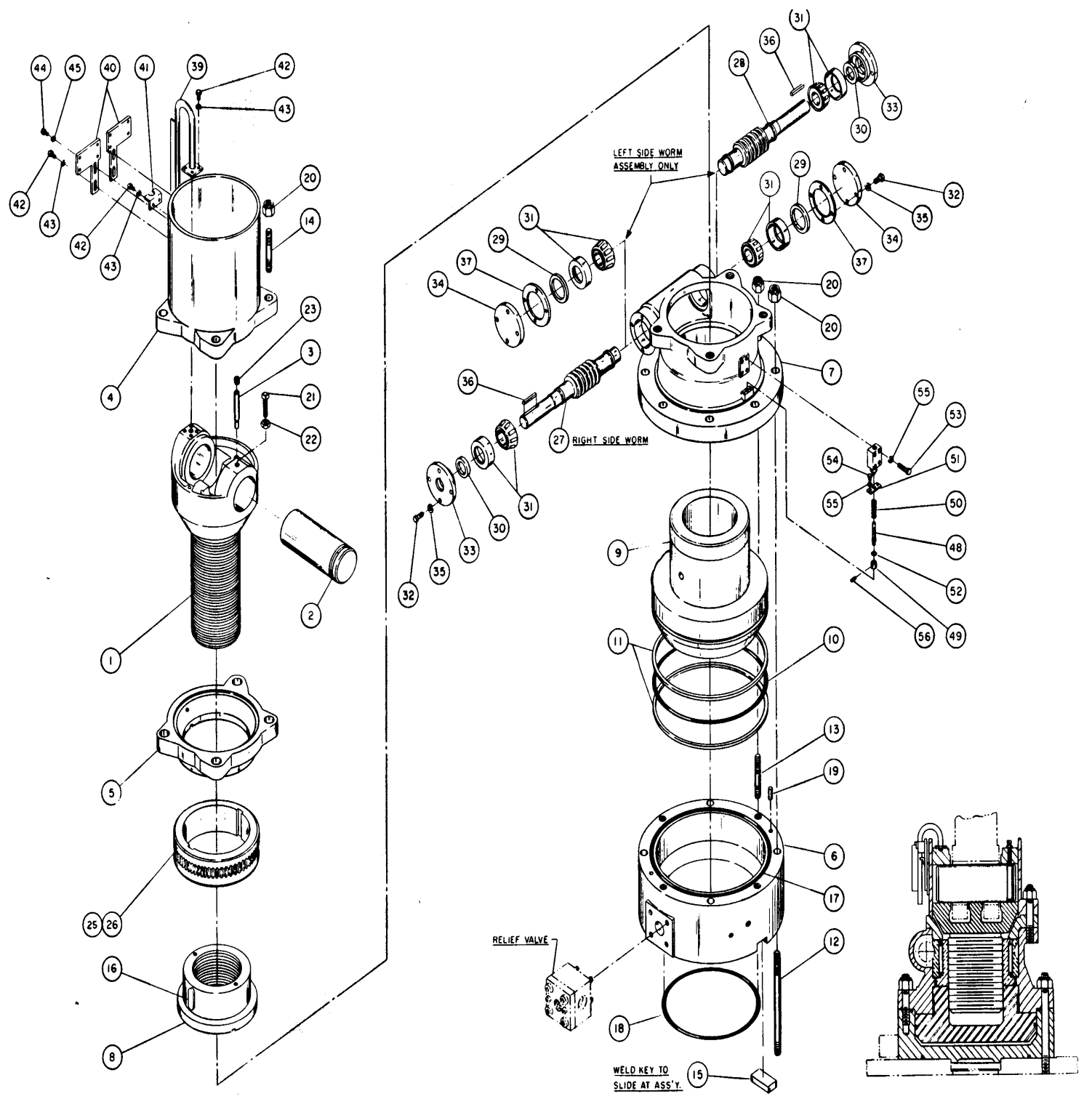

Fig. 6.3 Assembly diagram of press ram shut height adjustment

\subsection{Friction test Procedure}

The experimental procedure can be classified into the following categories:

1. Preparations prior to the test

2. Procedure for each test run

3. Quality control and adjustments after each run 


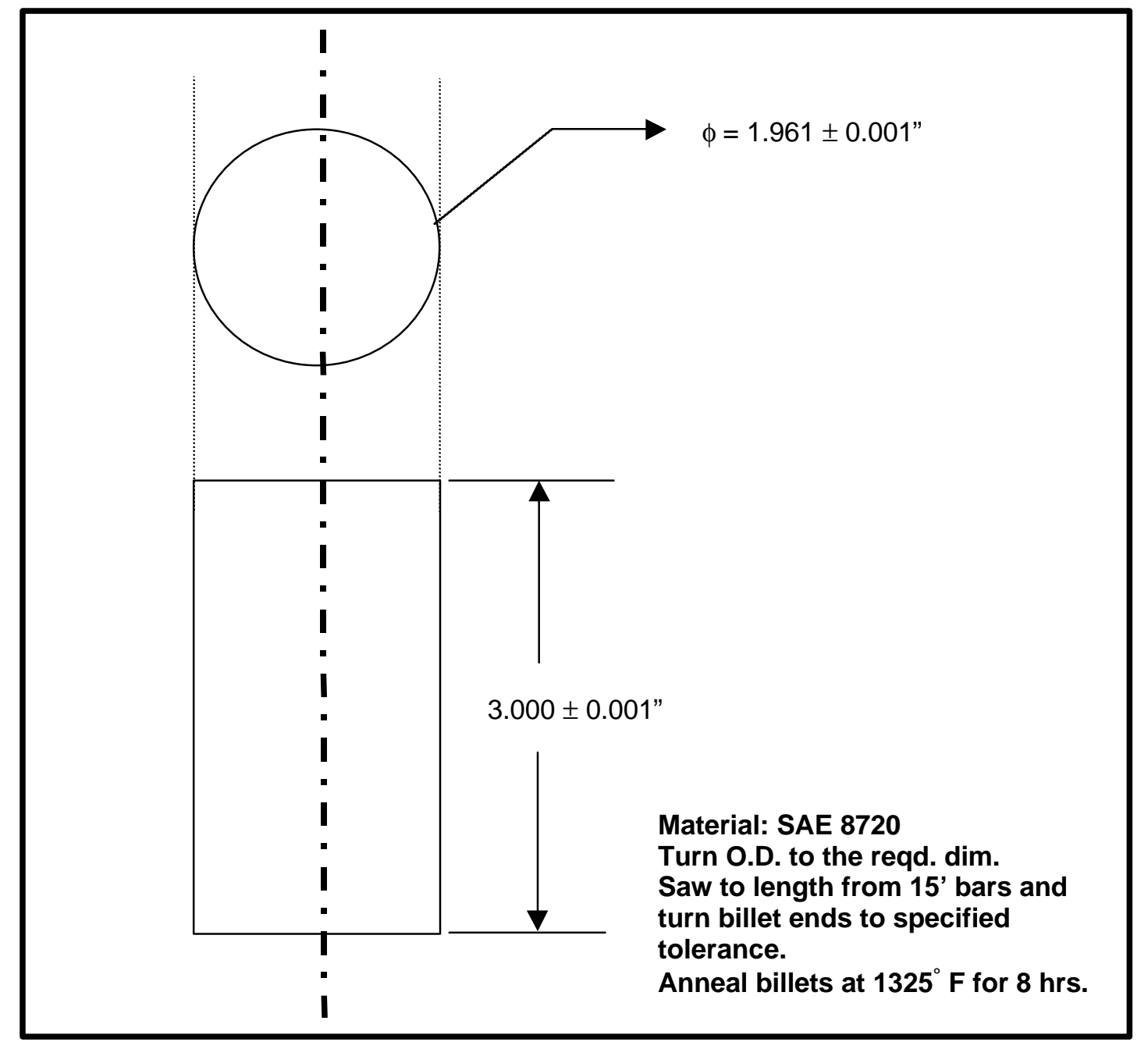

Fig. 6.4 Billet dimensions for the double-cup backward extrusion friction tests

\subsubsection{Preparations prior to the test}

\subsubsection{Design of experiment and Procurement of designed tooling}

- The perishable tooling in contact with the workpiece was designed and ordered from the fabrication source. The prints of the tooling designed and ordered are enclosed in Appendix C.

- The designed tooling was received and inspected against the prints and found to be acceptable

- Diameter of the punch

$=\quad 1.000 \pm 0.001 "$ 
- Diameter of the anvil

- Diameter of the container $=\quad 1.000 \pm 0.001 "$

$=1.9635^{\prime \prime}$

\subsubsection{The billet manufacturing and annealing process}

The tests were conducted using annealed cylindrical billets of ASTM 8620 steel. The dimensions of the billet are as shown in figure 6.4.

- The test plan / design of experiment was completed. Number of billets of steel required for testing was determined. The test plan is as shown in table 6.1.

- 14 - 16 feet long hot rolled bars of 8620 steel were procured from steel supplier (Republic Steel Co.).

- Procured Bars were 2.5" in diameter.

- Bars were sawn and CNC machined down to $3 " \pm 0.001$ " in length. Thereafter, the diameters were turned down to $1.961 " \pm 0.001 "$.

- The sawn billets were then annealed through cycle of $1325^{\circ} \pm 10^{\circ}$ for 8 hours. This annealing cycle is used for processing billets used in production.

- Predetermined number of billets were put in enclosed baskets and processed with regular production billets through both the Fitch and Karst coater in plant 4. Similarly, billets were processed through the "pickle house" (the coating department) at plant 5 and coated with the Conventional ("Black lubricant") coating and the Polymer coating.

- Billets were sent to Acheson Colloids and IRMCO to have them apply their coatings. They were provided instructions on the number of billets required with each formulation of their coating. The method of application was not standardized.

- Detailed charts were drawn up to capture the order of the experiments and the lubricant type used on each billet of material. Chart is shown in Appendix 
- The tooling was pre-assembled into the compression rings to facilitate the assembly of tooling in the press and reduce time lost on press.

\subsubsection{The billet coating process on site}

The typical steps involved in phosphate coating at the plants at Saginaw include the following steps:

- Clean the surface to remove rust, anneal scale, soap lubricants, other foreign soils, etc. with an alkaline cleaner

- Rinse the above alkaline cleaner with hot water to prevent contamination of the subsequent baths

- Pickle the steel in sulfuric acid baths maintained at an elevated temperature $\left(150^{\circ} \mathrm{F}\right)$ for a few minutes to remove any leftover hot-rolled mill scale and any oxides of iron.

- Rinse in cold water

- Rinse immediately in hot water

- Deposit the phosphate coating through a chemically reactive process. The phosphate coating forms a covalent bond with the iron surface.

- Rinse in cold water

- Neutralize the acidic surface from the previous phosphating bath

- Apply the necessary lubricant (black lubricant, synthetic, stearate, etc.)

- Dry

\subsubsection{Test procedure for each run}

- The deformation stroke was calculated using Aluminum test pieces ordered specifically for this. Eight pieces were used to set-up. The ram was very slowly lowered until it just touched the top of the billet surface and then the press was run on automatic. Once the starting point was established, subsequent increases in relative stroke was adjusted by electrically turning 
the worm wheel as described before. As an additional check, the amount of travel on the vertical guide pins of the press were also observed and noted down.

- The set up was repeated to ensure that start of relative stroke was accurate.

- The coated billets were manually loaded into the die cavity and the press operated by the plant's press operator. Six billets were loaded into each experimental set up combination of relative stroke and coating one after the other to ensure repeatability. After each extrusion the punch, anvil and die container was examined visually to ensure that there was no "pickup" or galling.

- The order of the test was carefully noted down and the now extruded double cup marked with permanent ink immediately after ejecting it from the die for future reference for checking the cup height ratios. The table into which the experiment number that was recorded on the billet is shown in Appendix $A$.

- Occasionally, the top punch would gall indicating breakdown of lubricant between the punch and the workpiece. This happened especially at higher percentages of deformation and with the experimental coatings from the outside suppliers.

- Those coatings that caused galling on the punches were discontinued from the test in order to ensure that the punch and the anvil could be used for the remaining coatings. When galling occurred, the punch was polished with emery paper to remove the galling. 
TABLE 6.1: PARAMETER COMBINATIONS FOR THE DESIGN OF THE EXPERIMENT

\begin{tabular}{|c|c|c|c|c|c|c|c|c|c|c|c|c|}
\hline Materia & $\left|\begin{array}{c}\% \text { Rel. } \\
\text { Stroke }\end{array}\right|$ & $\begin{array}{c}\text { IRMCO } \\
1\end{array}$ & $\begin{array}{c}\text { IRMCO } \\
2\end{array}$ & $\begin{array}{c}\text { IRMCO } \\
3\end{array}$ & $\begin{array}{c}\text { IRMCO } \\
4\end{array}$ & $\begin{array}{c}\mathrm{AC} \\
3\end{array}$ & POLYMER & $\begin{array}{c}A C \\
2\end{array}$ & KARST & FITCH & $\begin{array}{c}\text { AC } \\
1\end{array}$ & $\begin{array}{l}\text { "BLACK } \\
\text { LUBE" }\end{array}$ \\
\hline \multirow{3}{*}{8620} & $30 \%$ & 6 pcs. & 6 pcs. & 6 pcs. & 6 pcs. & 6 pcs. & 6 pcs. & 6 pcs. & 6 pcs. & 6 pcs. & 6 pcs. & 6 pcs. \\
\hline & $40 \%$ & 6 pcs. & 6 pcs. & 6 pcs. & 6 pcs. & 6 pcs. & 6 pcs. & 6 pcs. & 6 pcs. & 6 pcs. & 6 pcs. & 6 pcs. \\
\hline & $50 \%$ & 6 pcs. & 6 pcs. & 6 pcs. & 6 pcs. & 6 pcs. & 6 pcs. & 6 pcs. & 6 pcs. & 6 pcs. & 6 pcs. & 6 pcs. \\
\hline
\end{tabular}




\section{CHAPTER 7 \\ FINITE ELEMENT ANALYSIS OF DOUBLE CUP BACKWARD FRICTION TEST}

\subsection{Introduction}

The biggest challenge to applying FEA to metal forming problems is setting up the conditions, preparing the mesh and then applying the boundary conditions. Thereafter, the problem is in interpreting the results to optimize the shape of the workpiece and the dies.

Generic steps in the Finite Element Method

1. Start with the preform in contact with one or more dies.

2. Approach the other dies until first point is touched.

3. Initialize the problem.

4. Calculate the velocity field.

5. Choose the time increment.

6. Update positions, strains, strain-rates

7. Update boundary conditions

8. Force sliding nodes onto surface

\subsection{Procedure for setting up simulation along with parameters used}

The ANTARES software package is installed on a HP C-10 UNIX workstation. Typing in the command ANTARES opens it. The opening screen depicts six different buttons, which are menus for performing different components of the simulation. The six sub menus are as follows: 
Material Data

Results
Input

Animation
Simulate

Utilities

\subsubsection{Material specification in the Material Data sub menu}

The material data menu allows for the definition of the mechanical properties in a generic format that can then be imported into the preprocessor. The preprocessor window is the menu under which all the variables in the simulation process is defines. The workpiece material was chosen to be AISI 8620 because that is the material used in the manufacturing of formed Halfshaft components. The material was specified in terms of KCmn values. For the FEA, the workpiece material is defined as a rigid viscoplastic material whose stress strain curve is defined by the relationship:

$$
\bar{\sigma}=K \bar{\varepsilon}^{n}
$$

Where

$$
\begin{array}{ll}
\bar{\sigma} & =\text { Flow stress of the deforming material } \\
\boldsymbol{K} & =\text { proportionality constant }=827 \mathrm{Ksi} \\
\bar{\varepsilon} & =\text { Strain imparted to the material } \\
\boldsymbol{n} & =\text { strain hardening coefficient }=0.12
\end{array}
$$

The contact tooling for the FEA is defined as an elastic material and is defined by defining the Young's modulus and Poisson's ratio. Since the punch and the anvil are of carbide material, the Young's modulus for carbide is $60,000 \mathrm{Ksi}$. The $\mathrm{C}$ and $m$ values were set at zero because of cold forming.

\subsubsection{Input sub menu}

\subsubsection{Equipment specification}

Entering the following characteristics specified the mechanical press on which the double cup backward extrusion friction tests were run on:

- Mechanical Ram Name: Clearing Press 9101 
- Ram Axis:

- Maximum Stroke:

- Number of strokes:

- Deformation Stroke: negative $Y$ axis

20.000 inches

45 per minute

1.8 inch (max.)

After entering the above data the window allows for graphing the velocity of the ram against the time taken to complete the down stroke of the press. The time required is captured to be used later in specifying the run parameters.

\subsubsection{Lubricant specifications}

Lubricants used for the simulation were specified as shown below. The friction type chosen was the shear type because that closely simulated the friction between the dies and the workpiece. This range was chosen because the friction factor between the dies and the workpiece varies between these two limits in cold forging [3]. The interface heat transfer coefficient table was left empty as this test was being run cold on the assumption was that there would no effects of heat transfer.

The shear friction coefficient was changed for each iteration of the simulation between 0.05 and 0.19 in increments of 0.02 . The change in the extruded cup heights due to this change is what led to the generation of the calibration curves.

- Lubricant Name:

- Friction Type:

- Shear Friction Coefficient $\mathbf{m}$ :
Phoscoat (or any other name as required) Shear

0.05 to 0.19 in steps of 0.02 / iteration

\subsubsection{Construction of geometry}

The geometry of the punch, die and the workpiece is constructed in ANTARES' pre-processor using straight lines, angles and fillet radii. The geometry of the punch, anvil, container and the billet are all individually constructed. They are then aligned as required for the simulation in the view menu. The geometry is constructed such that only half the details have been drawn. This is because the 
tooling and the workpiece are cylindrical and are symmetrical about their vertical axes.

\subsubsection{Defining / Specifying boundary conditions}

Here, the boundary conditions that require to be specified are the contact conditions and the symmetry conditions of the geometric entities that have been created. In defining the contact boundary condition, the names for the boundary condition being defined along with the contact placement axis have to be specified. This software package can be adapted to simulate heat exchange amongst other things. In defining the symmetry boundary condition, the name for the boundary condition being defined along with the constrained degree of freedom have to be specified.

\subsubsection{Assigning parameters}

Under this menu, all the parameters defined this far need to be correlated to each other appropriately.

The equipment requires to be assigned to the punch created in the geometry sub menu in order for the punch to simulate the movement of the press's RAM.

The materials need to be assigned appropriately.

The lubricant requires to be assigned to the contact surfaces between the workpiece, the die and the punch.

The boundary conditions need to assigned with due care. In ANTARES, the workpiece is considered to be stationary while the die and the punch move to contact it. This condition needs to be incorporated in assigning the boundary conditions.

The mesh type and density for the billet, die and workpiece is specified. The simulation of the test setup being a two dimension axisymmetric problem, the type of mesh specified was quad mesh. For this set - up a mesh density of "8x8" 
was specified for the workpiece. This translates into eight nodes per inch along the boundary of the specified geometry and eight mesh elements connected to each node on the interior. Since only the workpiece is to be studied, no mesh needs to be specified for the dies.

In this window, the simulation control parameters are also specified. The time step value, the save interval, the number of time steps per mesh, the strain increment value, the number of iterations per time step, the object dimension type (plane strain or axisymmetric), etc., are all specified. These are the parameters that are crucial for running the simulation. This is an iterative process and fine-tuning of the above individual parameters is likely.

Once all the above parameters have been specified appropriately, all the data is written to a database, the geometry written to a file containing information about the geometry and the run parameters written to a run file that provides the key for initiating the simulation under a different window.

\subsubsection{Simulate sub menu}

The "simulate" menu is one in which the problem is submitted for simulation either as a 2D or 3D set-up. The simulation is initiated from the "simulate" subwindow. If the above parameters have been appropriately specified, the simulation should proceed with minimal anomalies. The progress of the simulation can be tracked on the "simulate" window by plotting the load-stroke curve. This graph shows the load (tonnage) as a function of the deformation stroke completed. The "simulate" menu appears as a green icon when the simulation is in progress. It turns red when the simulation is either completed or stops due to computational errors. This serves as an additional indicator of the progress of the simulation. 


\subsection{Post processing simulation results}

The results are accessed through the "results" database. The "results" menu is one in which the results of the simulation are post processed. The animate menu is to create user-defined animation of the deforming mesh.

The results of a completed simulation, i.e., of a simulation in which the deformation stroke has been completed, can be accessed by opening the results menu from the main window. The result database is loaded. The deformed mesh of the workpiece can be viewed along with the punch and die. The deformation of the mesh can be tracked from start to finish incrementally by moving the step button cursor one step at a time. Fig. 7.1 shows an example of the deformed mesh along with the dies.

The individual results of the friction test, i.e.; the cup heights were tracked through a feature called point tracking in the result window under operations. This feature allows tracking of steps incrementally and allows for documenting the length of the extruded cups as a function of incremental strokes of the press. The individual results are documented in an Excel spreadsheet and shown in Appendix B of this report

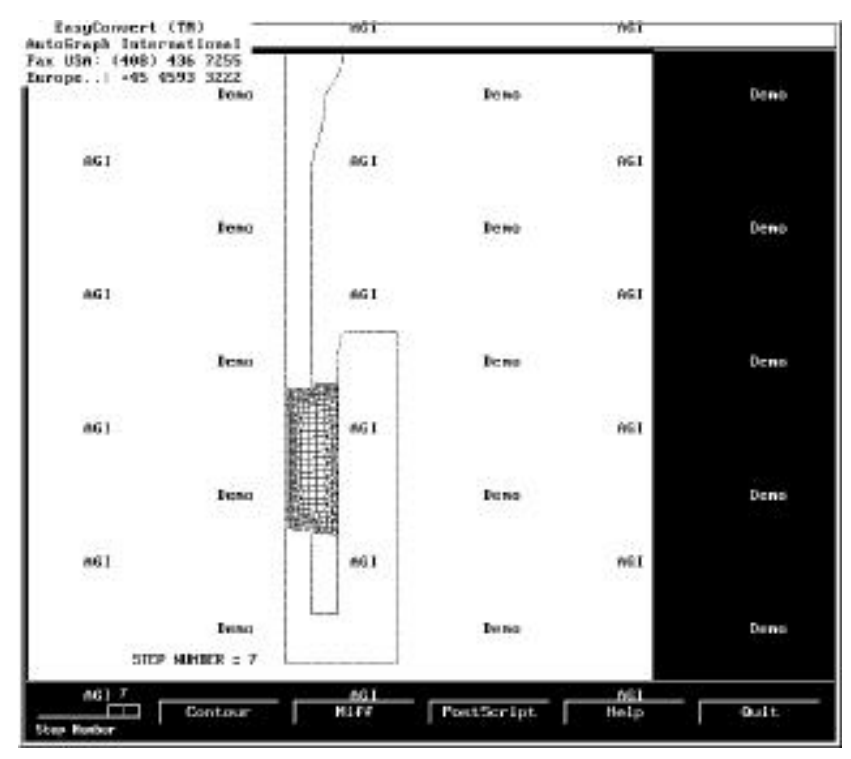

Fig. 7.1 Deformed mesh along with the punch and die 


\section{CHAPTER 8}

\section{FRICTION TEST RESULTS}

\subsection{Computer simulation results}

The results required from the simulation were plots of the ratio of the extruded cup heights as a function of the deformation stroke of the press under incrementally varying lubricant conditions at the workpiece - dies interface.

The results from the simulation were extracted from the Unix workstation by tracking the cup heights using the FEA software code ANTARES. The stroke of the press at each increment of the cup height was extrapolated by going into the "utilities" menu of the code and generating the load stroke curve of the press. The stroke of the press at each time step interval was obtained from the raw data generated by doing this step. Thereafter, the time step value common to both the stroke and the cup height increment was found and the two correlated.

The data from the correlation were then entered into a Microsoft Excel file as shown in Appendix B. Data for each lubricant value, i.e., value of $\mathbf{m}$ was entered under a specific file name. The collected data was then formatted as shown in figure 8.1 to generate the graph of the cup height ratios $\mathrm{v} / \mathrm{s}$ deformation as shown in fig.8.2.

In the Fig. 8.1 below the step number in the computer simulation is arrived at as follows:

- The time taken for the ram to reach zero velocity (at the bottom of the stroke) is found by plotting the velocity against time in the equipment specification menu. For the experimental set up is $0.1295 \mathrm{~min}$.

- This time interval is divided by 100 (arbitrary number - this number is suggested by the software developer) to specify the time step value in specifying the run parameters before submitting the problem to the solver. 
Time step value requires to be specified to prompt the solver to check for convergence of the computations. This number for the simulation of the experimental setup was chosen to be 1.12e-3. This number was arrived at after fine-tuning to ensure the simulation to run to completion.

- Space (any shape for that matter) is finite and is infinitely divisible. A continuous quantity is therefore made up of divisible elements. Similarly time is also continuous and is infinitely divisible. This divisibility of shape and time allows one to divide continuos things into smaller components or finite elements. Convergence can be described as the process of successively moving to the exact or correct solution of the computations required to quantify the change in shape.

- The simulation solver then requires the save interval of all the iterations in which the computations converge. Data associated with every time step at which convergence is reached can be saved. This results in a very large database in which not all the information is useful. Therefore only every $10^{\text {th }}$ step is saved in the setup. This is how the step number is specified.

- CHR in the table stands for "Cup Height Ratio" which the ratio of the extruded upper cup height to the extruded lower cup height.

\subsection{Discussion on shape of calibration curves}

The computer simulations of the test setup using different shear friction coefficients yielded data of the extruded cup heights as a function of the deformation stroke of the press. As discussed before, the cup heights were recorded for increments of the Ram stroke. The plot of the cup height ratio v/s the Ram deformation stroke was expected to be smooth curve in which the curve of cup height ratio would linearly grow to reach a maximum and gradually taper downwards. The expectation for curve reaching a maximum was due the lower cup growth being hindered by the presence of the extrusion land on the lower anvil. 
When curves generated using different shear friction coefficients were overlaid all on the same graph, the expectation was that there would be clear demarcation between curves. Curves of cup height ratios generated using a higher shear friction coefficient "m" were expected to have a higher slope.

However, the plotted results yielded curves that were wavy and at some places even intersected other curves generated using a different shear friction coefficient. Curves of cup height ratios generated using a higher shear friction coefficient " $m$ " as expected did have higher slope until it reached a maximum.

These errors in the calibration curves could be attributed to two factors:

1. Volume loss in the extruded billet during ANTARES ${ }^{\mathrm{Tm}}$ simulations. This occurs due to the penetration of the mesh area into the punch surfaces at the sharp corner of the radius. After a certain amount of strain and a corresponding distortion of the mesh the solver in the software pauses the simulation to remesh the new deformed geometry profile. The volume associated with the mesh that has penetrated the punch/die geometry is lost. This causes the changes in the cup height ratios.

2. The cup heights from the simulation setup were recorded using a geometry-tracking tool available in the software. Recording the cup heights, especially in the early parts of the deformation stroke, was more prone to error because of poor resolution of the mesh in the software. This also lent to the waviness of the calibration curves.

\subsection{Actual test results}

The cup height ratios from the deformed billets were measured using a "depth mike" (a dial type micrometer with a tail to measure depth). The tail of the "depth mike" was used to measure the depth of the cup and the larger and the smaller cup heights/depths were measured sequentially for each formed billet and entered into a table prepared for this purpose. Individual results of this measurement are shown in Appendix A. The cup height ratios derived from the 
actual tests for each lubricant type is shown in table format in fig. 8.3. Lower $\left(h_{1} /\right.$ $h_{2}$ ) ratio indicates lower friction factor, and therefore better lubricity. The ' $X$ ' mark means that results for that lubricant at the corresponding 'relative stroke' are not tabulated or unavailable. (The tests were discontinued and no data recorded either due the parts repeatedly getting stuck to the upper punch or due to the "loading up" of the upper punch).

\begin{tabular}{|c|c|c|c|c|}
\hline STEP NO. & STROKE & h1 (in.) & h2 (in.) & CHR \\
\hline 1 & 0.104 & 0.056 & 0.038 & 1.489 \\
\hline 2 & 0.172 & 0.100 & 0.052 & 1.931 \\
\hline 3 & 0.271 & 0.155 & 0.084 & 1.853 \\
\hline 4 & 0.335 & 0.205 & 0.105 & 1.942 \\
\hline 5 & 0.367 & 0.242 & 0.108 & 2.240 \\
\hline 6 & 0.460 & 0.357 & 0.116 & 3.064 \\
\hline 7 & 0.521 & 0.433 & 0.118 & 3.674 \\
\hline 8 & 0.580 & 0.501 & 0.129 & 3.877 \\
\hline 9 & 0.667 & 0.595 & 0.148 & 4.020 \\
\hline 10 & 0.722 & 0.665 & 0.148 & 4.479 \\
\hline 11 & 0.736 & 0.683 & 0.148 & 4.598 \\
\hline 12 & 0.817 & 0.784 & 0.154 & 5.101 \\
\hline 13 & 0.869 & 0.849 & 0.154 & 5.506 \\
\hline 14 & 0.920 & 0.910 & 0.168 & 5.412 \\
\hline 15 & 0.994 & 0.985 & 0.182 & 5.407 \\
\hline 16 & 1.041 & 1.034 & 0.197 & 5.244 \\
\hline 17 & 1.109 & 1.102 & 0.225 & 4.897 \\
\hline 18 & 1.153 & 1.146 & 0.235 & 4.872 \\
\hline 19 & 1.217 & 1.210 & 0.255 & 4.736 \\
\hline 20 & 1.257 & 1.250 & 0.269 & 4.646 \\
\hline 21 & 1.315 & 1.310 & 0.286 & 4.587 \\
\hline 22 & 1.352 & 1.347 & 0.297 & 4.543 \\
\hline 23 & 1.404 & 1.400 & 0.314 & 4.459 \\
\hline 24 & 1.473 & 1.433 & 0.324 & 4.418 \\
\hline 25 & 1.485 & 1.480 & 0.340 & 4.356 \\
\hline 26 & 1.514 & 1.510 & 0.349 & 4.321 \\
\hline 27 & 1.556 & 1.552 & 0.363 & 4.273 \\
\hline 28 & 1.582 & 1.578 & 0.372 & 4.242 \\
\hline 29 & 1.618 & 1.614 & 0.384 & 4.202 \\
\hline 30 & 1.641 & 1.636 & 0.391 & 4.180 \\
\hline 31 & 1.672 & 1.667 & 0.402 & 4.147 \\
\hline 32 & 1.690 & 1.685 & 0.408 & 4.126 \\
\hline 33 & 1.716 & 1.710 & 0.417 & 4.104 \\
\hline 34 & 1.731 & 1.726 & 0.422 & 4.093 \\
\hline 35 & 1.751 & 1.745 & 0.428 & 4.073 \\
\hline 36 & 1.762 & 1.756 & 0.432 & 4.063 \\
\hline 37 & 1.776 & 1.770 & 0.438 & 4.045 \\
\hline 38 & 1.784 & 1.777 & 0.440 & 4.038 \\
\hline 39 & 1.793 & 1.785 & 0.444 & 4.026 \\
\hline 40 & 1.797 & 1.789 & 0.445 & 4.021 \\
\hline 41 & 1.800 & 1.792 & 0.446 & 4.018 \\
\hline 42 & 1.800 & 1.793 & 0.446 & 4.017 \\
\hline & & & & \\
\hline 27 & & & \\
\hline & & & & \\
\hline & & & &
\end{tabular}

Fig. 8.1 Table showing format used for recording simulation data 


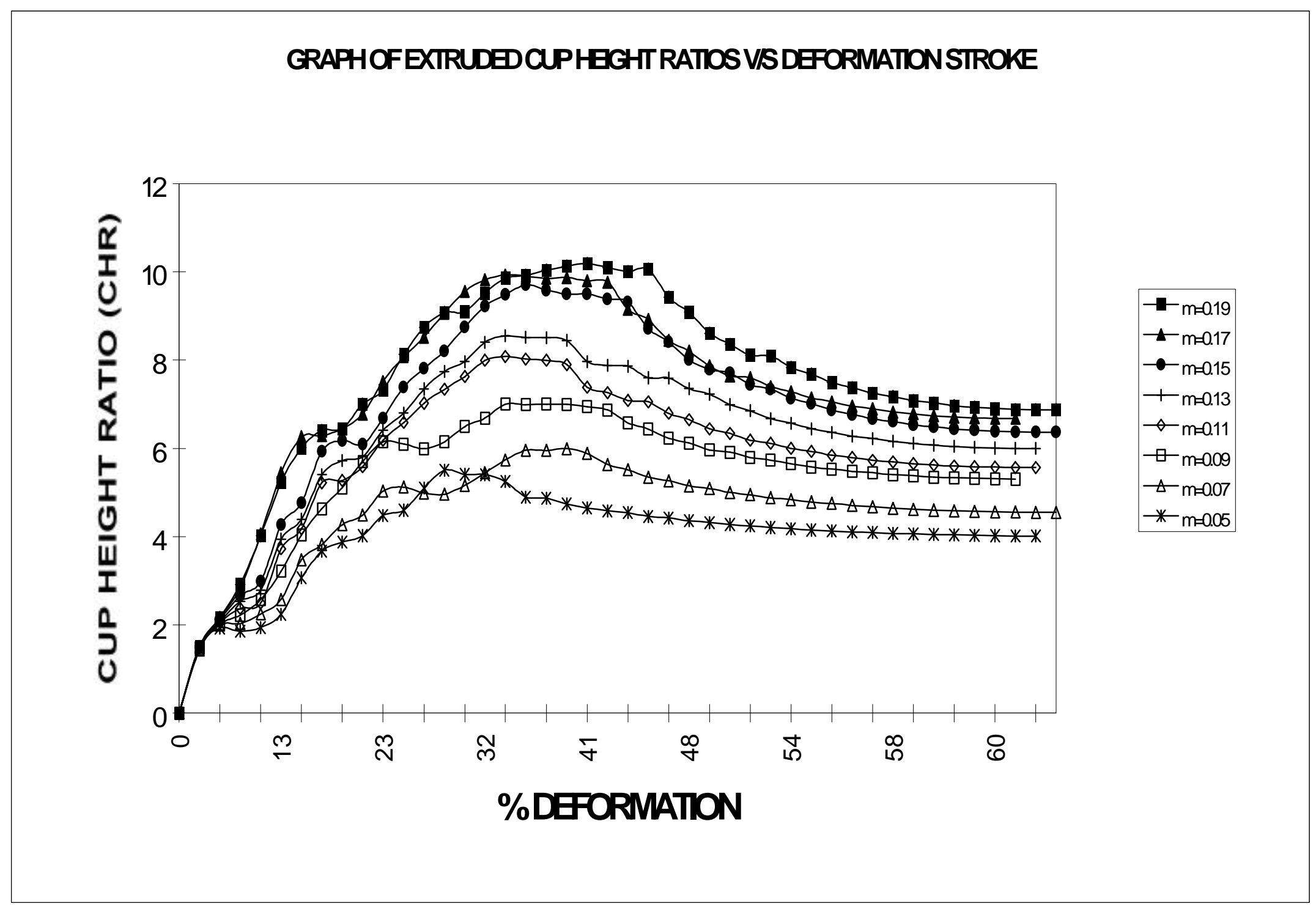

Fig. 8.2 Calibration curves generated from the results of simulation of the double cup backward extrude friction test method 


\section{Table 8.1 - FRICTION TEST RESULTS}

\begin{tabular}{|c|c|c|c|c|c|c|c|c|c|c|c|c|}
\hline Material & $\begin{array}{l}\text { \% Rel. } \\
\text { Stroke }\end{array}$ & $\begin{array}{c}\text { IRMCO } \\
1\end{array}$ & $\begin{array}{c}\text { IRMCO } \\
2\end{array}$ & $\begin{array}{c}\text { IRMCO } \\
3\end{array}$ & $\begin{array}{c}\text { IRMCO } \\
4\end{array}$ & $\begin{array}{c}\mathrm{AC} \\
3\end{array}$ & POLYMER & $\begin{array}{c}\mathrm{AC} \\
2\end{array}$ & KARST & FITCH & $\begin{array}{c}\mathrm{AC} \\
1\end{array}$ & $\begin{array}{l}\text { "BLACK } \\
\text { LUBE" }\end{array}$ \\
\hline \multirow{3}{*}{8620} & 30 & 3.547 & 3.983 & 4.417 & 4.462 & 5.030 & 5.6216 & 5.7443 & 6.059 & 6.060 & 6.887 & 9.245 \\
\hline & 40 & 5.236 & $x$ & $x$ & $x$ & 8.011 & 6.820 & $x$ & 6.931 & 6.756 & 7.750 & 10.394 \\
\hline & 50 & 5.817 & $x$ & $x$ & $x$ & $x$ & 6.751 & $x$ & 8.016 & 7.441 & $x$ & 9.889 \\
\hline
\end{tabular}

- Data listed above are the average $\left(h_{1} / h_{2}\right)$ ratios of the cup heights from the extruded samples. Table 8.1: Results of the actual test. 


\subsection{Discussion of friction test results}

From table 8.1, it appears that the coating "IRMCO -- 1" provided by IRMCO showed promise. It performed very well at the lower as well as the higher percentages of 'relative stroke'. The coating was a polymer lubricant applied on to a phosphated surface. The only drawbacks of the IRMCO --1 were that the lubricant coating liquefied at the temperatures encountered during the deformation processes and that it left a "gummy" residue on the surface of the die containers that needed to be regularly cleaned with a special solution. None of the other coatings provided by IRMCO could be evaluated due to the coatings breaking down at higher percentages of 'relative stroke'.

None of the coatings provided by ACHESON COLLOIDS withstood a 'relative stroke' of $50 \%$. The coatings withstood lower 'relative stroke' values, however the corresponding cup height ratios were higher than both the coatings currently used here and from IRMCO, indicating that their lubricity was lower than the coatings currently in use.

The "POLYMER" lubricant used at plant \#5 performed much better than the FITCH \& KARST coater at plant \#4. That result is very encouraging, and suggests replacement of the current Phoscoater at \#4 with the "polymer lubricant" line. Additionally, the polymer coatings from plant \#5 are cleaner and have lesser tendency of leaving a residue, either inside the dies or on the parts. Interestingly, the FITCH performed better than the KARST at higher percentages of 'relative stroke', while there was no difference between the two at lower percentages of 'relative stroke'.

Shown below is the correlation of the simulation results and the actual test results. The cup height ratios from the actual test are plotted on the $\mathrm{m}$ - curves generated with the results from the simulations.

The table 8.2 shown contains data both from the simulations and the experimental samples. The first column shows the ram stroke increments (in inches) in the computer simulation at which the cup height ratios have been 
computed. The maximum ram stroke used for the simulations is 1.8 inches. The second column computes the corresponding percentage deformation at each step of the ram stroke increment. The percentage deformation varies from $0 \%$ to $60 \%$. Columns 3-11 show cup height ratios from the computer simulations for different shear friction coefficient values at the corresponding percentage deformation. The shear friction coefficient " $\mathrm{m}$ " is varied in the simulation from 0.05 to 0.19 in increments of 0.02 . This data is used to generate the calibration curves.

The cup height ratio data obtained from the billets backward extruded in the test are entered in rows at the appropriate percentage deformation / relative stroke of the punch in the simulation. The graph with the superimposed extruded $\mathrm{CHR}$ data from the test is shown in fig. 8.3.

The graph shows that while the friction conditions i.e. the friction factor $\mathbf{m}$ of the lubricants KARST, FITCH and POLYMER are around $\mathrm{m}=0.09$ the friction coefficient of the black lubricant used in plant 5 is around $m=0.19$. This clearly shows that the black lubricant is worse than the other three lubricants.

The lubricant that is worthy of attention is the IRMCO 1. This lubricant shows friction coefficients around $m=0.05$ and $m=0.07$ which are really very low for cold forging lubricants. This shows that the IRMCO 1 coating is a lubricant that has high slip properties and is worthy of further investigation. 


\begin{tabular}{|c|c|c|c|c|c|c|c|c|c|c|c|c|c|c|c|c|}
\hline STROKE & IEFORMAT & $\mathrm{m}=0.05$ & $\mathrm{~m}=0.06$ & $\mathrm{~m}=0.07$ & $\mathrm{~m}=0.09$ & $\mathrm{~m}=0.11$ & $\mathrm{~m}=0.13$ & $\mathrm{~m}=0.15$ & $\mathrm{~m}=0.17$ & $\mathrm{~m}=0.19$ & Karst & Fitch & Polymer & $\begin{array}{l}\text { Black } \\
\text { Lube }\end{array}$ & AC-1 & AC-2 \\
\hline 0 & 0 & 0 & 0 & 0 & 0 & 0 & 0 & 0 & 0 & 0 & & & & & & \\
\hline 0.104 & 3 & 1.489 & 1.254 & 1.436 & 1.466 & 1.484 & 1.493 & 1.498 & 1.508 & 1.509 & & & & & & \\
\hline 0.172 & 6 & 1.931 & 2.008 & 1.998 & 2.020 & 2.048 & 2.061 & 2.117 & 2.163 & 2.160 & & & & & & \\
\hline 0.271 & 9 & 1.853 & 2.295 & 2.029 & 2.217 & 2.370 & 2.539 & 2.662 & 2.834 & 2.920 & & & & & & \\
\hline 0.303 & 10 & 1.942 & 2.487 & 2.247 & 2.576 & 2.490 & 2.791 & 2.990 & 4.056 & 4.020 & & & & & & \\
\hline 0.398 & 13 & 2.240 & 3.234 & 2.573 & 3.215 & 3.724 & 3.947 & 4.268 & 5.440 & 5.230 & & & & & & \\
\hline 0.430 & 14 & 3.064 & 3.959 & 3.476 & 4.037 & 4.182 & 4.396 & 4.771 & 6.258 & 6.014 & & & & & & \\
\hline 0.521 & 17 & 3.674 & 4.333 & 3.816 & 4.633 & 5.221 & 5.403 & 5.928 & 6.284 & 6.406 & & & & & & \\
\hline 0.551 & 18 & 3.877 & 4.512 & 4.270 & 5.108 & 5.272 & 5.722 & 6.175 & 6.441 & 6.441 & & & & & & \\
\hline 0.638 & 21 & 4.020 & 4.526 & 4.487 & 5.698 & 5.583 & 5.812 & 6.090 & 6.772 & 7.003 & & & & & & \\
\hline 0.695 & 23 & 4.479 & 4.397 & 5.029 & 6.146 & 6.186 & 6.408 & 6.681 & 7.515 & 7.322 & & & & & & \\
\hline 0.736 & 25 & 4.598 & 4.400 & 5.117 & 6.094 & 6.585 & 6.802 & 7.391 & 8.072 & 8.122 & & & & & & \\
\hline 0.763 & 25 & 5.101 & 4.485 & 4.986 & 5.994 & 7.023 & 7.345 & 7.809 & 8.521 & 8.740 & & & & & & \\
\hline 0.843 & 28 & 5.506 & 4.544 & 4.959 & 6.143 & 7.336 & 7.735 & 8.204 & 9.065 & 9.073 & & & & & & \\
\hline 0.895 & 30 & 5.412 & 4.678 & 5.164 & 6.494 & 7.622 & 7.966 & 8.746 & 9.552 & 9.093 & 6.059 & 6.060 & 5.622 & 9.246 & 6.887 & 5.744 \\
\hline 0.969 & 32 & 5.407 & 4.641 & 5.439 & 6.683 & 7.990 & 8.405 & 9.221 & 9.816 & 9.523 & & & & & & \\
\hline 1.018 & 34 & 5.244 & 4.685 & 5.742 & 7.003 & 8.077 & 8.551 & 9.479 & 9.928 & 9.856 & & & & & & \\
\hline 1.041 & 35 & 4.897 & 4.741 & 5.956 & 6.989 & 8.026 & 8.510 & 9.702 & 9.901 & 9.917 & & & & & & \\
\hline 1.109 & 37 & 4.872 & 4.703 & 5.952 & 7.002 & 7.991 & 8.508 & 9.586 & 9.848 & 10.034 & & & & & & \\
\hline 1.153 & 38 & 4.736 & 4.718 & 5.992 & 6.995 & 7.894 & 8.439 & 9.497 & 9.869 & 10.131 & & & & & & \\
\hline 1.217 & 41 & 4.646 & 4.736 & 5.882 & 6.942 & 7.385 & 7.968 & 9.495 & 9.796 & 10.185 & 6.931 & 6.756 & 6.820 & 10.394 & 7.749 & $X X X X X X X$ \\
\hline 1.257 & 42 & 4.587 & 4.666 & 5.635 & 6.871 & 7.261 & 7.874 & 9.389 & 9.768 & 10.100 & & & & & & \\
\hline 1.315 & 44 & 4.543 & 4.598 & 5.510 & 6.579 & 7.086 & 7.856 & 9.317 & 9.147 & 10.008 & & & & & & \\
\hline 1.352 & 45 & 4.459 & 4.544 & 5.345 & 6.438 & 7.051 & 7.601 & 8.714 & 8.917 & 10.059 & & & & & & \\
\hline 1.404 & 47 & 4.418 & 4.489 & 5.265 & 6.231 & 6.790 & 7.591 & 8.414 & 8.450 & 9.422 & & & & & & \\
\hline 1.437 & 48 & 4.356 & 4.436 & 5.153 & 6.120 & 6.648 & 7.351 & 8.006 & 8.203 & 9.080 & & & & & & \\
\hline 1.485 & 49 & 4.321 & 4.399 & 5.089 & 5.960 & 6.445 & 7.223 & 7.789 & 7.867 & 8.608 & & & & & & \\
\hline 1.514 & 50 & 4.273 & 4.362 & 4.997 & 5.912 & 6.334 & 6.990 & 7.707 & 7.641 & 8.358 & & & & & & \\
\hline 1.556 & 52 & 4.242 & 4.327 & 4.945 & 5.791 & 6.186 & 6.849 & 7.444 & 7.596 & 8.114 & & & & & & \\
\hline 1.582 & 53 & 4.202 & 4.297 & 4.875 & 5.732 & 6.113 & 6.671 & 7.337 & 7.398 & 8.093 & & & & & & \\
\hline 1.618 & 54 & 4.180 & 4.270 & 4.841 & 5.649 & 5.998 & 6.571 & 7.131 & 7.284 & 7.832 & & & & & & \\
\hline 1.641 & 55 & 4.147 & 4.250 & 4.784 & 5.575 & 5.933 & 6.441 & 7.013 & 7.141 & 7.683 & & & & & & \\
\hline 1.672 & 56 & 4.126 & 4.228 & 4.752 & 5.532 & 5.844 & 6.361 & 6.862 & 7.056 & 7.493 & & & & & & \\
\hline 1.690 & 56 & 4.104 & 4.212 & 4.704 & 5.477 & 5.788 & 6.274 & 6.769 & 6.955 & 7.376 & & & & & & \\
\hline 1.716 & 57 & 4.093 & 4.198 & 4.674 & 5.446 & 5.728 & 6.223 & 6.668 & 6.896 & 7.250 & & & & & & \\
\hline 1.731 & 58 & 4.073 & 4.186 & 4.645 & 5.404 & 5.690 & 6.157 & 6.610 & 6.823 & 7.177 & & & & & & \\
\hline 1.751 & 58 & 4.063 & 4.173 & 4.620 & 5.379 & 5.648 & 6.115 & 6.535 & 6.778 & 7.083 & & & & & & \\
\hline 1.762 & 59 & 4.045 & 4.164 & 4.597 & 5.350 & 5.622 & 6.071 & 6.489 & 6.735 & 7.025 & & & & & & \\
\hline 1.776 & 59 & 4.038 & 4.156 & 4.583 & 5.334 & 5.597 & 6.044 & 6.440 & 6.710 & 6.965 & & & & & & \\
\hline 1.784 & 59 & 4.026 & 4.154 & 4.571 & 5.321 & 5.583 & 6.022 & 6.411 & 6.690 & 6.930 & & & & & & \\
\hline 1.793 & 60 & 4.021 & 4.151 & 4.563 & 5.309 & 5.573 & 6.008 & 6.386 & 6.681 & 6.899 & 8.016 & 7.441 & 6.751 & 9.889 & $X X X X X X X$ & $X X X X X X X$ \\
\hline 1.797 & 60 & 4.018 & 4.151 & 4.556 & 5.301 & 5.564 & 6.002 & 6.372 & 6.679 & 6.882 & & & & & & \\
\hline 1.800 & 60 & 4.017 & & 4.550 & & 5.564 & 6.001 & 6.366 & & 6.874 & & & & & & \\
\hline 1.800 & 60 & & & 4.550 & & & & 6.365 & & 6.874 & & & & & & \\
\hline
\end{tabular}

Table 8.2 showing the format used to record the correlated results 


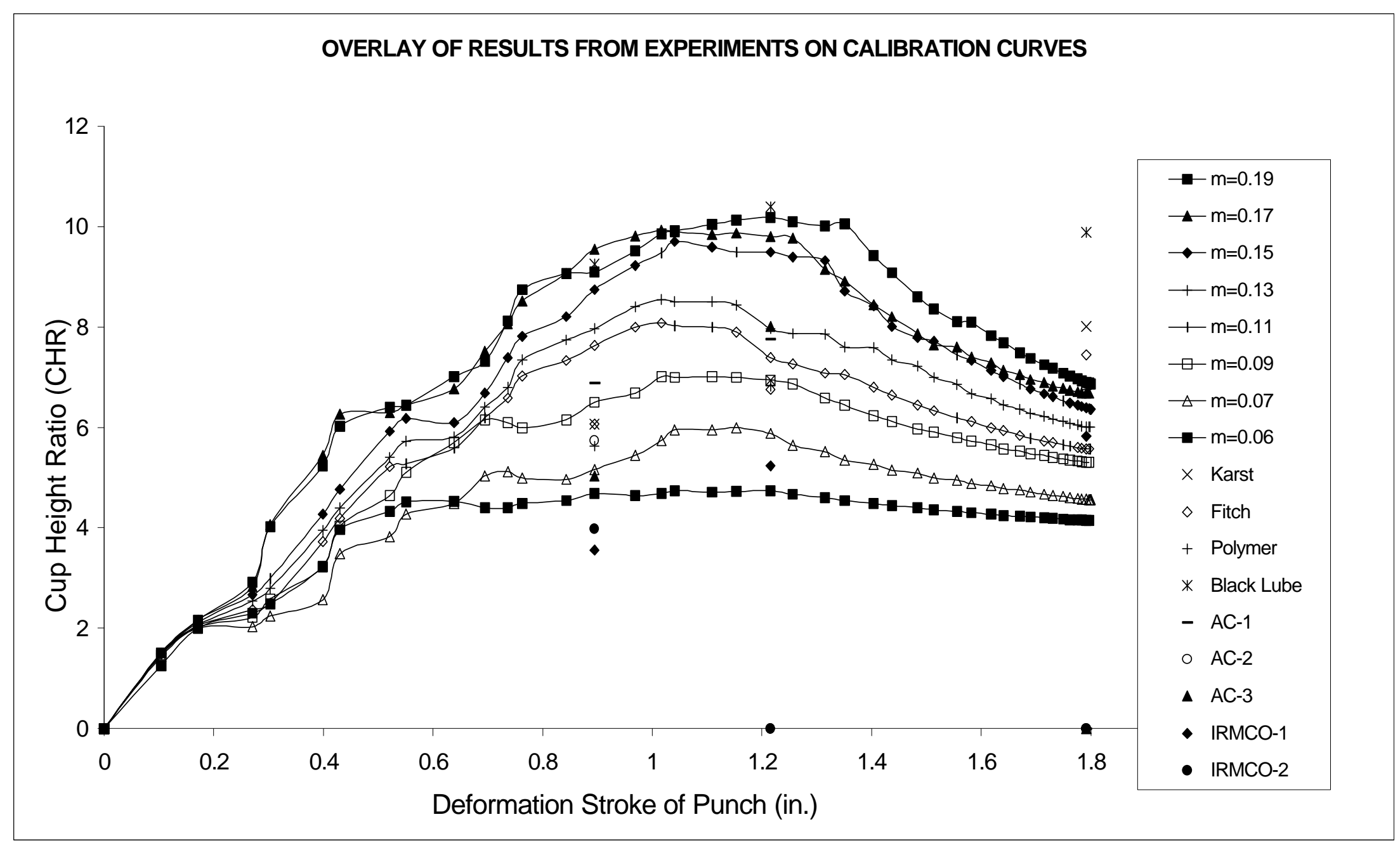

Fig. 8.3 Graph showing the superimposed results of results from the simulation and actual tests 


\section{CHAPTER 9 - OVERALL CONCLUSIONS}

\subsection{Conclusions}

The double cup backward extrusion friction test method is an effective way of determining the lubricity of coatings in "near" production conditions. The preparations required for running this test closely simulated the production processes. The heat treatment and coating processes were exactly replicated. Billet manufacture was the only activity that was not from the production process. This was due to the fact that no billets off of the current production processes had the required billet geometry. The expectation was that in the future, if this test were to be used as the standard test for determining quality of coatings, then billets with required geometry would be sheared, coated and tested as and when needed.

However, as can be seen from the results and the graphs, the test method is not sensitive enough to distinguish between good and bad coatings. This can be partly attributed to the small sample of test billets used for testing.

The coatings used were a snap shot of coatings used in every day operations of the plants in Delphi Saginaw Steering Systems. The coating quality does vary on a day to day basis. More testing over a longer period of time incorporating more samples would be required to validate this test method as a tool to distinguish the quality of particular coating.

\subsection{Contributions}

This thesis along with the experimental work has explored in depth the domain of friction testing of cold forging lubricants with special emphasis on the double cup backward extrusion friction test method. The main contribution of this thesis is in investigating the "robustness" of the double cup backward extrusion friction test method under "near" production conditions. While past work has been in the area of computer simulations to generate friction coefficient calibration curves and 
limited testing in laboratory conditions, this is the first attempt to investigate the method under "near" production conditions.

The experimental work establishes the lubricity of coatings that are currently in use. It compares the lubricity of all the coatings used in Delphi Saginaw Steering Systems. In addition it presents a tool that can be used to explore the lubricity of new coatings that are being formulated to either substitute or replace current coating methods.

\subsection{Recommendations}

The results indicate that the test is not sensitive enough to distinguish within a coating type to aid in the decision to either run production or re-coat parts that have come off of a coating line. Additional testing with large sample sizes would be required to establish the "lubricity band" - the " $m$ " values that a specific coating would vary within. This would help boundary samples for "good" and "bad" coatings.

This experimental setup explored one specific reduction ratio $e=0.26$. Future testing should include other reduction ratios to determine if better sensitivity in the test method can be achieved.

A length to diameter ratio of 1.53 was used for this setup. Testing that explores using billets from a production process (which would have a different length to diameter ratio) would be beneficial. It would avoid having to specially manufacture billets. Appropriate changes to the die design would have to be made in order to accommodate new length to diameter ratios.

This test lends itself to an ideal situation for conducting a complete design of experiments to study, in addition to the lubricity of coatings, the effect of punch design on pressure required for backward extrusion, design of die tooling, etc.

Possible modifications to this test method could also be explored to improve the sensitivity of the test. 


\section{REFERENCES}

1. Kobayashi, Oh S, Altan T., "Metal Forming And The Finite Element Method", Oxford Univ. Press, 1989.

2. Altan, Oh S., Gegel H., "Metal Forming - Fundamentals and Applications", ASM, 1983.

3. "ANTARES ${ }^{\mathrm{TM}}$ - Theory of Metalworking Analysis"

4. Schey J.A, "Tribology in Metal working, Friction, Lubrication and Wear" Carnes Publication Services, 1983.

5. Lange, "Handbook of Metal Forming", McGraw-Hill, 1985.

6. Witron, "Applied Metal Working", 1979, vol.1, no.1.

7. Nam P. Suh, "Tribophysics", Prentice-Hall, 1986.

8. Bowden and Tabor D., "The Friction and Lubrication of Solids", vol.1, Oxford Clarendon Press, 1953.

9. Kuhn and Lynn Ferguson B., "Powder Forging", MP1F, 1990.

10. Wanheim, Bay N., "A Model for friction in metal forming processes," Annals of CIRP, 27: 189.

11. Kamaekers and Kals J.A.G., "Mathematical representation of friction in Metal forming Analysis", Annals of the CIRP, vol. 35111, 1986.

12. Danckert and Wanheim T., "The friction shear stress distribution at the material-tool interface, when upsetting flat circular cylinder between flat parallel platens", Proc. Modeling Fundamentals and applications to metals, ASM, 1980.

13. Wilson, "Friction Modeling in, forging", ASM Materials Science Seminar, Florida, 1986.

14. Byner T.B., Ed. by, "Forging Handbook", FIA, ASM, 1985.

15. Lee and Altan T., "Influence of flow stress and friction upon metal flow in upset forging of Rings and Cylinders", Trans. ASME, J. of Engr. Industry vol.94, no.3, 1972.

16. Male and DePierre W., "The Validity of Mathematical solutions for determining friction from the Ring Compression Test.", Trans. ASME, J. of Lubrications Technology, vol.92, 1978.

17. Douglas and Altan T., "Flow stress determination for Metals at Forging Rates and Temperatures," Trans. ASME, J. of Engr. Industry, Feb. 1975.

18. Avitzur, "Metalforming: Processes and Analyses", New York, McGraw-Hill, 1968.

19. Hawkyard, Johnson W., "An analysis of the changes in geometry of a short hollow cylinder during axial compression", Int. J. of Mech. Sci., vol. 9, 1967. 
20. Male, DePierre V., and G. Sand, ASLE Trans., vol.16, 1973.

21. Misra N., Pope M.H. and Berry J.T., "Lubricant selection in the warm-working of sheetmaterial using the ring deformation test", Spring Lubrication Symposium, Boston, MASS, 1972.

22. Polakowski and Schmitt C.B., Trans. AIME, 218, 1960.

23. Sachs, Metallwirstchaft, 9, 1950.

24. Nittel, "A new method of lubricant evaluation for deformation processes by measuring friction", 1968.

25. Doege, Melching R., and Kowallick G., "Investigation into the behavior of lubricants and the wear resistance of die materials in Hot and Warm Forging" J. Mech. Work Tech., 2, 1978.

26. Pawelski "A new device for measuring friction in plastic deformation", Stahl U. Eisen, 84, 1964.

27. Kropp E., Udagawa T., and Altan T., "Investigation of Metal flow and lubrication in Isothermal precision forging of aluminum alloys", Report No. EREJNSM-B-89-03.

28. Shen, WedhanaYagam A., Kropp E., and Altan T., "Evaluation of lubrication for forging of aluminum-lithium alloy by ring and bucket tests", ERB/NSM-B-90-50.

29. Renaudin, Batit G., Bournicon O., "A simulation of cold forging operations for testing the tribological properties of solid lubricant coatings", Adv. Tech of Plasticity, vol. 1, 1990.

30. Male, "Metal working lubrication ', Spring lubrication symposium, June 1972.

31. Male, "Variations in friction coefficients of metals during compressive deformation", J. Institute of Metals, 2347s, vol. 94, 1966.

32. Verson Allsteel press company, "Impact machining", 1969.

33. Buschhausen A., Weinmann K. and Lee J.Y. and Altan T., "Evaluation of lubrication in cold forging using a double backward extrusion process", J. of Materials Processing Technology, 33, 1992

34. Ghobrial M.I., Lee J.Y., Altan T., Bay N, Hansen B.G., "Factors affecting the double cup extrusion test for evaluation of friction in cold and warm forging", 1993 
APPENDIX A - TABLES OF EXTRUDED CUP HEIGHTS FROM ACTUAL TESTING

\begin{tabular}{|c|c|c|c|c|c|c|c|c|c|}
\hline $\begin{array}{c}\text { Sl. } \\
\text { No.: }\end{array}$ & $\begin{array}{c}\text { Type of } \\
\text { Steel }\end{array}$ & $\begin{array}{l}\text { Type of } \\
\text { coating }\end{array}$ & $\begin{array}{c}\% \text { Rel. } \\
\text { Strk. }\end{array}$ & $\begin{array}{c}\text { Expt. } \\
\text { No.: }\end{array}$ & h1 & h 2 & $\begin{array}{c}y_{i} \\
(h 1 / h 2)\end{array}$ & $\begin{array}{c}\bar{y} \\
\text { Avg. }\end{array}$ & $\begin{array}{l}\text { Std. } \\
\text { Dev. }\end{array}$ \\
\hline 1 & 8620 & KARST & 30 & 1 & 0.759 & 0.116 & 6.543 & & \\
\hline 2 & 8620 & KARST & 30 & 2 & 0.758 & 0.135 & 5.615 & & \\
\hline 3 & 8620 & KARST & 30 & 3 & 0.758 & 0.128 & 5.922 & 6.059 & 0.305 \\
\hline 4 & 8620 & KARST & 30 & 4 & 0.759 & 0.126 & 6.024 & & \\
\hline 5 & 8620 & KARST & 30 & 5 & 0.784 & 0.129 & 6.078 & & \\
\hline 6 & 8620 & KARST & 30 & 6 & 0.759 & 0.123 & 6.171 & & \\
\hline 7 & 8620 & KARST & 40 & 70 & 1.162 & 0.157 & 6.078 & & \\
\hline 8 & 8620 & KARST & 40 & 71 & 1.16 & 0.148 & 6.171 & & \\
\hline 9 & 8620 & KARST & 40 & 72 & 1.16 & 0.161 & 7.401 & & \\
\hline 10 & 8620 & KARST & 40 & 73 & 1.151 & 0.167 & 7.838 & 6.931 & 0.697 \\
\hline 11 & 8620 & KARST & 40 & 74 & 1.16 & 0.16 & 7.205 & & \\
\hline 12 & 8620 & KARST & 40 & 75 & 1.155 & 0.172 & 6.892 & & \\
\hline 13 & 8620 & KARST & 50 & 117 & 1.535 & 0.18 & 7.250 & & \\
\hline 14 & 8620 & KARST & 50 & 118 & 1.535 & 0.175 & 6.715 & & \\
\hline 15 & 8620 & KARST & 50 & 119 & 1.529 & 0.162 & 8.528 & & \\
\hline 16 & 8620 & KARST & 50 & 120 & 1.519 & 0.203 & 8.771 & & \\
\hline 17 & 8620 & KARST & 50 & 121 & 1.515 & 0.196 & 9.438 & 8.016 & 0.890 \\
\hline 18 & 8620 & KARST & 50 & 122 & 1.528 & 0.186 & 7.483 & & \\
\hline 19 & 8620 & KARST & 50 & 123 & 1.517 & 0.201 & 7.730 & & \\
\hline 20 & 8620 & KARST & 50 & 124 & 1.522 & 0.195 & 8.215 & & \\
\hline
\end{tabular}

$$
\text { Standard Deviation } \quad \sigma=\sqrt{\frac{\sum\left(y_{i}-\bar{y}\right)^{2}}{(n-1)}}
$$




\begin{tabular}{|c|c|c|c|c|c|c|c|c|c|}
\hline SI. No.: & $\begin{array}{c}\text { Type of } \\
\text { Steel }\end{array}$ & $\begin{array}{l}\text { Type of } \\
\text { coating }\end{array}$ & $\begin{array}{c}\text { \% Rel. } \\
\text { Strk. }\end{array}$ & $\begin{array}{c}\text { Expt. } \\
\text { No.: }\end{array}$ & h1 & h2 & $\begin{array}{c}y_{i} \\
(h 1 / h 2)\end{array}$ & $\begin{array}{c}\bar{y} \\
\text { Avg. }\end{array}$ & $\begin{array}{l}\text { Std. } \\
\text { Dev. }\end{array}$ \\
\hline 40 & 8620 & POLYMER & 30 & 13 & 0.756 & 0.144 & 5.250 & & \\
\hline 41 & 8620 & POLYMER & 30 & 14 & 0.763 & 0.12 & 6.358 & & \\
\hline 42 & 8620 & POLYMER & 30 & 15 & 0.77 & 0.137 & 5.620 & & \\
\hline 43 & 8620 & POLYMER & 30 & 16 & 0.772 & 0.141 & 5.475 & 5.622 & 0.447 \\
\hline 44 & 8620 & POLYMER & 30 & 17 & 0.761 & 0.148 & 5.142 & & \\
\hline 45 & 8620 & POLYMER & 30 & 18 & 0.759 & 0.129 & 5.884 & & \\
\hline 46 & 8620 & POLYMER & 40 & 82 & 1.175 & 0.148 & 7.939 & & \\
\hline 47 & 8620 & POLYMER & 40 & 83 & 1.155 & 0.162 & 7.130 & & \\
\hline 48 & 8620 & POLYMER & 40 & 84 & 1.151 & 0.174 & 6.615 & & \\
\hline 49 & 8620 & POLYMER & 40 & 85 & 1.138 & 0.186 & 6.118 & 6.820 & 0.637 \\
\hline 50 & 8620 & POLYMER & 40 & 86 & 1.141 & 0.172 & 6.634 & & \\
\hline 51 & 8620 & POLYMER & 40 & 87 & 1.148 & 0.177 & 6.486 & & \\
\hline 52 & 8620 & POLYMER & 50 & 132 & 1.507 & 0.215 & 7.009 & & \\
\hline 53 & 8620 & POLYMER & 50 & 133 & 1.498 & 0.232 & 6.457 & & \\
\hline 54 & 8620 & POLYMER & 50 & 134 & 1.493 & 0.235 & 6.353 & & \\
\hline 55 & 8620 & POLYMER & 50 & 135 & 1.482 & 0.238 & 6.227 & & \\
\hline 56 & 8620 & POLYMER & 50 & 136 & 1.505 & 0.225 & 6.689 & 6.751 & 0.629 \\
\hline 57 & 8620 & POLYMER & 50 & 137 & 1.522 & 0.19 & 8.011 & & \\
\hline 58 & 8620 & POLYMER & 50 & 138 & 1.511 & 0.211 & 7.161 & & \\
\hline 59 & 8620 & POLYMER & 50 & 139 & 1.476 & 0.242 & 6.099 & & \\
\hline
\end{tabular}

Standard Deviation $\quad \sigma=\sqrt{\frac{\sum\left(y_{i}-\bar{y}\right)^{2}}{(n-1)}}$ 


\begin{tabular}{|c|c|c|c|c|c|c|c|c|c|}
\hline SI. No.: & $\begin{array}{c}\text { Type of } \\
\text { Steel }\end{array}$ & $\begin{array}{c}\text { Type of } \\
\text { coating }\end{array}$ & $\begin{array}{c}\text { \% Rel. } \\
\text { Strk. }\end{array}$ & $\begin{array}{c}\text { Expt. } \\
\text { No.: }\end{array}$ & h1 & h2 & $\begin{array}{c}\mathbf{y}_{\mathbf{i}} \\
\text { (h1/h2) }\end{array}$ & $\begin{array}{c}\bar{y} \\
\text { Avg. }\end{array}$ & $\begin{array}{c}\text { Std. } \\
\text { Dev. }\end{array}$ \\
\hline 21 & 8620 & FITCH & 30 & 7 & 0.765 & 0.126 & 6.071 & \\
\hline 22 & 8620 & FITCH & 30 & 8 & 0.76 & 0.125 & 6.080 & & \\
\hline 23 & 8620 & FITCH & 30 & 9 & 0.755 & 0.123 & 6.138 & 6.060 & 0.132 \\
\hline 24 & 8620 & FITCH & 30 & 10 & 0.763 & 0.129 & 5.915 & & \\
\hline 25 & 8620 & FITCH & 30 & 11 & 0.756 & 0.121 & 6.248 & & \\
\hline 26 & 8620 & FITCH & 30 & 12 & 0.762 & 0.129 & 5.907 & & \\
\hline 27 & 8620 & FITCH & 40 & 76 & 1.146 & 0.176 & 6.511 & & \\
\hline 28 & 8620 & FITCH & 40 & 77 & 1.146 & 0.175 & 6.549 & & \\
\hline 29 & 8620 & FITCH & 40 & 78 & 1.151 & 0.173 & 6.653 & & \\
\hline 30 & 8620 & FITCH & 40 & 79 & 1.156 & 0.164 & 7.049 & 6.756 & 0.277 \\
\hline 31 & 8620 & FITCH & 40 & 80 & 1.16 & 0.162 & 7.160 & & \\
\hline 32 & 8620 & FITCH & 40 & 81 & 1.144 & 0.173 & 6.613 & & \\
\hline 33 & 8620 & FITCH & 50 & 125 & 1.51 & 0.208 & 7.260 & & \\
\hline 34 & 8620 & FITCH & 50 & 126 & 1.522 & 0.206 & 7.388 & & \\
\hline 35 & 8620 & FITCH & 50 & 127 & 1.511 & 0.21 & 7.195 & & \\
\hline 36 & 8620 & FITCH & 50 & 128 & 1.518 & 0.199 & 7.628 & 7.441 & 0.209 \\
\hline 37 & 8620 & FITCH & 50 & 129 & 1.523 & 0.2 & 7.615 & & \\
\hline 38 & 8620 & FITCH & 50 & 130 & 1.515 & 0.208 & 7.284 & & \\
\hline 39 & 8620 & FITCH & 50 & 131 & 1.528 & 0.198 & 7.717 & & \\
\hline
\end{tabular}

$$
\text { Standard Deviation } \quad \sigma=\sqrt{\frac{\sum\left(y_{i}-\bar{y}\right)^{2}}{(n-1)}}
$$




\begin{tabular}{|c|c|c|c|c|c|c|c|c|c|}
\hline $\begin{array}{c}\text { Sl. } \\
\text { No.: }\end{array}$ & $\begin{array}{c}\text { Type of } \\
\text { Steel }\end{array}$ & $\begin{array}{l}\text { Type of } \\
\text { coating }\end{array}$ & $\begin{array}{c}\% \text { Rel. } \\
\text { Strk. }\end{array}$ & $\begin{array}{c}\text { Expt. } \\
\text { No.: }\end{array}$ & h1 & h2 & $\begin{array}{c}\mathbf{y}_{i} \\
(h 1 / h 2)\end{array}$ & $\begin{array}{c}\bar{y} \\
\text { Avg. }\end{array}$ & $\begin{array}{l}\text { Std. } \\
\text { Dev. }\end{array}$ \\
\hline 60 & 8620 & CONVENTIONAL & 30 & 19 & 0.813 & 0.09 & 9.033 & & \\
\hline 61 & 8620 & CONVENTIONAL & 30 & 20 & 0.812 & 0.105 & 7.733 & & \\
\hline 62 & 8620 & CONVENTIONAL & 30 & 21 & 0.836 & 0.08 & 10.450 & 9.246 & 0.904 \\
\hline 63 & 8620 & CONVENTIONAL & 30 & 22 & 0.818 & 0.087 & 9.402 & & \\
\hline 64 & 8620 & CONVENTIONAL & 30 & 23 & 0.829 & 0.085 & 9.753 & & \\
\hline 65 & 8620 & CONVENTIONAL & 30 & 24 & 0.81 & 0.089 & 9.101 & & \\
\hline 66 & 8620 & CONVENTIONAL & 40 & 88 & 1.197 & 0.112 & 10.688 & & \\
\hline 67 & 8620 & CONVENTIONAL & 40 & 89 & 1.21 & 0.108 & 11.204 & & \\
\hline 68 & 8620 & CONVENTIONAL & 40 & 90 & 1.188 & 0.127 & 9.354 & & \\
\hline 69 & 8620 & CONVENTIONAL & 40 & 91 & 1.198 & 0.116 & 10.328 & 10.394 & 0.647 \\
\hline 70 & 8620 & CONVENTIONAL & 40 & 92 & 1.204 & 0.12 & 10.033 & & \\
\hline 71 & 8620 & CONVENTIONAL & 40 & 93 & 1.205 & 0.112 & 10.759 & & \\
\hline 72 & 8620 & CONVENTIONAL & 50 & 140 & 1.559 & 0.146 & 10.678 & & \\
\hline 73 & 8620 & CONVENTIONAL & 50 & 141 & 1.552 & 0.156 & 9.949 & & \\
\hline 74 & 8620 & CONVENTIONAL & 50 & 142 & 1.536 & 0.164 & 9.366 & & \\
\hline 75 & 8620 & CONVENTIONAL & 50 & 143 & 1.544 & 0.16 & 9.650 & 9.889 & 1.047 \\
\hline 77 & 8620 & CONVENTIONAL & 50 & 144 & 1.523 & 0.172 & 8.855 & & \\
\hline 78 & 8620 & CONVENTIONAL & 50 & 145 & 1.562 & 0.137 & 11.401 & & \\
\hline 79 & 8620 & CONVENTIONAL & 50 & 146 & 1.51 & 0.181 & 8.343 & & \\
\hline 80 & 8620 & CONVENTIONAL & 50 & 147 & 1.555 & 0.143 & 10.874 & & \\
\hline
\end{tabular}

Standard Deviation

$$
\sigma=\sqrt{\frac{\sum\left(y_{i}-\bar{y}\right)^{2}}{(n-1)}}
$$




\begin{tabular}{|c|c|c|c|c|c|c|c|c|c|}
\hline SI. No.: & $\begin{array}{c}\text { Type of } \\
\text { Steel }\end{array}$ & Type of coating & $\begin{array}{c}\% \text { Rel. } \\
\text { Strk. }\end{array}$ & $\begin{array}{l}\text { Expt. } \\
\text { No.: }\end{array}$ & h1 & h2 & $\begin{array}{c}y_{i} \\
(h 1 / h 2)\end{array}$ & $\begin{array}{c}\bar{y} \\
\text { Avg. }\end{array}$ & $\begin{array}{l}\text { Std. } \\
\text { Dev. }\end{array}$ \\
\hline 81 & 8620 & $A C-1(G M-66273)$ & 30 & 25 & 0.782 & 0.113 & 6.920 & & \\
\hline 82 & 8620 & $A C-1(G M-66273)$ & 30 & 26 & 0.789 & 0.127 & 6.213 & & \\
\hline 83 & 8620 & $A C-1(G M-66273)$ & 30 & 27 & 0.783 & 0.126 & 6.214 & & \\
\hline 84 & 8620 & $A C-1(G M-66273)$ & 30 & 28 & 0.784 & 0.107 & 7.327 & 6.887 & 0.578 \\
\hline 85 & 8620 & $A C-1(G M-66273)$ & 30 & 29 & 0.786 & 0.103 & 7.631 & & \\
\hline 86 & 8620 & $A C-1(G M-66273)$ & 30 & 30 & 0.786 & 0.112 & 7.018 & & \\
\hline 87 & 8620 & $A C-1(G M-66273)$ & 40 & 94 & 1.16 & 0.156 & 7.436 & & \\
\hline 88 & 8620 & $A C-1(G M-66273)$ & 40 & 95 & 1.169 & 0.151 & 7.742 & & \\
\hline 89 & 8620 & $A C-1(G M-66273)$ & 40 & 96 & 1.168 & 0.158 & 7.392 & & \\
\hline 90 & 8620 & $A C-1(G M-66273)$ & 40 & 97 & 1.17 & 0.154 & 7.597 & 7.749 & 0.349 \\
\hline 91 & 8620 & $A C-1(G M-66273)$ & 40 & 98 & 1.178 & 0.146 & 8.068 & & \\
\hline 92 & 8620 & $A C-1(G M-66273)$ & 40 & 99 & 1.181 & 0.143 & 8.259 & & \\
\hline 93 & 8620 & $A C-1(G M-66273)$ & 50 & & & & & & \\
\hline 94 & 8620 & $A C-1(G M-66273)$ & 50 & & & & & & \\
\hline 95 & 8620 & $A C-1(G M-66273)$ & 50 & & & & & & \\
\hline 96 & 8620 & $A C-1(G M-66273)$ & 50 & & & & & & \\
\hline 97 & 8620 & $A C-1(G M-66273)$ & 50 & & & & & & \\
\hline 98 & 8620 & $A C-1(G M-66273)$ & 50 & & & & & & \\
\hline 99 & 8620 & $A C-1(G M-66273)$ & 50 & & & & & & \\
\hline 100 & 8620 & $A C-1(G M-66273)$ & 50 & & & & & & \\
\hline
\end{tabular}

$$
\text { Standard Deviation } \quad \sigma=\sqrt{\frac{\sum\left(y_{i}-\bar{y}\right)^{2}}{(n-1)}}
$$

* Blackened cells are those experiments in which the double cup extrusion were stopped midway through the stroke the press due to breakdown of the lubricant film at these percentages of deformation stroke 


\begin{tabular}{|c|c|c|c|c|c|c|c|c|c|}
\hline SI. No.: & $\begin{array}{c}\text { Type of } \\
\text { Steel }\end{array}$ & Type of coating & $\begin{array}{c}\% \text { Rel. } \\
\text { Strk. }\end{array}$ & $\begin{array}{c}\text { Expt. } \\
\text { No.: }\end{array}$ & h1 & h2 & $\begin{array}{c}y_{i} \\
(h 1 / h 2)\end{array}$ & $\begin{array}{c}\bar{y} \\
\text { Avg. }\end{array}$ & $\begin{array}{l}\text { Std. } \\
\text { Dev. }\end{array}$ \\
\hline 101 & 8620 & $A C-2(G M-66270)$ & 30 & 31 & 0.748 & 0.132 & 5.667 & & \\
\hline 102 & 8620 & $A C-2(G M-66270)$ & 30 & 32 & 0.774 & 0.145 & 5.338 & & \\
\hline 103 & 8620 & $A C-2(G M-66270)$ & 30 & 33 & 0.781 & 0.138 & 5.659 & & \\
\hline 104 & 8620 & $A C-2(G M-66270)$ & 30 & 34 & 0.79 & 0.131 & 6.031 & 5.744 & 0.323 \\
\hline 105 & 8620 & $A C-2(G M-66270)$ & 30 & 35 & 0.772 & 0.139 & 5.554 & & \\
\hline 106 & 8620 & $A C-2(G M-66270)$ & 30 & 36 & 0.771 & 0.124 & 6.218 & & \\
\hline 107 & 8620 & $A C-2(G M-66270)$ & 40 & 100 & 1.169 & 0.155 & & & \\
\hline 108 & 8620 & $A C-2(G M-66270)$ & 40 & 101 & 1.151 & 0.167 & & & \\
\hline 109 & 8620 & $A C-2(G M-66270)$ & 40 & & & & & & \\
\hline 110 & 8620 & $A C-2(G M-66270)$ & 40 & & & & & & \\
\hline 111 & 8620 & $A C-2(G M-66270)$ & 40 & & & & & & \\
\hline 112 & 8620 & $A C-2(G M-66270)$ & 40 & & & & & & \\
\hline 113 & 8620 & $A C-2(G M-66270)$ & 50 & & & & & & \\
\hline 114 & 8620 & $A C-2(G M-66270)$ & 50 & & & & & & \\
\hline 115 & 8620 & $A C-2(G M-66270)$ & 50 & & & & & & \\
\hline 116 & 8620 & $A C-2(G M-66270)$ & 50 & & & & & & \\
\hline 117 & 8620 & $A C-2(G M-66270)$ & 50 & & & & & & \\
\hline 118 & 8620 & $A C-2(G M-66270)$ & 50 & & & & & & \\
\hline 119 & 8620 & $A C-2(G M-66270)$ & 50 & & & & & & \\
\hline 120 & 8620 & $A C-2(G M-66270)$ & 50 & & & & & & \\
\hline
\end{tabular}

$$
\text { Standard Deviation } \quad \sigma=\sqrt{\frac{\sum\left(y_{i}-\bar{y}\right)^{2}}{(n-1)}}
$$

* Blackened cells are those experiments in which the double cup extrusion were stopped midway through the stroke the press due to breakdown of the lubricant film at these percentages of deformation stroke 


\begin{tabular}{|c|c|c|c|c|c|c|c|c|c|}
\hline SI. No.: & $\begin{array}{c}\text { Type of } \\
\text { Steel }\end{array}$ & Type of coating & $\begin{array}{c}\text { \% Rel. } \\
\text { Strk. }\end{array}$ & $\begin{array}{l}\text { Expt. } \\
\text { No.: }\end{array}$ & h1 & h2 & $\begin{array}{c}y_{i} \\
(h 1 / h 2)\end{array}$ & $\begin{array}{c}\bar{y} \\
\text { Avg. }\end{array}$ & $\begin{array}{l}\text { Std. } \\
\text { Dev. }\end{array}$ \\
\hline 121 & 8620 & $A C-3(G M-66273 J)$ & 30 & 37 & 0.692 & 0.19 & 3.642 & & \\
\hline 122 & 8620 & $A C-3(G M-66273 J)$ & 30 & 38 & 0.74 & 0.157 & 4.713 & & \\
\hline 123 & 8620 & $A C-3(G M-66273 J)$ & 30 & 39 & 0.76 & 0.13 & 5.846 & & \\
\hline 124 & 8620 & $A C-3(G M-66273 J)$ & 30 & 40 & 0.747 & 0.132 & 5.659 & 5.030 & 0.793 \\
\hline 125 & 8620 & $A C-3(G M-66273 J)$ & 30 & 41 & 0.753 & 0.149 & 5.054 & & \\
\hline 126 & 8620 & $A C-3(G M-66273 J)$ & 30 & 42 & 0.753 & 0.143 & 5.266 & & \\
\hline 127 & 8620 & $A C-3(G M-66273 J)$ & 40 & 102 & 1.165 & 0.154 & 7.565 & & \\
\hline 128 & 8620 & $A C-3(G M-66273 J)$ & 40 & 103 & 1.175 & 0.137 & 8.577 & & \\
\hline 129 & 8620 & $A C-3(G M-66273 J)$ & 40 & 104 & 1.168 & 0.145 & 8.055 & & \\
\hline 130 & 8620 & $A C-3(G M-66273 J)$ & 40 & 105 & 1.169 & 0.143 & 8.175 & 8.012 & 0.355 \\
\hline 131 & 8620 & $A C-3(G M-66273 J)$ & 40 & 106 & 1.164 & 0.146 & 7.973 & & \\
\hline 132 & 8620 & $A C-3(G M-66273 J)$ & 40 & 107 & 1.159 & 0.15 & 7.727 & & \\
\hline 133 & 8620 & $A C-3(G M-66273 J)$ & 50 & 156 & 1.55 & 0.161 & & & \\
\hline 134 & 8620 & $A C-3(G M-66273 J)$ & 50 & 157 & 1.472 & 0.235 & & & \\
\hline 135 & 8620 & $A C-3(G M-66273 J)$ & 50 & & & & & & \\
\hline 136 & 8620 & $A C-3(G M-66273 J)$ & 50 & & & & & & \\
\hline 137 & 8620 & $A C-3(G M-66273 J)$ & 50 & & & & & & \\
\hline 138 & 8620 & $A C-3(G M-66273 J)$ & 50 & & & & & & \\
\hline 139 & 8620 & $A C-3(G M-66273 J)$ & 50 & & & & & & \\
\hline 140 & 8620 & $A C-3(G M-66273 J)$ & 50 & & & & & & \\
\hline
\end{tabular}

Standard Deviation

$$
\sigma=\sqrt{\frac{\sum\left(y_{i}-\bar{y}\right)^{2}}{(n-1)}}
$$

* Blackened cells are those experiments in which the double cup extrusion were stopped midway through the stroke of the press due to breakdown of the lubricant film at these percentages of deformation stroke 


\begin{tabular}{|c|c|c|c|c|c|c|c|c|c|}
\hline Sl. No.: & $\begin{array}{c}\text { Type of } \\
\text { Steel }\end{array}$ & Type of coating & $\begin{array}{c}\text { \% Rel. } \\
\text { Strk. }\end{array}$ & $\begin{array}{l}\text { Expt. } \\
\text { No.: }\end{array}$ & h1 & h2 & $\begin{array}{c}\mathbf{y}_{\mathbf{i}} \\
(\mathrm{h} 1 / \mathrm{h} 2)\end{array}$ & $\begin{array}{r}\overline{y^{\prime}} \\
\text { Avg. }\end{array}$ & $\begin{array}{l}\text { Std. } \\
\text { Dev. }\end{array}$ \\
\hline 141 & 8620 & IRMCO - 1 (601A - PHOS) & 30 & 43 & 0.701 & 0.195 & 3.595 & & \\
\hline 142 & 8620 & IRMCO - 1 (601A - PHOS) & 30 & 44 & 0.674 & 0.209 & 3.225 & & \\
\hline 143 & 8620 & IRMCO - 1 (601A - PHOS) & 30 & 45 & 0.709 & 0.185 & 3.832 & & \\
\hline 144 & 8620 & IRMCO - 1 (601A - PHOS) & 30 & 46 & 0.71 & 0.18 & 3.944 & 3.547 & 0.293 \\
\hline 145 & 8620 & IRMCO - 1 (601A - PHOS) & 30 & 47 & 0.689 & 0.205 & 3.361 & & \\
\hline 146 & 8620 & IRMCO - 1 (601A - PHOS) & 30 & 48 & 0.682 & 0.205 & 3.327 & & \\
\hline 147 & 8620 & IRMCO - 1 (601A - PHOS) & 40 & 108 & 1.1 & 0.219 & 5.023 & & \\
\hline 148 & 8620 & IRMCO - 1 (601A - PHOS) & 40 & 109 & 1.132 & 0.205 & 5.522 & & \\
\hline 149 & 8620 & IRMCO - 1 (601A - PHOS) & 40 & 110 & 1.142 & 0.206 & 5.544 & & \\
\hline 150 & 8620 & IRMCO - 1 (601A - PHOS) & 40 & 111 & 1.111 & 0.217 & 5.120 & 5.236 & 0.260 \\
\hline 151 & 8620 & IRMCO - 1 (601A - PHOS) & 40 & 112 & 1.112 & 0.226 & 4.920 & & \\
\hline 152 & 8620 & IRMCO - 1 (601A - PHOS) & 40 & 113 & 1.116 & 0.211 & 5.289 & & \\
\hline 153 & 8620 & IRMCO - 1 (601A - PHOS) & 50 & 148 & 1.495 & 0.22 & 5.120 & & \\
\hline 154 & 8620 & IRMCO - 1 (601A - PHOS) & 50 & 149 & 1.479 & 0.229 & 4.920 & & \\
\hline 156 & 8620 & IRMCO - 1 (601A - PHOS) & 50 & 150 & 1.464 & 0.247 & 5.289 & & \\
\hline 158 & 8620 & IRMCO - 1 (601A - PHOS) & 50 & 151 & 1.467 & 0.244 & 6.012 & & \\
\hline 159 & 8620 & IRMCO - 1 (601A - PHOS) & 50 & 152 & 1.47 & 0.242 & 6.795 & 5.817 & 0.657 \\
\hline 160 & 8620 & IRMCO - 1 (601A - PHOS) & 50 & 153 & 1.467 & 0.243 & 6.459 & & \\
\hline 161 & 8620 & IRMCO - 1 (601A - PHOS) & 50 & 154 & 1.462 & 0.25 & 5.927 & & \\
\hline 162 & 8620 & IRMCO - 1 (601A - PHOS) & 50 & 155 & 1.464 & 0.246 & 6.012 & & \\
\hline
\end{tabular}

Standard Deviation

$$
\sigma=\sqrt{\frac{\sum\left(y_{i}-\bar{y}\right)^{2}}{(n-1)}}
$$




\begin{tabular}{|c|c|c|c|c|c|c|c|c|c|}
\hline SI. No.: & $\begin{array}{c}\text { Type of } \\
\text { Steel }\end{array}$ & Type of coating & $\begin{array}{c}\text { \% Rel. } \\
\text { Strk. }\end{array}$ & $\begin{array}{l}\text { Expt. } \\
\text { No.: }\end{array}$ & h1 & h2 & $\begin{array}{c}y_{i} \\
(h 1 / h 2)\end{array}$ & $\begin{array}{l}y \\
\text { Avg. }\end{array}$ & Std. Dev. \\
\hline 163 & 8620 & IRMCO - 2 (601++ - PHOS) & 30 & 49 & 0.678 & 0.215 & 3.153 & & \\
\hline 164 & 8620 & IRMCO - 2 (601++ - PHOS) & 30 & 50 & 0.73 & 0.155 & 4.710 & & \\
\hline 165 & 8620 & IRMCO - 2 (601++ - PHOS) & 30 & 51 & 0.7 & 0.185 & 3.784 & & \\
\hline 166 & 8620 & IRMCO - 2 (601++ - PHOS) & 30 & 52 & 0.723 & 0.165 & 4.382 & 3.983 & 0.578 \\
\hline 167 & 8620 & IRMCO - 2 (601++ - PHOS) & 30 & 53 & 0.698 & 0.195 & 3.579 & & \\
\hline 168 & 8620 & IRMCO - 2 (601++ - PHOS) & 30 & 54 & 0.725 & 0.169 & 4.290 & & \\
\hline 169 & 8620 & IRMCO - 2 (601++ - PHOS) & 40 & & & & & & \\
\hline 170 & 8620 & IRMCO - 2 (601++ - PHOS) & 40 & & & & & & \\
\hline 171 & 8620 & IRMCO - 2 (601++ - PHOS) & 40 & & & & & & \\
\hline 172 & 8620 & IRMCO - 2 (601++ - PHOS) & 40 & & & & & & \\
\hline 173 & 8620 & IRMCO - 2 (601++ - PHOS) & 40 & & & & & & \\
\hline 174 & 8620 & IRMCO - 2 (601++ - PHOS) & 40 & & & & & & \\
\hline 175 & 8620 & IRMCO - 2 (601++ - PHOS) & 50 & 158 & 1.463 & 0.25 & & & \\
\hline 176 & 8620 & IRMCO - 2 (601++ - PHOS) & 50 & 159 & 1.489 & 0.22 & & & \\
\hline 177 & 8620 & IRMCO - 2 (601++ - PHOS) & 50 & 160 & 1.462 & 0.257 & & & \\
\hline 178 & 8620 & IRMCO - 2 (601++ - PHOS) & 50 & & & & & & \\
\hline 179 & 8620 & IRMCO - 2 (601++ - PHOS) & 50 & & & & & & \\
\hline 180 & 8620 & IRMCO - 2 (601++ - PHOS) & 50 & & & & & & \\
\hline 181 & 8620 & IRMCO - 2 (601++ - PHOS) & 50 & & & & & & \\
\hline 182 & 8620 & IRMCO - 2 (601++ - PHOS) & 50 & & & & & & \\
\hline
\end{tabular}

$$
\text { Standard Deviation } \quad \sigma=\sqrt{\frac{\sum\left(y_{i}-\bar{y}\right)^{2}}{(n-1)}}
$$

* Blackened cells are those experiments in which the double cup extrusion were stopped midway through the stroke the press due to breakdown of the lubricant film at these percentages of deformation stroke 


\section{APPENDIX B - COMPUTER SIMULATION (ANTARES) GENERATED}

DATA

For shear coefficient $\mathrm{m}=0.05$

\begin{tabular}{|c|c|c|c|c|}
\hline STEP NO. & \begin{tabular}{|l} 
STROKE \\
\end{tabular} & $\mathrm{H} 1$ (in.) & $\mathrm{H} 2$ (in.) & $\mathrm{CHR}$ \\
\hline 1 & 0.104 & 0.056 & 0.038 & 1.489 \\
\hline 2 & 0.172 & 0.100 & 0.052 & 1.931 \\
\hline 3 & 0.271 & 0.155 & 0.084 & 1.853 \\
\hline 4 & 0.335 & 0.205 & 0.105 & 1.942 \\
\hline 5 & 0.367 & 0.242 & 0.108 & 2.240 \\
\hline 6 & 0.460 & 0.357 & 0.116 & 3.064 \\
\hline 7 & 0.521 & 0.433 & 0.118 & 3.674 \\
\hline 8 & 0.580 & 0.501 & 0.129 & 3.877 \\
\hline 9 & 0.667 & 0.595 & 0.148 & 4.020 \\
\hline 10 & 0.722 & 0.665 & 0.148 & 4.479 \\
\hline 11 & 0.736 & 0.683 & 0.148 & 4.598 \\
\hline 12 & 0.817 & 0.784 & 0.154 & 5.101 \\
\hline 13 & 0.869 & 0.849 & 0.154 & 5.506 \\
\hline 14 & 0.920 & 0.910 & 0.168 & 5.412 \\
\hline 15 & 0.994 & 0.985 & 0.182 & 5.407 \\
\hline 16 & 1.041 & 1.034 & 0.197 & 5.244 \\
\hline 17 & 1.109 & 1.102 & 0.225 & 4.897 \\
\hline 18 & 1.153 & 1.146 & 0.235 & 4.872 \\
\hline 19 & 1.217 & 1.210 & 0.255 & 4.736 \\
\hline 20 & 1.257 & 1.250 & 0.269 & 4.646 \\
\hline 21 & 1.315 & 1.310 & 0.286 & 4.587 \\
\hline 22 & 1.352 & 1.347 & 0.297 & 4.543 \\
\hline 23 & 1.404 & 1.400 & 0.314 & 4.459 \\
\hline 24 & 1.473 & 1.433 & 0.324 & 4.418 \\
\hline 25 & 1.485 & 1.480 & 0.340 & 4.356 \\
\hline 26 & 1.514 & 1.510 & 0.349 & 4.321 \\
\hline 27 & 1.556 & 1.552 & 0.363 & 4.273 \\
\hline 28 & 1.582 & 1.578 & 0.372 & 4.242 \\
\hline 29 & 1.618 & 1.614 & 0.384 & 4.202 \\
\hline 30 & 1.641 & 1.636 & 0.391 & 4.180 \\
\hline 31 & 1.672 & 1.667 & 0.402 & 4.147 \\
\hline 32 & 1.690 & 1.685 & 0.408 & 4.126 \\
\hline 33 & 1.716 & 1.710 & 0.417 & 4.104 \\
\hline 34 & 1.731 & 1.726 & 0.422 & 4.093 \\
\hline 35 & 1.751 & 1.745 & 0.428 & 4.073 \\
\hline 36 & 1.762 & 1.756 & 0.432 & 4.063 \\
\hline 37 & 1.776 & 1.770 & 0.438 & 4.045 \\
\hline 38 & 1.784 & 1.777 & 0.440 & 4.038 \\
\hline 39 & 1.793 & 1.785 & 0.444 & 4.026 \\
\hline 40 & 1.797 & 1.789 & 0.445 & 4.021 \\
\hline 41 & 1.800 & 1.792 & 0.446 & 4.018 \\
\hline 42 & 1.800 & 1.793 & 0.446 & 4.017 \\
\hline
\end{tabular}


For shear coefficient $\mathrm{m}=0.06$

\begin{tabular}{|c|c|c|c|c|}
\hline STEP NO. & STROKE & H1(in.) & H2(in.) & CHR \\
\hline 1 & 0.009 & 0.045 & 0.036 & 1.254 \\
\hline 2 & 0.172 & 0.101 & 0.050 & 2.008 \\
\hline 3 & 0.254 & 0.154 & 0.067 & 2.295 \\
\hline 4 & 0.335 & 0.220 & 0.089 & 2.487 \\
\hline 5 & 0.398 & 0.299 & 0.093 & 3.234 \\
\hline 6 & 0.475 & 0.395 & 0.100 & 3.959 \\
\hline 7 & 0.550 & 0.482 & 0.111 & 4.333 \\
\hline 8 & 0.623 & 0.565 & 0.125 & 4.512 \\
\hline 9 & 0.694 & 0.642 & 0.142 & 4.526 \\
\hline 10 & 0.763 & 0.714 & 0.162 & 4.397 \\
\hline 11 & 0.830 & 0.786 & 0.179 & 4.400 \\
\hline 12 & 0.894 & 0.859 & 0.192 & 4.485 \\
\hline 13 & 0.957 & 0.929 & 0.204 & 4.544 \\
\hline 14 & 1.017 & 0.999 & 0.214 & 4.678 \\
\hline 15 & 1.075 & 1.062 & 0.229 & 4.641 \\
\hline 16 & 1.131 & 1.124 & 0.240 & 4.685 \\
\hline 17 & 1.185 & 1.184 & 0.250 & 4.741 \\
\hline 18 & 1.236 & 1.240 & 0.264 & 4.703 \\
\hline 19 & 1.295 & 1.294 & 0.274 & 4.718 \\
\hline 20 & 1.333 & 1.346 & 0.284 & 4.736 \\
\hline 21 & 1.378 & 1.392 & 0.298 & 4.666 \\
\hline 22 & 1.420 & 1.435 & 0.312 & 4.598 \\
\hline 23 & 1.461 & 1.475 & 0.325 & 4.544 \\
\hline 24 & 1.499 & 1.513 & 0.337 & 4.489 \\
\hline 25 & 1.535 & 1.549 & 0.349 & 4.436 \\
\hline 26 & 1.569 & 1.583 & 0.360 & 4.399 \\
\hline 27 & 1.600 & 1.614 & 0.370 & 4.362 \\
\hline 28 & 1.629 & 1.644 & 0.380 & 4.327 \\
\hline 29 & 1.656 & 1.670 & 0.389 & 4.297 \\
\hline 30 & 1.681 & 1.695 & 0.397 & 4.270 \\
\hline 31 & 1.703 & 1.717 & 0.404 & 4.250 \\
\hline 32 & 1.723 & 1.737 & 0.411 & 4.228 \\
\hline 33 & 1.741 & 1.754 & 0.417 & 4.212 \\
\hline 34 & 1.756 & 1.770 & 0.422 & 4.198 \\
\hline 35 & 1.769 & 1.782 & 0.426 & 4.186 \\
\hline 36 & 1.780 & 1.793 & 0.430 & 4.173 \\
\hline 37 & 1.788 & 1.801 & 0.432 & 4.164 \\
\hline 38 & 1.795 & 1.807 & 0.435 & 4.156 \\
\hline 39 & 1.798 & 1.810 & 0.436 & 4.154 \\
\hline 40 & 1.800 & 1.812 & 0.436 & 4.151 \\
\hline 41 & 1.800 & 1.812 & 0.436 & 4.151 \\
\hline & & & & \\
\hline
\end{tabular}


For shear coefficient $\mathrm{m}=\mathbf{0 . 0 7}$

\begin{tabular}{|c|c|c|c|c|}
\hline STEP NO. & STROKE & H1(in.) & $\mathrm{H} 2$ (in.) & $\mathrm{CHR}$ \\
\hline 1 & 0.104 & 0.056 & 0.039 & 1.436 \\
\hline 2 & 0.172 & 0.101 & 0.051 & 1.998 \\
\hline 3 & 0.271 & 0.160 & 0.079 & 2.029 \\
\hline 4 & 0.335 & 0.214 & 0.095 & 2.247 \\
\hline 5 & 0.367 & 0.253 & 0.098 & 2.573 \\
\hline 6 & 0.460 & 0.368 & 0.106 & 3.476 \\
\hline 7 & 0.491 & 0.406 & 0.106 & 3.816 \\
\hline 8 & 0.551 & 0.477 & 0.112 & 4.270 \\
\hline 9 & 0.638 & 0.576 & 0.128 & 4.487 \\
\hline 10 & 0.695 & 0.647 & 0.129 & 5.029 \\
\hline 11 & 0.736 & 0.695 & 0.136 & 5.117 \\
\hline 12 & 0.763 & 0.722 & 0.145 & 4.986 \\
\hline 13 & 0.843 & 0.810 & 0.163 & 4.959 \\
\hline 14 & 0.895 & 0.873 & 0.169 & 5.164 \\
\hline 15 & 0.969 & 0.964 & 0.177 & 5.439 \\
\hline 16 & 1.018 & 1.024 & 0.178 & 5.742 \\
\hline 17 & 1.087 & 1.108 & 0.186 & 5.956 \\
\hline 18 & 1.109 & 1.134 & 0.191 & 5.952 \\
\hline 19 & 1.175 & 1.209 & 0.202 & 5.992 \\
\hline 20 & 1.217 & 1.253 & 0.213 & 5.882 \\
\hline 21 & 1.277 & 1.313 & 0.233 & 5.635 \\
\hline 22 & 1.315 & 1.351 & 0.245 & 5.510 \\
\hline 23 & 1.370 & 1.406 & 0.263 & 5.345 \\
\hline 24 & 1.404 & 1.441 & 0.274 & 5.265 \\
\hline 25 & 1.454 & 1.490 & 0.289 & 5.153 \\
\hline 26 & 1.485 & 1.521 & 0.299 & 5.089 \\
\hline 27 & 1.529 & 1.565 & 0.313 & 4.997 \\
\hline 28 & 1.556 & 1.593 & 0.322 & 4.945 \\
\hline 29 & 1.595 & 1.631 & 0.335 & 4.875 \\
\hline 30 & 1.618 & 1.655 & 0.342 & 4.841 \\
\hline 31 & 1.651 & 1.688 & 0.353 & 4.784 \\
\hline 32 & 1.672 & 1.708 & 0.360 & 4.752 \\
\hline 33 & 1.699 & 1.736 & 0.369 & 4.704 \\
\hline 34 & 1.716 & 1.752 & 0.375 & 4.674 \\
\hline 35 & 1.738 & 1.774 & 0.382 & 4.645 \\
\hline 36 & 1.751 & 1.787 & 0.387 & 4.620 \\
\hline 37 & 1.767 & 1.803 & 0.392 & 4.597 \\
\hline 38 & 1.776 & 1.812 & 0.395 & 4.583 \\
\hline 39 & 1.787 & 1.823 & 0.399 & 4.571 \\
\hline 40 & 1.793 & 1.828 & 0.401 & 4.563 \\
\hline 41 & 1.798 & 1.834 & 0.402 & 4.556 \\
\hline 42 & 1.800 & 1.835 & 0.403 & 4.550 \\
\hline 43 & 1.800 & 1.836 & 0.403 & 4.550 \\
\hline
\end{tabular}


For shear coefficient $\mathrm{m}=0.09$

\begin{tabular}{|c|c|c|c|c|}
\hline STEP NO. & STROKE & H1 (in.) & H2 (in.) & CHR \\
\hline 1 & 0.104 & 0.056 & 0.038 & 1.466 \\
\hline 2 & 0.172 & 0.101 & 0.050 & 2.020 \\
\hline 3 & 0.271 & 0.164 & 0.074 & 2.217 \\
\hline 4 & 0.335 & 0.224 & 0.087 & 2.576 \\
\hline 5 & 0.398 & 0.301 & 0.094 & 3.215 \\
\hline 6 & 0.491 & 0.414 & 0.103 & 4.037 \\
\hline 7 & 0.551 & 0.488 & 0.105 & 4.633 \\
\hline 8 & 0.638 & 0.592 & 0.116 & 5.108 \\
\hline 9 & 0.695 & 0.662 & 0.116 & 5.698 \\
\hline 10 & 0.777 & 0.764 & 0.124 & 6.146 \\
\hline 11 & 0.856 & 0.853 & 0.140 & 6.094 \\
\hline 12 & 0.907 & 0.910 & 0.152 & 5.994 \\
\hline 13 & 0.982 & 0.998 & 0.162 & 6.143 \\
\hline 14 & 1.029 & 1.057 & 0.163 & 6.494 \\
\hline 15 & 1.053 & 1.089 & 0.163 & 6.683 \\
\hline 16 & 1.121 & 1.174 & 0.168 & 7.003 \\
\hline 17 & 1.164 & 1.224 & 0.175 & 6.989 \\
\hline 18 & 1.227 & 1.296 & 0.185 & 7.002 \\
\hline 19 & 1.247 & 1.319 & 0.189 & 6.995 \\
\hline 20 & 1.305 & 1.385 & 0.199 & 6.942 \\
\hline 21 & 1.343 & 1.425 & 0.207 & 6.871 \\
\hline 22 & 1.396 & 1.478 & 0.225 & 6.579 \\
\hline 23 & 1.429 & 1.512 & 0.235 & 6.438 \\
\hline 24 & 1.477 & 1.560 & 0.250 & 6.231 \\
\hline 25 & 1.507 & 1.590 & 0.260 & 6.120 \\
\hline 26 & 1.549 & 1.632 & 0.274 & 5.960 \\
\hline 27 & 1.563 & 1.646 & 0.278 & 5.912 \\
\hline 28 & 1.601 & 1.683 & 0.291 & 5.791 \\
\hline 29 & 1.624 & 1.707 & 0.298 & 5.732 \\
\hline 30 & 1.657 & 1.740 & 0.308 & 5.649 \\
\hline 31 & 1.686 & 1.769 & 0.317 & 5.575 \\
\hline 32 & 1.703 & 1.786 & 0.323 & 5.532 \\
\hline 33 & 1.727 & 1.810 & 0.330 & 5.477 \\
\hline 34 & 1.741 & 1.824 & 0.335 & 5.446 \\
\hline 35 & 1.759 & 1.842 & 0.341 & 5.404 \\
\hline 36 & 1.769 & 1.852 & 0.344 & 5.379 \\
\hline 37 & 1.782 & 1.865 & 0.349 & 5.350 \\
\hline 38 & 1.789 & 1.871 & 0.351 & 5.334 \\
\hline 39 & 1.796 & 1.878 & 0.353 & 5.321 \\
\hline 40 & 1.799 & 1.881 & 0.354 & 5.309 \\
\hline 41 & 1.800 & 1.882 & 0.355 & 5.301 \\
\hline & & & & \\
\hline
\end{tabular}


For shear coefficient $m=0.11$

\begin{tabular}{|c|c|c|c|c|}
\hline STEP NO. & STROKE & H1(in.) & H2 (in.) & CHR \\
\hline 1 & 0.104 & 0.056 & 0.038 & 1.484 \\
\hline 2 & 0.172 & 0.102 & 0.050 & 2.048 \\
\hline 3 & 0.271 & 0.167 & 0.071 & 2.370 \\
\hline 4 & 0.303 & 0.194 & 0.078 & 2.490 \\
\hline 5 & 0.398 & 0.310 & 0.083 & 3.724 \\
\hline 6 & 0.430 & 0.350 & 0.084 & 4.182 \\
\hline 7 & 0.521 & 0.463 & 0.089 & 5.221 \\
\hline 8 & 0.580 & 0.527 & 0.100 & 5.272 \\
\hline 9 & 0.667 & 0.627 & 0.112 & 5.583 \\
\hline 10 & 0.722 & 0.697 & 0.113 & 6.186 \\
\hline 11 & 0.763 & 0.749 & 0.114 & 6.585 \\
\hline 12 & 0.843 & 0.848 & 0.121 & 7.023 \\
\hline 13 & 0.895 & 0.911 & 0.124 & 7.336 \\
\hline 14 & 0.969 & 1.003 & 0.132 & 7.622 \\
\hline 15 & 1.018 & 1.063 & 0.133 & 7.990 \\
\hline 16 & 1.087 & 1.146 & 0.142 & 8.077 \\
\hline 17 & 1.109 & 1.172 & 0.146 & 8.026 \\
\hline 18 & 1.175 & 1.247 & 0.156 & 7.991 \\
\hline 19 & 1.217 & 1.295 & 0.164 & 7.894 \\
\hline 20 & 1.277 & 1.356 & 0.184 & 7.385 \\
\hline 21 & 1.315 & 1.397 & 0.192 & 7.261 \\
\hline 22 & 1.370 & 1.457 & 0.206 & 7.086 \\
\hline 23 & 1.404 & 1.495 & 0.212 & 7.051 \\
\hline 24 & 1.454 & 1.545 & 0.227 & 6.790 \\
\hline 25 & 1.485 & 1.576 & 0.237 & 6.648 \\
\hline 26 & 1.529 & 1.620 & 0.251 & 6.445 \\
\hline 27 & 1.556 & 1.647 & 0.260 & 6.334 \\
\hline 28 & 1.595 & 1.686 & 0.272 & 6.186 \\
\hline 29 & 1.618 & 1.710 & 0.280 & 6.113 \\
\hline 30 & 1.651 & 1.743 & 0.291 & 5.998 \\
\hline 31 & 1.672 & 1.763 & 0.297 & 5.933 \\
\hline 32 & 1.699 & 1.790 & 0.306 & 5.844 \\
\hline 33 & 1.716 & 1.807 & 0.312 & 5.788 \\
\hline 34 & 1.738 & 1.829 & 0.319 & 5.728 \\
\hline 35 & 1.751 & 1.842 & 0.324 & 5.690 \\
\hline 36 & 1.767 & 1.858 & 0.329 & 5.648 \\
\hline 37 & 1.776 & 1.867 & 0.332 & 5.622 \\
\hline 38 & 1.787 & 1.878 & 0.336 & 5.597 \\
\hline 39 & 1.793 & 1.884 & 0.337 & 5.583 \\
\hline 40 & 1.798 & 1.889 & 0.339 & 5.573 \\
\hline 41 & 1.800 & 1.891 & 0.340 & 5.564 \\
\hline 42 & 1.800 & 1.891 & 0.340 & 5.564 \\
\hline & & & & \\
\hline
\end{tabular}


For shear coefficient $\mathrm{m}=0.13$

\begin{tabular}{|c|c|c|c|c|}
\hline STEP NO. & STROKE & H1(in.) & H2 (in.) & CHR \\
\hline 1 & 0.104 & 0.056 & 0.038 & 1.493 \\
\hline 2 & 0.172 & 0.102 & 0.049 & 2.061 \\
\hline 3 & 0.271 & 0.171 & 0.067 & 2.539 \\
\hline 4 & 0.303 & 0.201 & 0.072 & 2.791 \\
\hline 5 & 0.398 & 0.314 & 0.079 & 3.947 \\
\hline 6 & 0.430 & 0.352 & 0.080 & 4.396 \\
\hline 7 & 0.521 & 0.465 & 0.086 & 5.403 \\
\hline 8 & 0.580 & 0.532 & 0.093 & 5.722 \\
\hline 9 & 0.667 & 0.630 & 0.108 & 5.812 \\
\hline 10 & 0.722 & 0.699 & 0.109 & 6.408 \\
\hline 11 & 0.763 & 0.751 & 0.110 & 6.802 \\
\hline 12 & 0.843 & 0.851 & 0.116 & 7.345 \\
\hline 13 & 0.895 & 0.916 & 0.118 & 7.735 \\
\hline 14 & 0.920 & 0.948 & 0.119 & 7.966 \\
\hline 15 & 0.994 & 1.039 & 0.124 & 8.405 \\
\hline 16 & 1.018 & 1.069 & 0.125 & 8.551 \\
\hline 17 & 1.087 & 1.151 & 0.135 & 8.510 \\
\hline 18 & 1.153 & 1.229 & 0.144 & 8.508 \\
\hline 19 & 1.196 & 1.278 & 0.151 & 8.439 \\
\hline 20 & 1.257 & 1.343 & 0.169 & 7.968 \\
\hline 21 & 1.315 & 1.408 & 0.179 & 7.874 \\
\hline 22 & 1.352 & 1.451 & 0.185 & 7.856 \\
\hline 23 & 1.404 & 1.507 & 0.198 & 7.601 \\
\hline 24 & 1.437 & 1.545 & 0.203 & 7.591 \\
\hline 25 & 1.485 & 1.594 & 0.217 & 7.351 \\
\hline 26 & 1.514 & 1.625 & 0.225 & 7.223 \\
\hline 27 & 1.556 & 1.667 & 0.238 & 6.990 \\
\hline 28 & 1.582 & 1.693 & 0.247 & 6.849 \\
\hline 29 & 1.618 & 1.729 & 0.259 & 6.671 \\
\hline 30 & 1.641 & 1.751 & 0.267 & 6.571 \\
\hline 31 & 1.672 & 1.782 & 0.277 & 6.441 \\
\hline 32 & 1.690 & 1.801 & 0.283 & 6.361 \\
\hline 33 & 1.716 & 1.826 & 0.291 & 6.274 \\
\hline 34 & 1.731 & 1.841 & 0.296 & 6.223 \\
\hline 35 & 1.751 & 1.861 & 0.302 & 6.157 \\
\hline 36 & 1.762 & 1.872 & 0.306 & 6.115 \\
\hline 37 & 1.776 & 1.887 & 0.311 & 6.071 \\
\hline 38 & 1.784 & 1.894 & 0.313 & 6.044 \\
\hline 39 & 1.793 & 1.903 & 0.316 & 6.022 \\
\hline 40 & 1.797 & 1.907 & 0.317 & 6.008 \\
\hline 41 & 1.800 & 1.910 & 0.318 & 6.002 \\
\hline 42 & 1.800 & 1.911 & 0.318 & 6.001 \\
\hline & & & & \\
\hline
\end{tabular}


For shear coefficient $\mathrm{m}=\mathbf{0 . 1 5}$

\begin{tabular}{|c|c|c|c|c|}
\hline STEP NO & STROKE & $\mathrm{H} 1$ (in.) & $\mathrm{H} 2$ (in.) & $\mathrm{CHR}$ \\
\hline 1 & 0.104 & 0.056 & 0.038 & 1.498 \\
\hline 2 & 0.172 & 0.103 & 0.048 & 2.117 \\
\hline 3 & 0.271 & 0.174 & 0.065 & 2.662 \\
\hline 4 & 0.303 & 0.205 & 0.069 & 2.990 \\
\hline 5 & 0.398 & 0.319 & 0.075 & 4.268 \\
\hline 6 & 0.430 & 0.358 & 0.075 & 4.771 \\
\hline 7 & 0.521 & 0.472 & 0.080 & 5.928 \\
\hline 8 & 0.551 & 0.507 & 0.082 & 6.175 \\
\hline 9 & 0.638 & 0.604 & 0.099 & 6.090 \\
\hline 10 & 0.695 & 0.673 & 0.101 & 6.681 \\
\hline 11 & 0.777 & 0.778 & 0.105 & 7.391 \\
\hline 12 & 0.856 & 0.875 & 0.112 & 7.809 \\
\hline 13 & 0.907 & 0.940 & 0.115 & 8.204 \\
\hline 14 & 0.982 & 1.034 & 0.118 & 8.746 \\
\hline 15 & 1.029 & 1.093 & 0.119 & 9.221 \\
\hline 16 & 1.053 & 1.124 & 0.119 & 9.479 \\
\hline 17 & 1.121 & 1.208 & 0.125 & 9.702 \\
\hline 18 & 1.164 & 1.259 & 0.131 & 9.586 \\
\hline 19 & 1.227 & 1.332 & 0.140 & 9.497 \\
\hline 20 & 1.247 & 1.356 & 0.143 & 9.495 \\
\hline 21 & 1.305 & 1.423 & 0.152 & 9.389 \\
\hline 22 & 1.343 & 1.466 & 0.157 & 9.317 \\
\hline 23 & 1.396 & 1.519 & 0.174 & 8.714 \\
\hline 24 & 1.429 & 1.553 & 0.185 & 8.414 \\
\hline 25 & 1.477 & 1.601 & 0.200 & 8.006 \\
\hline 26 & 1.507 & 1.631 & 0.209 & 7.789 \\
\hline 27 & 1.521 & 1.645 & 0.213 & 7.707 \\
\hline 28 & 1.563 & 1.687 & 0.227 & 7.444 \\
\hline 29 & 1.588 & 1.713 & 0.234 & 7.337 \\
\hline 30 & 1.624 & 1.749 & 0.245 & 7.131 \\
\hline 31 & 1.646 & 1.771 & 0.253 & 7.013 \\
\hline 32 & 1.676 & 1.801 & 0.263 & 6.862 \\
\hline 33 & 1.695 & 1.820 & 0.269 & 6.769 \\
\hline 34 & 1.720 & 1.845 & 0.277 & 6.668 \\
\hline 35 & 1.734 & 1.859 & 0.281 & 6.610 \\
\hline 36 & 1.753 & 1.879 & 0.287 & 6.535 \\
\hline 37 & 1.764 & 1.890 & 0.291 & 6.489 \\
\hline 38 & 1.778 & 1.903 & 0.296 & 6.440 \\
\hline 39 & 1.786 & 1.911 & 0.298 & 6.411 \\
\hline 40 & 1.794 & 1.919 & 0.300 & 6.386 \\
\hline 41 & 1.797 & 1.922 & 0.302 & 6.372 \\
\hline 42 & 1.800 & 1.925 & 0.302 & 6.366 \\
\hline 43 & 1.800 & 1.925 & 0.302 & 6.365 \\
\hline
\end{tabular}


For shear coefficient $\mathrm{m}=0.17$

\begin{tabular}{|c|c|c|c|c|}
\hline STEP NO. & STROKE & H1 (in.) & H2 (in.) & CHR \\
\hline 1 & 0.104 & 0.057 & 0.038 & 1.508 \\
\hline 2 & 0.172 & 0.103 & 0.048 & 2.163 \\
\hline 3 & 0.271 & 0.177 & 0.062 & 2.834 \\
\hline 4 & 0.367 & 0.281 & 0.069 & 4.056 \\
\hline 5 & 0.460 & 0.399 & 0.073 & 5.440 \\
\hline 6 & 0.521 & 0.474 & 0.076 & 6.258 \\
\hline 7 & 0.580 & 0.541 & 0.086 & 6.284 \\
\hline 8 & 0.667 & 0.640 & 0.099 & 6.441 \\
\hline 9 & 0.695 & 0.675 & 0.100 & 6.772 \\
\hline 10 & 0.777 & 0.779 & 0.104 & 7.515 \\
\hline 11 & 0.856 & 0.879 & 0.109 & 8.072 \\
\hline 12 & 0.907 & 0.944 & 0.111 & 8.521 \\
\hline 13 & 0.982 & 1.038 & 0.114 & 9.065 \\
\hline 14 & 1.029 & 1.097 & 0.115 & 9.552 \\
\hline 15 & 1.053 & 1.128 & 0.115 & 9.816 \\
\hline 16 & 1.121 & 1.211 & 0.122 & 9.928 \\
\hline 17 & 1.164 & 1.263 & 0.128 & 9.901 \\
\hline 18 & 1.227 & 1.336 & 0.136 & 9.848 \\
\hline 19 & 1.247 & 1.361 & 0.138 & 9.869 \\
\hline 20 & 1.305 & 1.429 & 0.146 & 9.796 \\
\hline 21 & 1.343 & 1.472 & 0.151 & 9.768 \\
\hline 22 & 1.396 & 1.527 & 0.167 & 9.147 \\
\hline 23 & 1.429 & 1.562 & 0.175 & 8.917 \\
\hline 24 & 1.477 & 1.610 & 0.191 & 8.450 \\
\hline 25 & 1.507 & 1.640 & 0.200 & 8.203 \\
\hline 26 & 1.549 & 1.682 & 0.214 & 7.867 \\
\hline 27 & 1.588 & 1.722 & 0.225 & 7.641 \\
\hline 28 & 1.613 & 1.749 & 0.230 & 7.596 \\
\hline 29 & 1.646 & 1.783 & 0.241 & 7.398 \\
\hline 30 & 1.667 & 1.803 & 0.248 & 7.284 \\
\hline 31 & 1.695 & 1.832 & 0.256 & 7.141 \\
\hline 32 & 1.712 & 1.848 & 0.262 & 7.056 \\
\hline 33 & 1.734 & 1.871 & 0.269 & 6.955 \\
\hline 34 & 1.747 & 1.884 & 0.273 & 6.896 \\
\hline 35 & 1.764 & 1.901 & 0.279 & 6.823 \\
\hline 36 & 1.774 & 1.911 & 0.282 & 6.778 \\
\hline 37 & 1.786 & 1.922 & 0.285 & 6.735 \\
\hline 38 & 1.791 & 1.928 & 0.287 & 6.710 \\
\hline 39 & 1.797 & 1.934 & 0.289 & 6.690 \\
\hline 40 & 1.799 & 1.936 & 0.290 & 6.681 \\
\hline 41 & 1.800 & 1.937 & 0.290 & 6.679 \\
\hline & & & & \\
\hline
\end{tabular}


For shear coefficient $\mathrm{m}=0.19$

\begin{tabular}{|c|c|c|c|c|}
\hline STEP NO. & STROKE & H1 (in.) & H2 (in.) & CHR \\
\hline 1 & 0.104 & 0.057 & 0.038 & 1.509 \\
\hline 2 & 0.172 & 0.103 & 0.048 & 2.160 \\
\hline 3 & 0.271 & 0.179 & 0.061 & 2.920 \\
\hline 4 & 0.303 & 0.281 & 0.070 & 4.020 \\
\hline 5 & 0.398 & 0.397 & 0.076 & 5.230 \\
\hline 6 & 0.430 & 0.472 & 0.078 & 6.014 \\
\hline 7 & 0.521 & 0.543 & 0.085 & 6.406 \\
\hline 8 & 0.551 & 0.641 & 0.100 & 6.441 \\
\hline 9 & 0.638 & 0.710 & 0.101 & 7.003 \\
\hline 10 & 0.695 & 0.745 & 0.102 & 7.322 \\
\hline 11 & 0.736 & 0.848 & 0.104 & 8.122 \\
\hline 12 & 0.763 & 0.913 & 0.104 & 8.740 \\
\hline 13 & 0.843 & 0.961 & 0.106 & 9.073 \\
\hline 14 & 0.895 & 0.976 & 0.107 & 9.093 \\
\hline 15 & 0.969 & 1.066 & 0.112 & 9.523 \\
\hline 16 & 1.018 & 1.125 & 0.114 & 9.856 \\
\hline 17 & 1.041 & 1.207 & 0.122 & 9.917 \\
\hline 18 & 1.109 & 1.261 & 0.126 & 10.034 \\
\hline 19 & 1.153 & 1.336 & 0.132 & 10.131 \\
\hline 20 & 1.217 & 1.361 & 0.134 & 10.185 \\
\hline 21 & 1.257 & 1.383 & 0.137 & 10.100 \\
\hline 22 & 1.315 & 1.450 & 0.145 & 10.008 \\
\hline 23 & 1.352 & 1.494 & 0.149 & 10.059 \\
\hline 24 & 1.404 & 1.547 & 0.164 & 9.422 \\
\hline 25 & 1.437 & 1.581 & 0.174 & 9.080 \\
\hline 26 & 1.485 & 1.627 & 0.189 & 8.608 \\
\hline 27 & 1.514 & 1.657 & 0.198 & 8.358 \\
\hline 28 & 1.556 & 1.700 & 0.209 & 8.114 \\
\hline 29 & 1.582 & 1.729 & 0.214 & 8.093 \\
\hline 30 & 1.618 & 1.765 & 0.225 & 7.832 \\
\hline 31 & 1.641 & 1.787 & 0.233 & 7.683 \\
\hline 32 & 1.672 & 1.817 & 0.243 & 7.493 \\
\hline 33 & 1.690 & 1.835 & 0.249 & 7.376 \\
\hline 34 & 1.716 & 1.860 & 0.257 & 7.250 \\
\hline 35 & 1.731 & 1.875 & 0.261 & 7.177 \\
\hline 36 & 1.751 & 1.894 & 0.267 & 7.083 \\
\hline 37 & 1.762 & 1.905 & 0.271 & 7.025 \\
\hline 38 & 1.776 & 1.919 & 0.276 & 6.965 \\
\hline 39 & 1.784 & 1.926 & 0.278 & 6.930 \\
\hline 40 & 1.793 & 1.935 & 0.280 & 6.899 \\
\hline 41 & 1.797 & 1.938 & 0.282 & 6.882 \\
\hline 43 & 1.800 & 1.941 & 0.282 & 6.874 \\
\hline & 1.800 & 1.941 & 0.282 & 6.874 \\
\hline
\end{tabular}


APPENDIX C: CONTACT TOOLING FOR DOUBLE CUP BACKWARD EXTRUSION FRICTION TEST

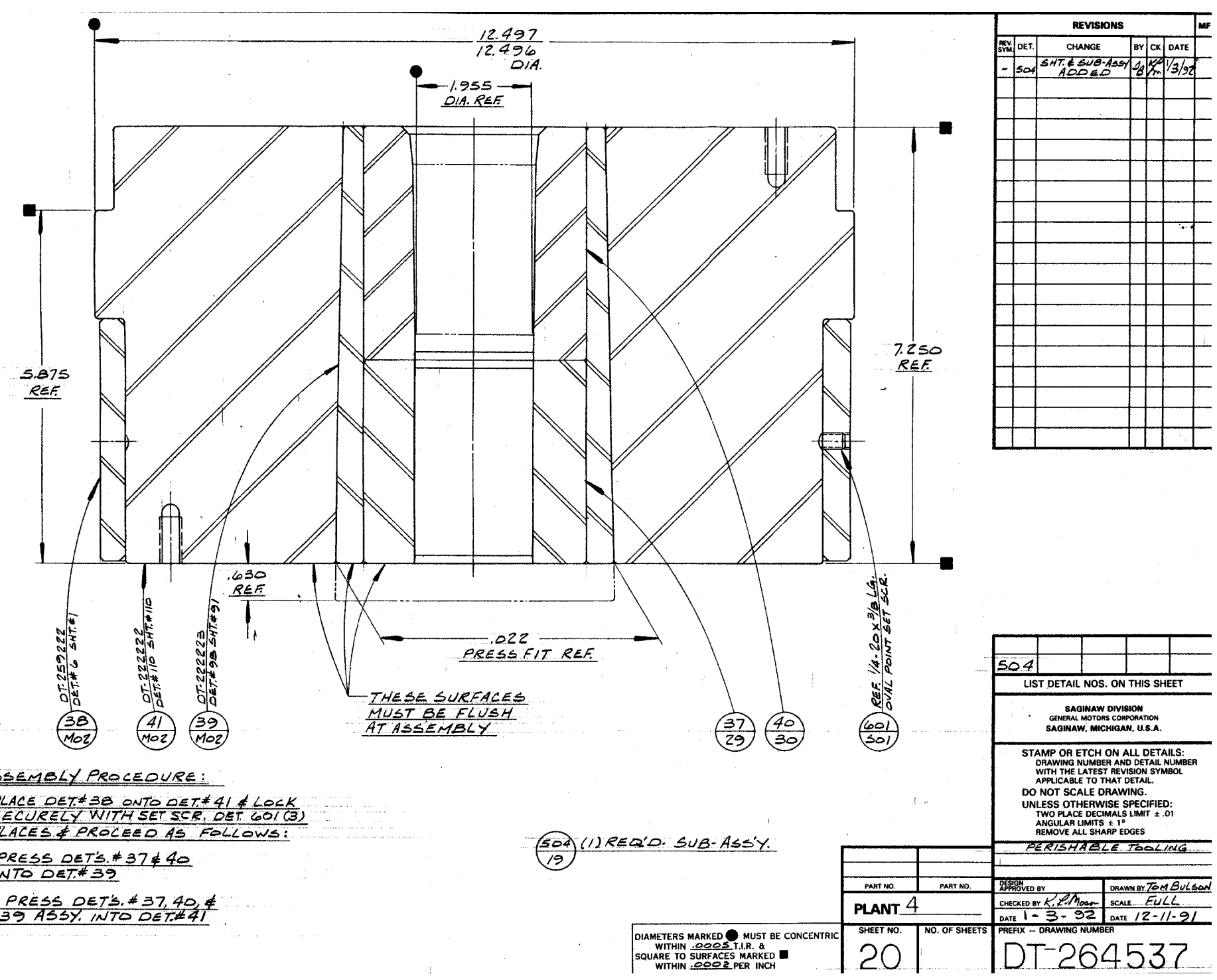




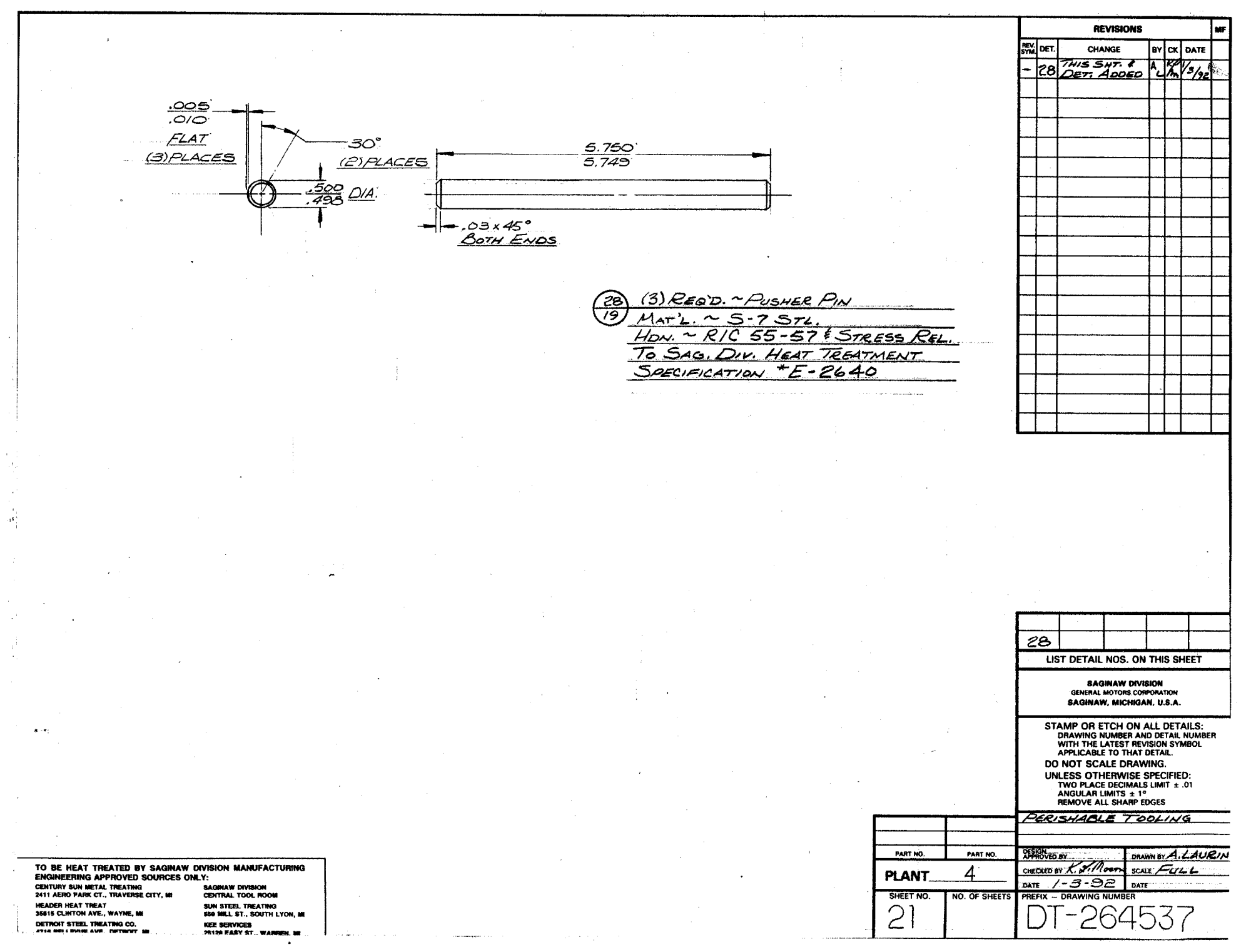




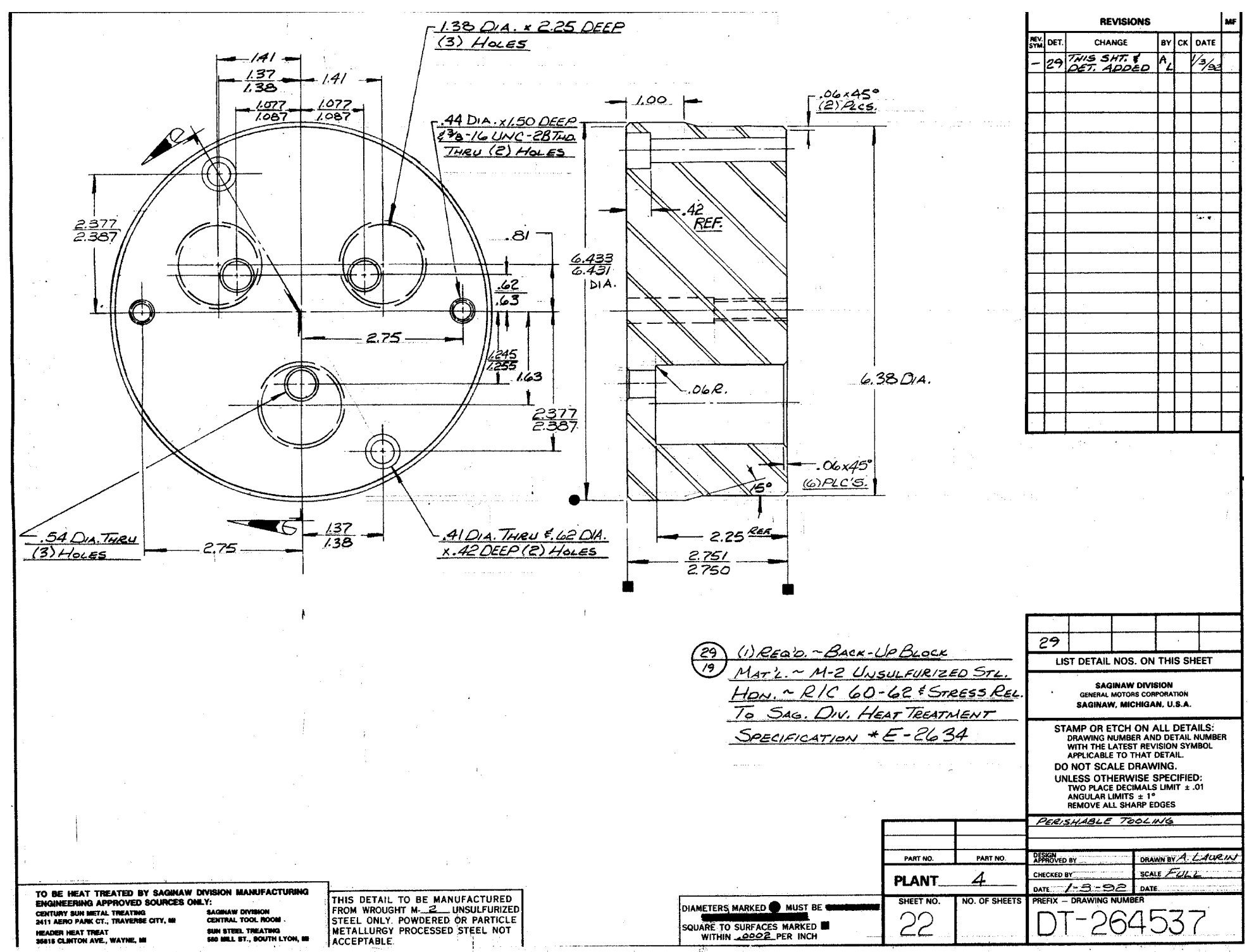




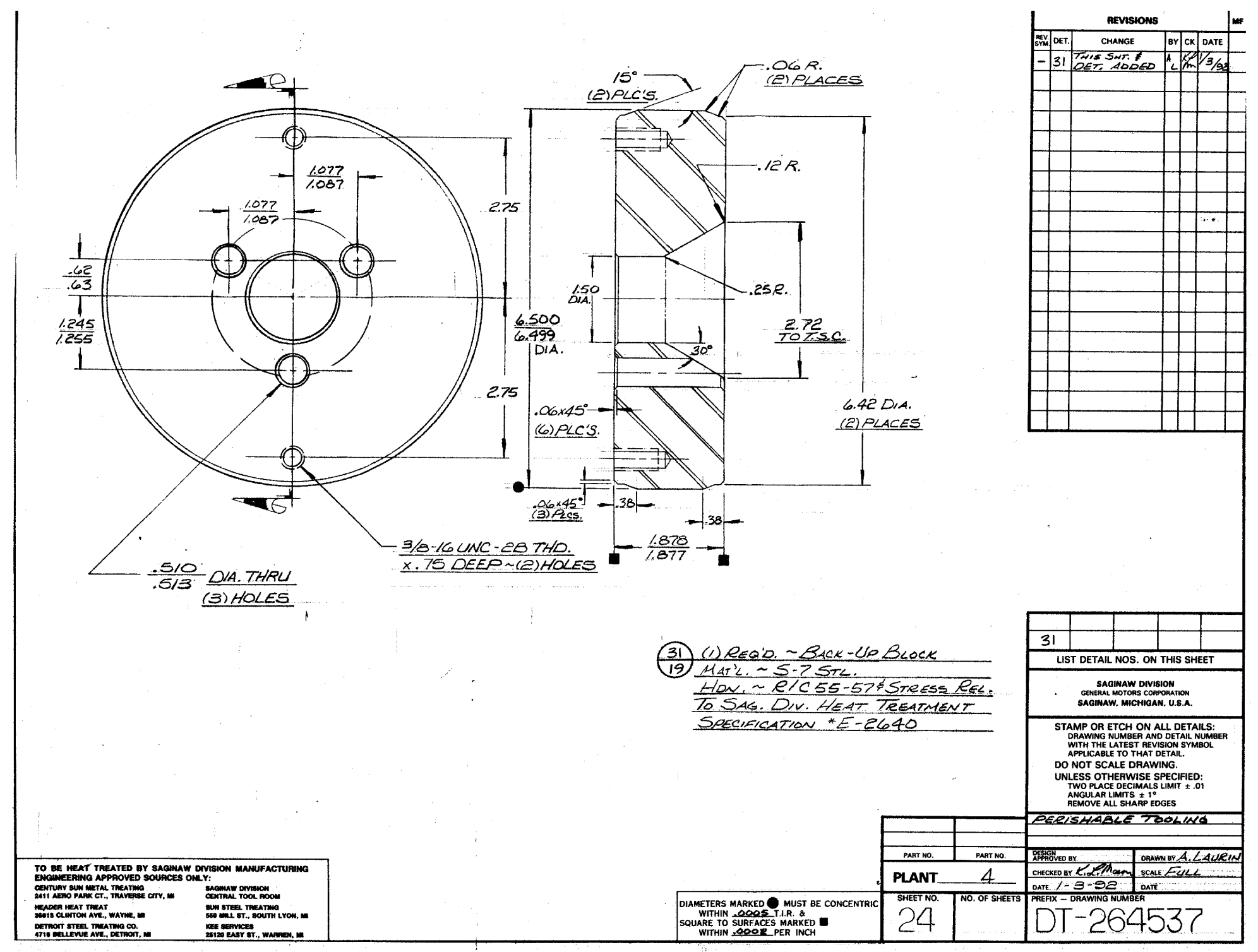




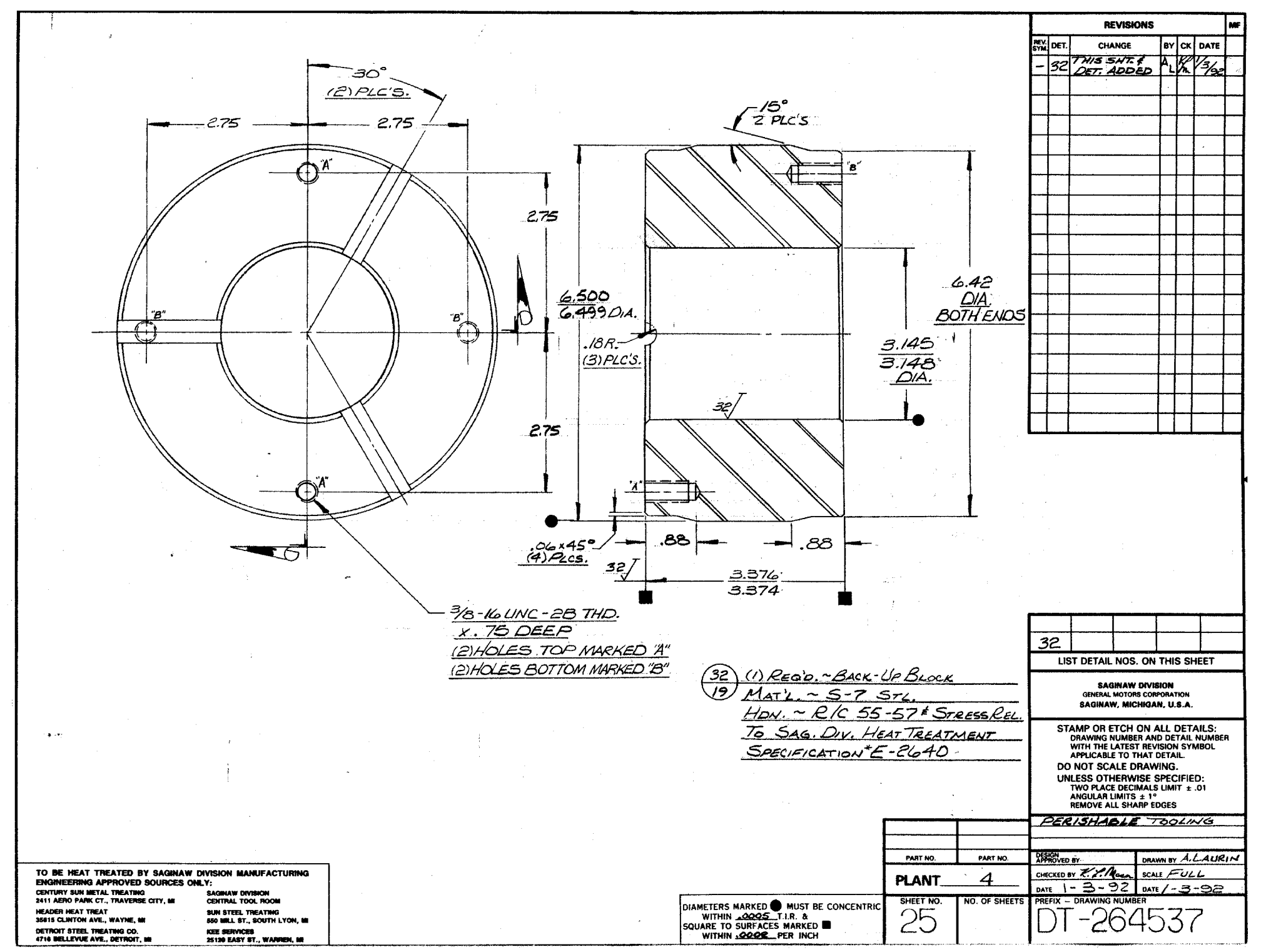




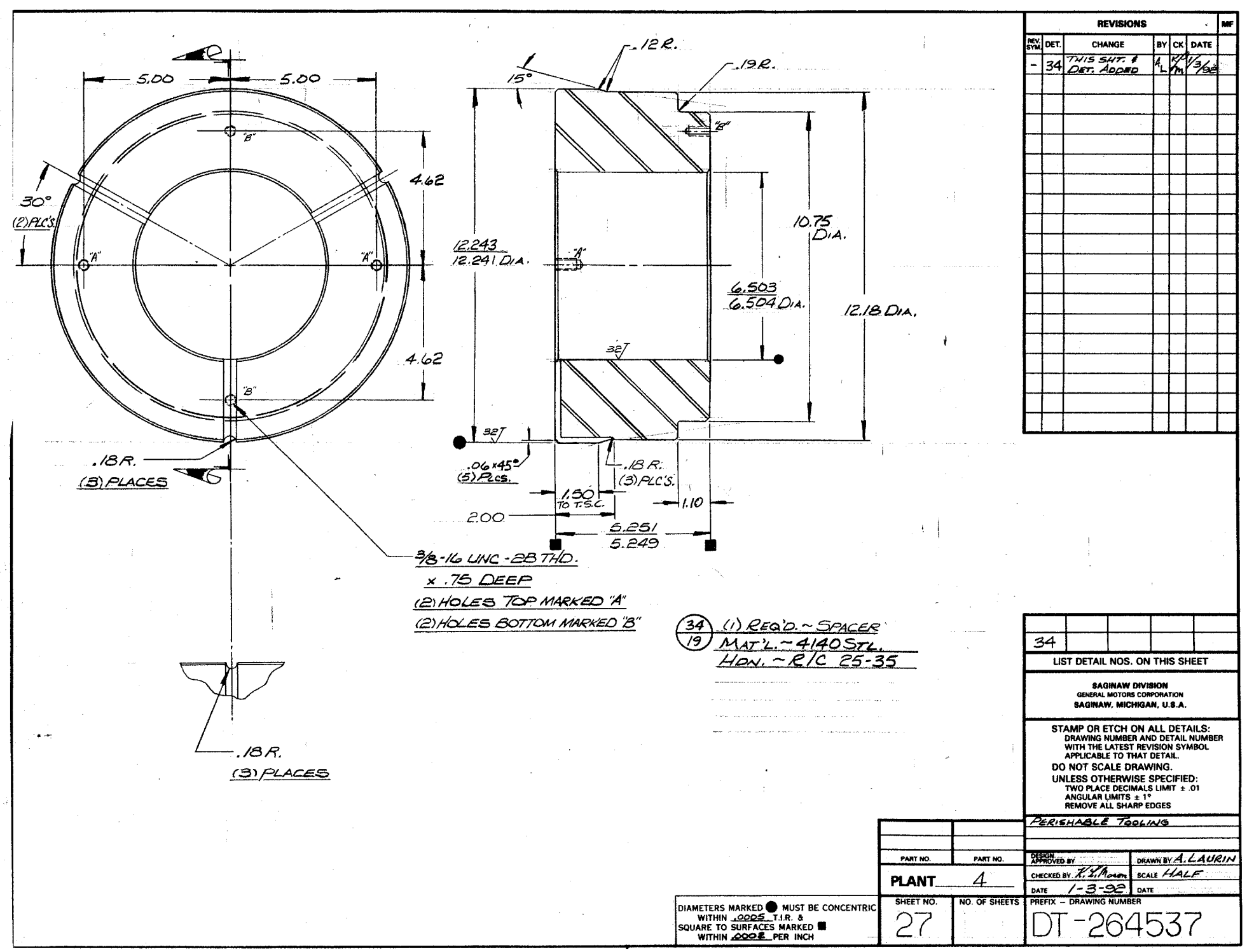




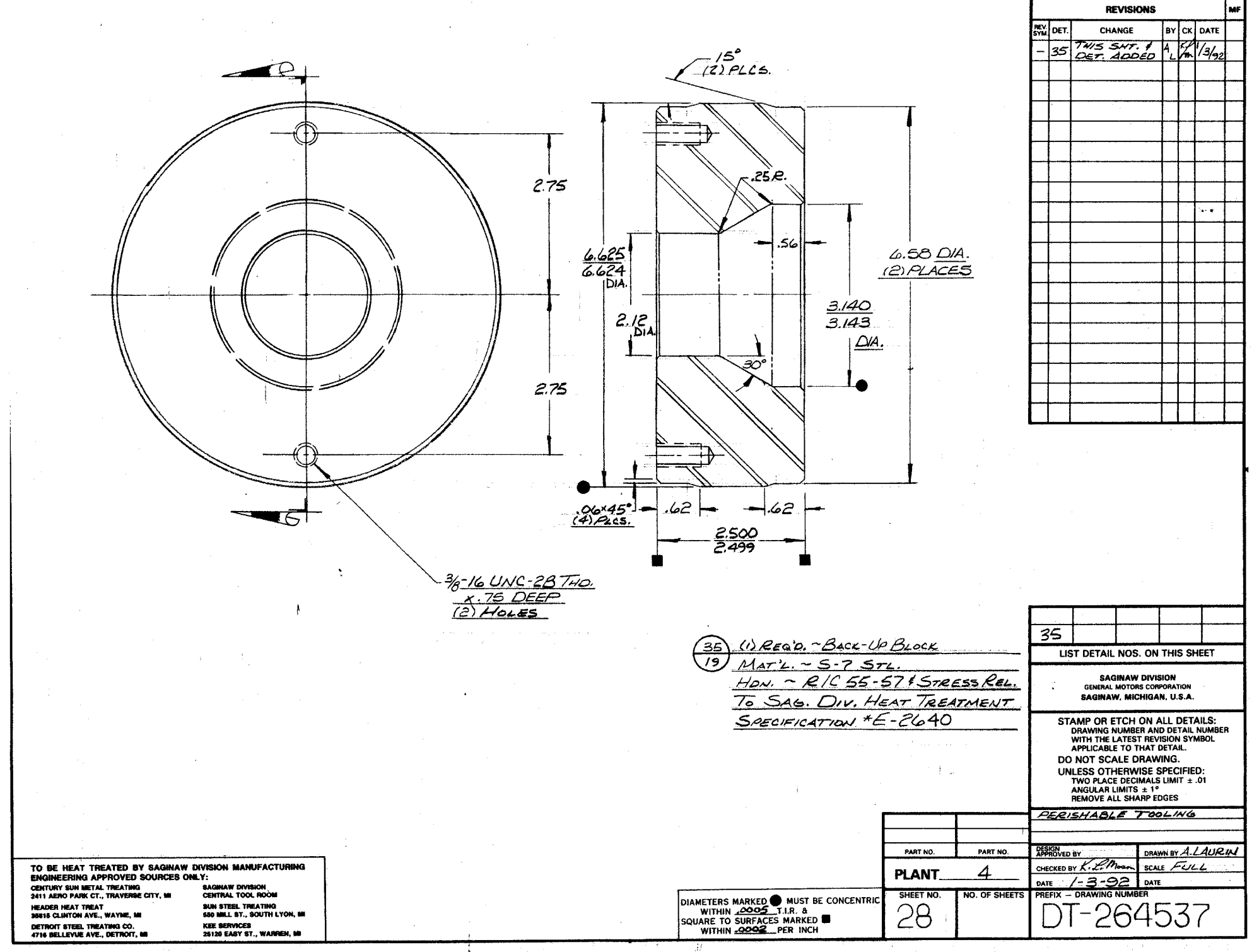




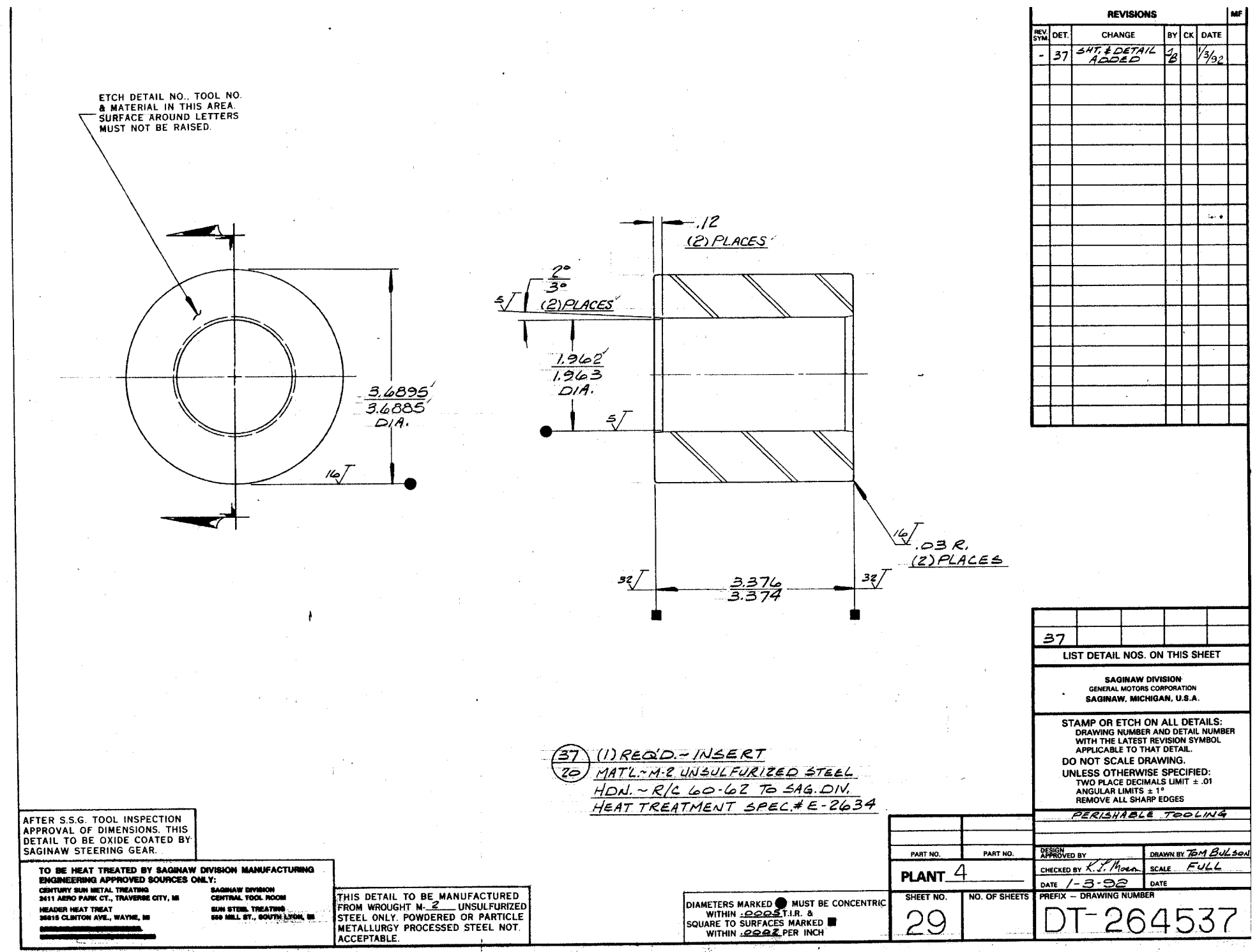




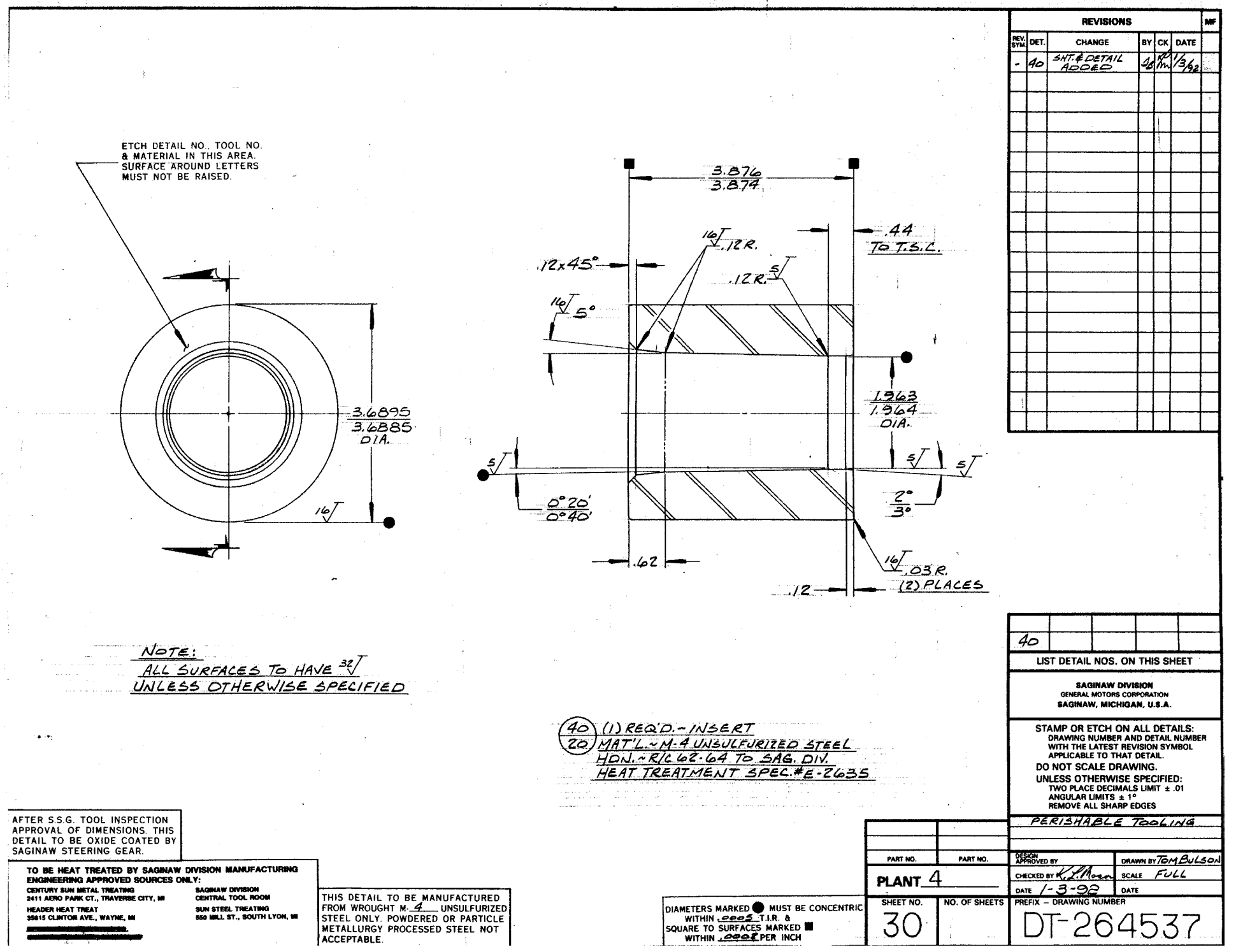




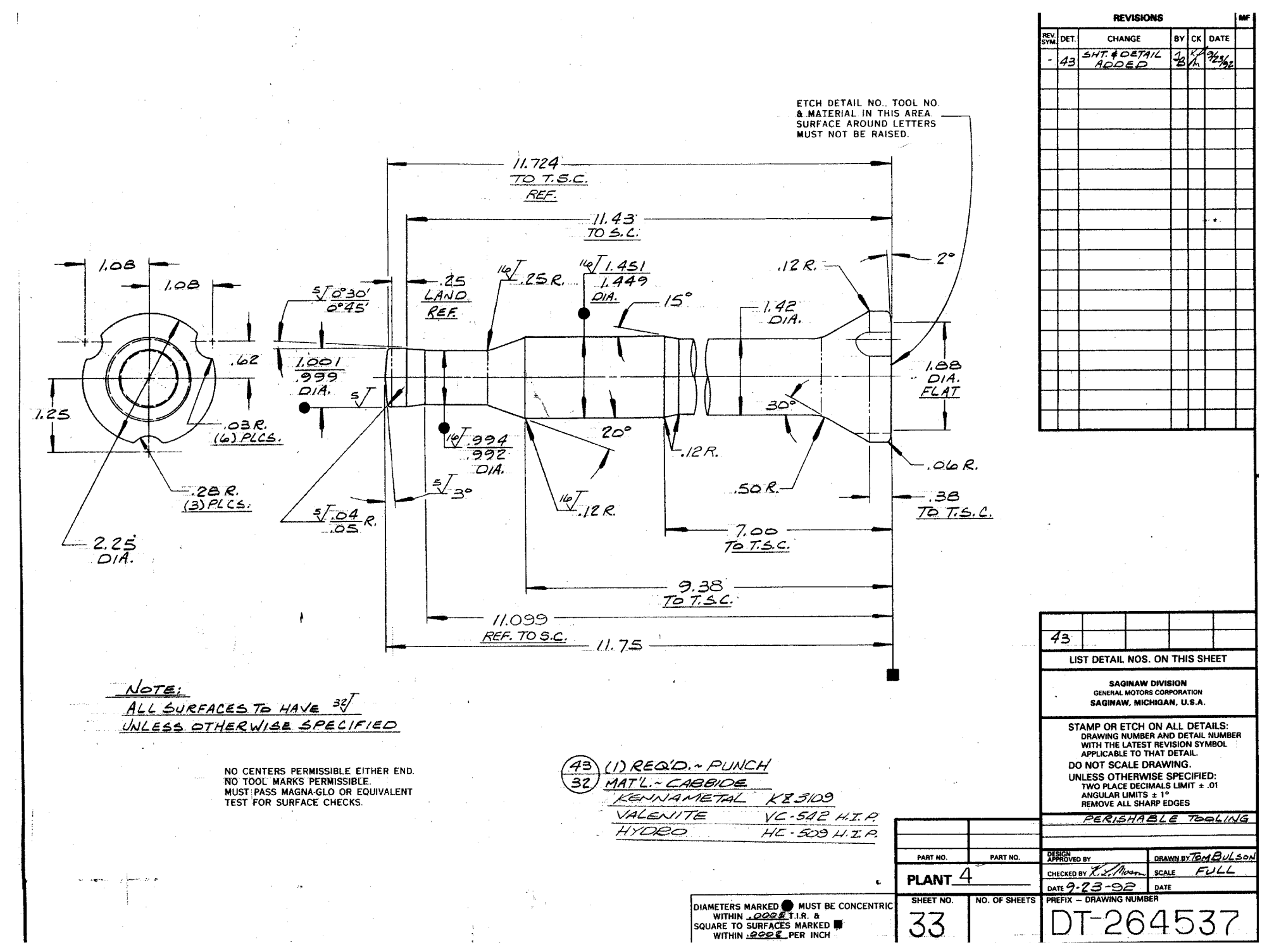




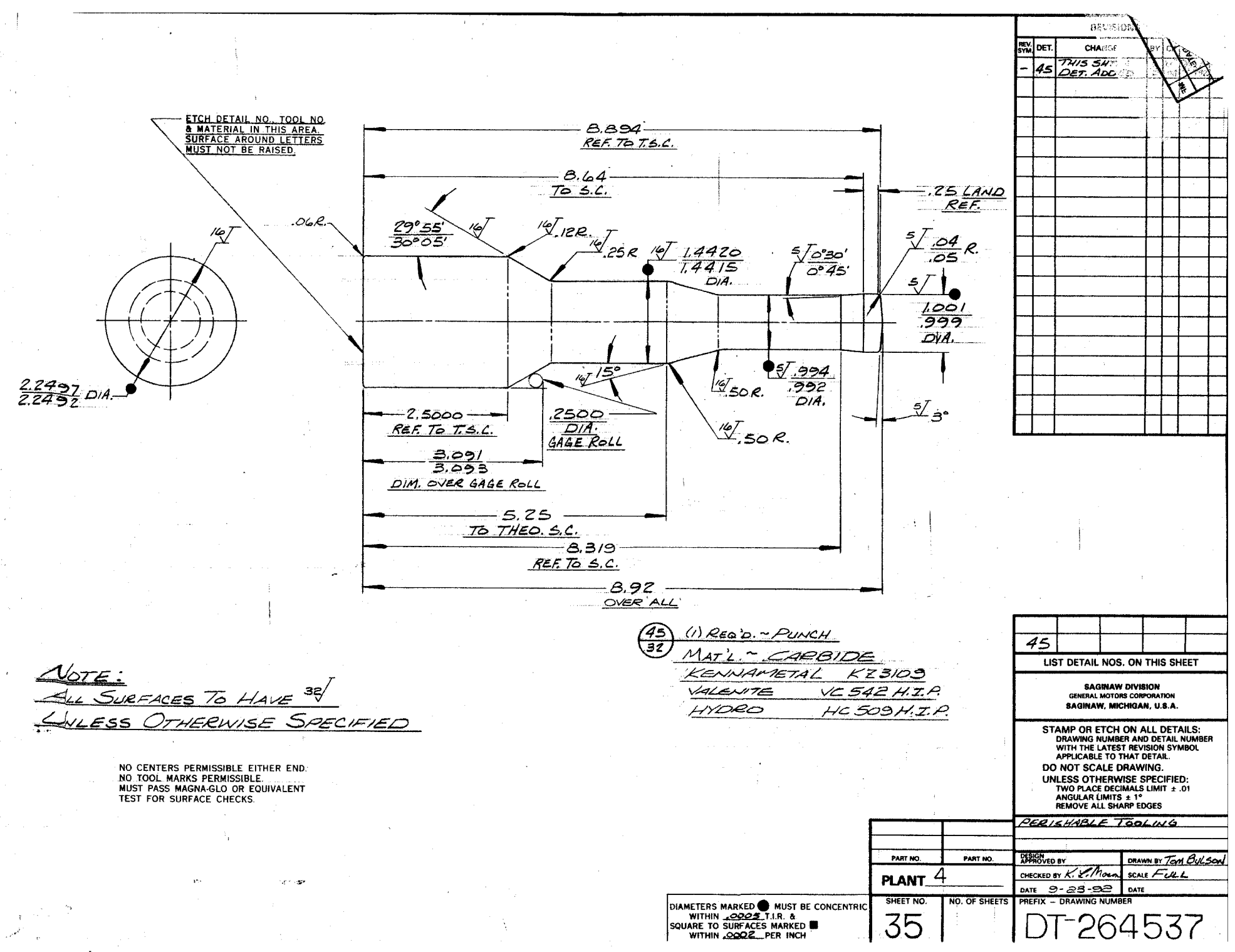




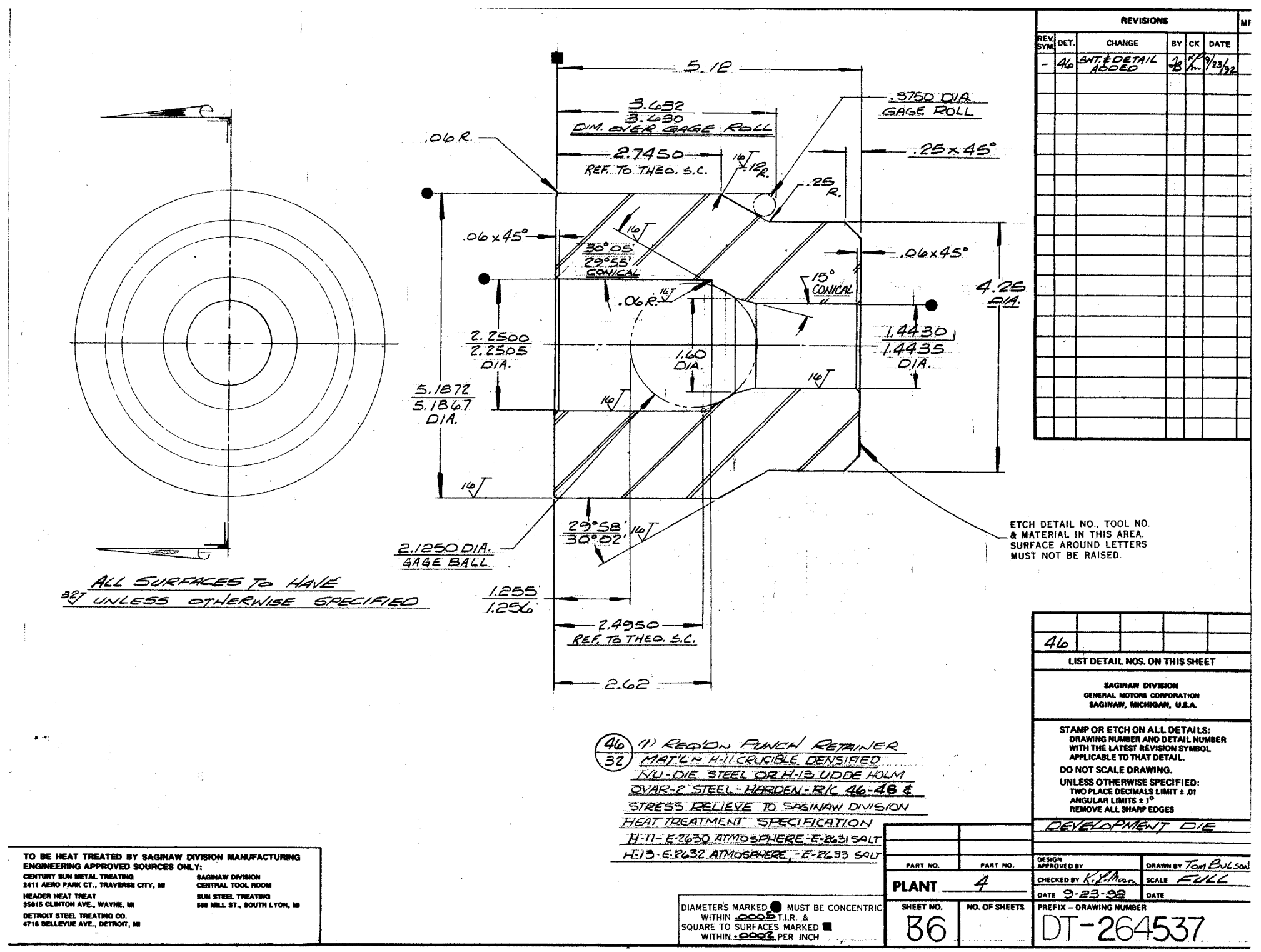

